\title{
Next Generation Nuclear Plant Project Technology Development Roadmaps: The Technical Path Forward for $750-800^{\circ} \mathrm{C}$ Reactor Outlet Temperature
}

August 2009

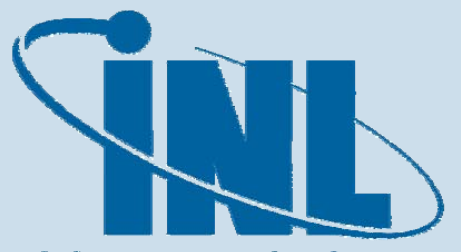

Idaho National Laboratory

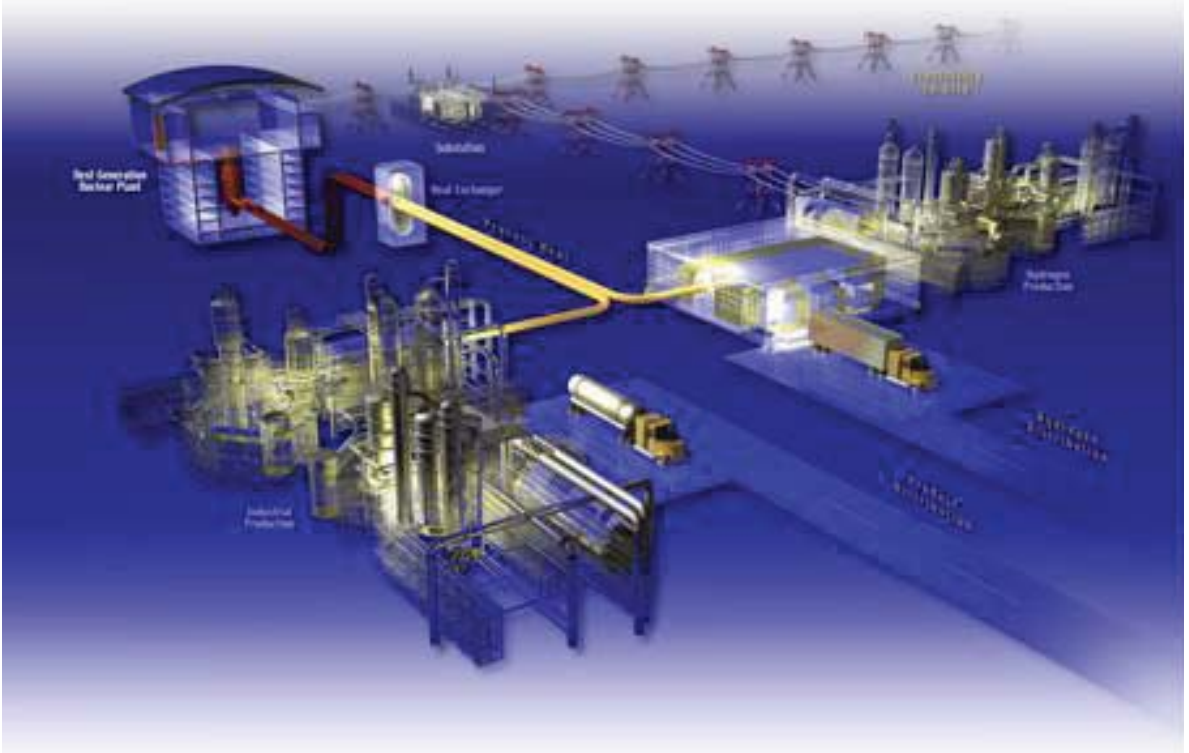




\section{DISCLAIMER}

This information was prepared as an account of work sponsored by an agency of the U.S. Government. Neither the U.S. Government nor any agency thereof, nor any of their employees, makes any warranty, expressed or implied, or assumes any legal liability or responsibility for the accuracy, completeness, or usefulness, of any information, apparatus, product, or process disclosed, or represents that its use would not infringe privately owned rights. References herein to any specific commercial product, process, or service by trade name, trade mark, manufacturer, or otherwise, does not necessarily constitute or imply its endorsement, recommendation, or favoring by the U.S. Government or any agency thereof. The views and opinions of authors expressed herein do not necessarily state or reflect those of the U.S. Government or any agency thereof. 


\section{Next Generation Nuclear Plant Project Technology Development Roadmaps: The Technical Path Forward for $750-800^{\circ} \mathrm{C}$ Reactor Outlet Temperature}

August 2009

Idaho National Laboratory Next Generation Nuclear Plant Project Idaho Falls, Idaho 83415

Prepared for the

U.S. Department of Energy

Office of Nuclear Energy

Under DOE Idaho Operations Office

Contract DE-AC07-05ID14517 
This page intentionally left blank. 
Next Generation Nuclear Plant Project

\section{Next Generation Nuclear Plant Project Technology Development Roadmaps: The Technical Path Forward for $750-800^{\circ} \mathrm{C}$ Reactor Outlet Temperature}

INL/EXT-09-16598

August 2009
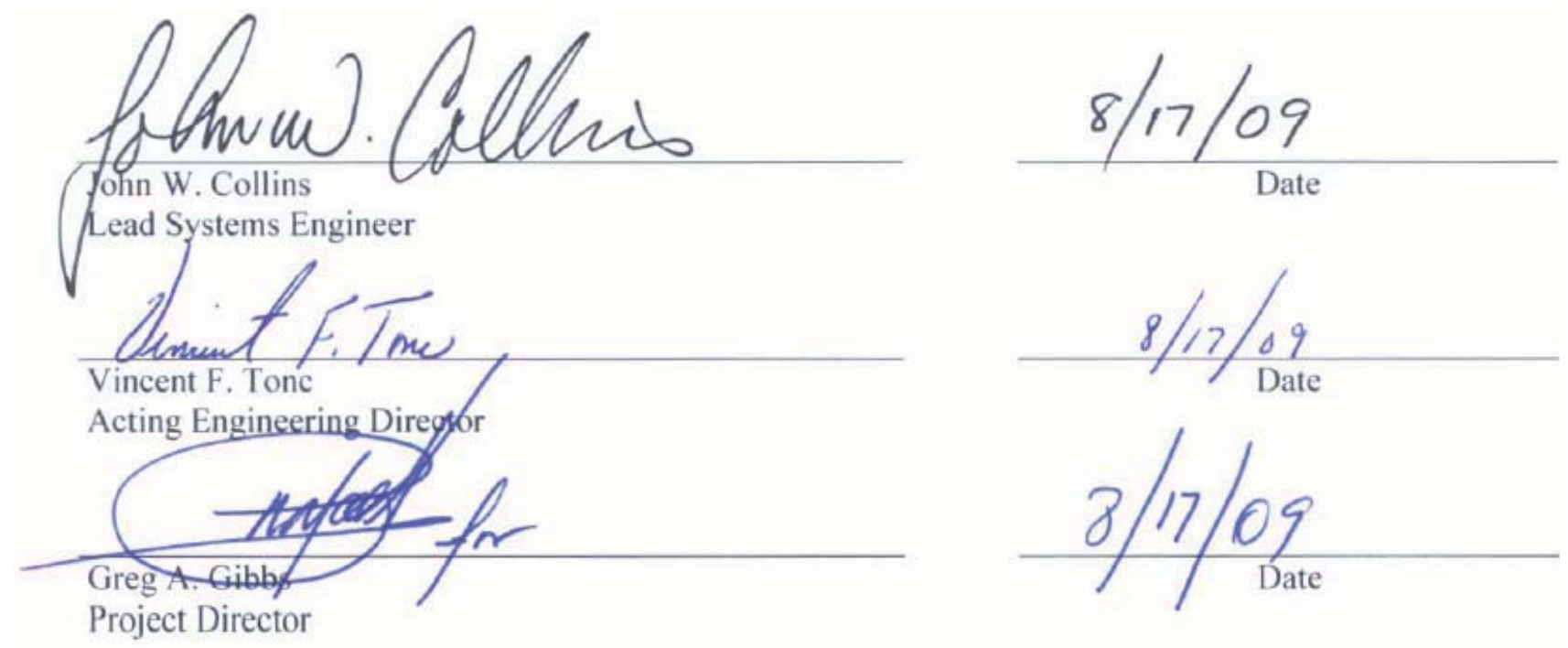
This page intentionally left blank. 


\section{EXECUTIVE SUMMARY}

Industry experience repeatedly demonstrates the consequences of proceeding with projects using technologies that are not sufficiently mature. The U.S. General Accounting Office noted that these consequences manifest themselves as cost overruns and schedule delays late in the project life cycle [GAO 2007]. To avoid these undesirable consequences, the Next Generation Nuclear Plant (NGNP) project initiated efforts to assess technology readiness of critical plant, areas, systems, subsystems, and components (PASSC) and identify the steps required to ensure sufficient maturity prior to inclusion into the NGNP design.

In January 2009, the NGNP project issued a report (INL/EXT-08-15148) entitled, Next Generation Nuclear Plant Project Technology Development Roadmaps: The Technical Path Forward. The report documents a Technology Readiness Assessment, critical PASSCs, and Technology Development Roadmaps (TDRM) to mature the technologies needed for a high-temperature gas reactor with an outlet temperature of $950^{\circ} \mathrm{C}$, as well as other requirements. The requirements and operating conditions are consistent with those found in the NGNP System Requirements Manual (SRM) [INL 2008a] and Summary of Bounding Requirements for the NGNP Demonstration Plant F\&ORs [INL 2008b]. This report is an update to the January 2009 report and documents the critical PASSCs, Technology Readiness Levels, and the TDRMs to mature the technologies needed for a high-temperature gas reactor with an outlet temperature of $750-800^{\circ} \mathrm{C}$, as well as other requirements and operating conditions consistent with those found in the SRM, Revision 2. As such, this document establishes a baseline for the current technology readiness status and provides a path forward to achieve increasing levels of technical maturity and reduce risk. The January 2009 report and TDRMs show numerous engineering studies and design tasks initiating in March 2009. These tasks were not initiated due to funding constraints and a lack of authorization to initiate design tasks. This report shows these studies and tasks initiating in October 2009 based on the assumption that design tasks will be funded and authorized by that time.

The salient features of the pre-conceptual design requirements are as follows:

- Reactor outlet temperature (ROT) of $750-800^{\circ} \mathrm{C}$

- $\quad$ Pressure of 5-9 MPa

- Indirect Configuration using pebble bed reactor design and a secondary gas loop to supply heat. - Westinghouse

\section{OR}

Indirect Configuration using a prismatic block reactor design with a secondary loop using steam as the heat transport fluid. - AREVA / General Atomics

- GenIV Advanced Gas Reactor (AGR) fuel type

- 60-year plant life.

As noted above, this document describes the technology readiness assessment and roadmapping process and features the resulting TRLs and TDRMs. This document includes:

- Identification of NGNP's Critical PASSCs

- Design Description of Critical PASSCs

- TRLs assessed against critical PASSCs

- TDRMs depicting the path forward for each critical PASSC 
- Supplier submitted TDRMs and TRLs (see Appendix A)

- Supplier submitted Test Plans to document tests required to increase Technical Maturity (see Appendix A).

\section{Technology Readiness of Critical NGNP PASSCs}

Of over 400 identified PASSCs, 15 were determined to be critical from a technology perspective. Critical PASSCs are defined as those components that are not commercially available or do not have proven industry experience. Three supplier teams (i.e., AREVA, General Atomics, and Westinghouse) were tasked to evaluate and identify the critical PASSCs of their proposed design configurations. The suppliers each identified 14-16 PASSCs. Additionally, the Idaho National Laboratory (INL) is currently conducting research on prismatic fuel elements. These PASSCs were consolidated into the 15 NGNP critical PASSCs as compared to 18 critical PASSCs identified for the $950^{\circ} \mathrm{C}$ ROT design. The mixing chamber was not determined to meet the definition of critical at $750-800^{\circ} \mathrm{C}$ ROT, and the Power Conversion System (PCS) equipment for Direct Combined Cycle was eliminated in favor of the steam generator in the primary loop. Although hydrogen production remains a critical PASSC, the hydrogen production system (HPS) TDRM was not updated pending a technology down selection. Upon down selection, a consolidated HPS TDRM for $750-800^{\circ} \mathrm{C}$ ROT will be generated to reflect the programs path forward.

Table ES-1 provides a mapping between the NGNP consolidated critical PASSCs and supplieridentified critical PASSCs. The table consists of five primary columns, representing the consolidated NGNP critical PASSCs, the AREVA critical PASSCs, the General Atomics critical PASSCs, the Westinghouse Electric Company critical PASSCs, and the INL Fuel Element and HPS PASSCs. The subcolumns to the left of the PASSC names identify the section number of the supplier report wherein the technology readiness assessment details are provided. In the case of NGNP consolidated PASSCs, the number represents the section in this document. Blank cells in the table represent an absence of supplieridentified PASSCs corresponding to the NGNP consolidated PASSCs. PASSCs are organized according to the five NGNP areas: Nuclear Heat Supply System (NHS), Heat Transport System (HTS), HPS, PCS, and Balance of Plant (BOP). One addition to the table not used in the rest of the document is Other Development Issues. This is presented to provide a place holder for additional PASSCs that suppliers deemed important, but not critical, in the TDRM work and activities associated with the scope of work tasked to them. As the design matures and requirements change, additional PASSCs may be added to those already identified in this report. 
Table ES-1. NGNP Critical PASSCs for $750-800^{\circ} \mathrm{C}$ ROT

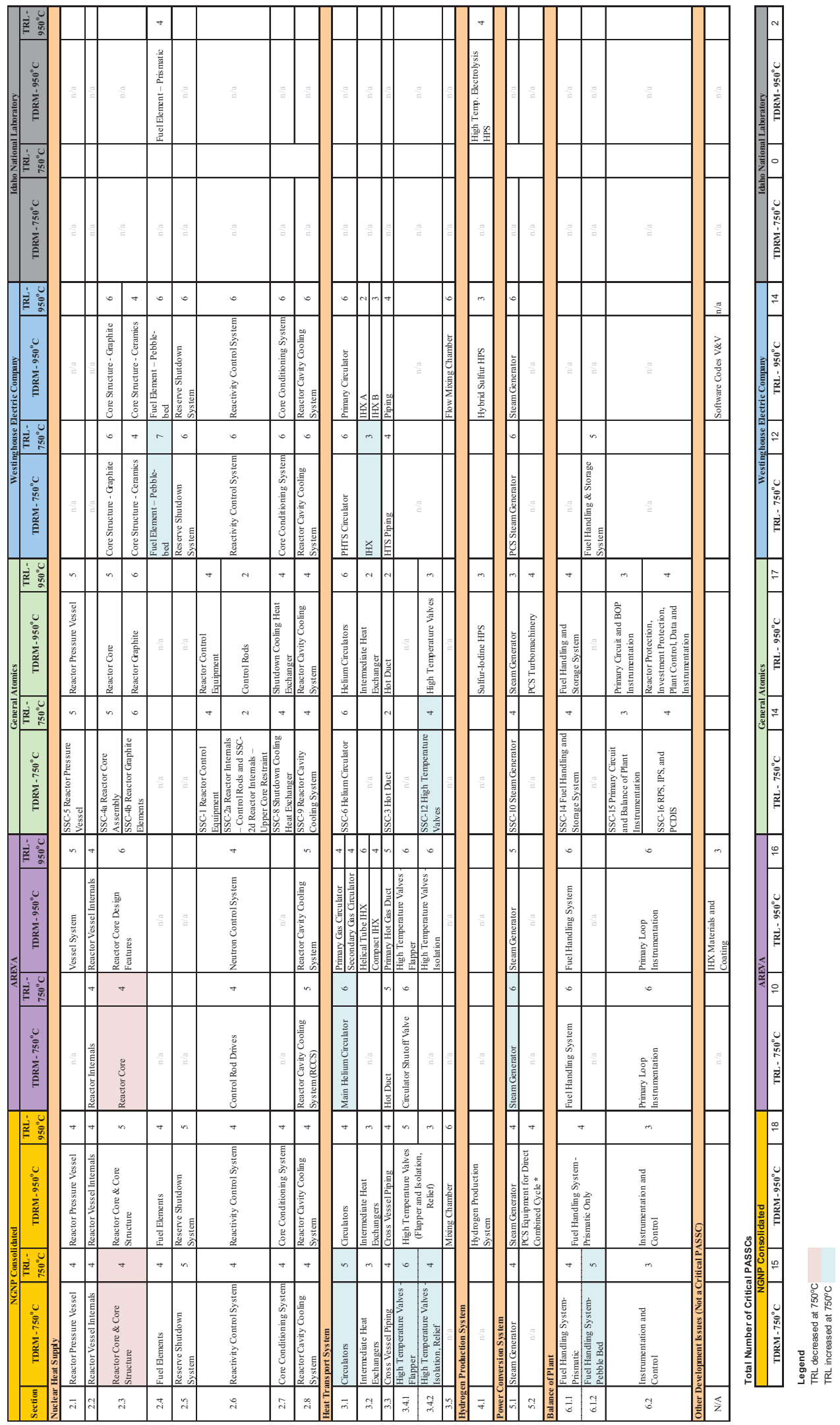


Each critical PASSC was evaluated through a Technology Readiness Assessment and assigned a TRL based on the technical maturity of the PASSC. TRLs are an input to inform NGNP project management of the readiness of a particular PASSC. The TRL provides one measure of the level of risk encountered by the project. For TRLs 1-5, assessment typically occurs on an individual technology or component with a calculated roll up TRL for the associated subsystems, systems, and areas. As the technology or component progress to further maturity, integrated testing occurs, allowing TRL assessments directly against subsystems and systems. The integrated testing or modeling occurs at increasingly larger scales and in increasingly relevant environments, thus achieving higher TRL ratings. Abbreviated TRL definitions are shown in Figure ES-1.
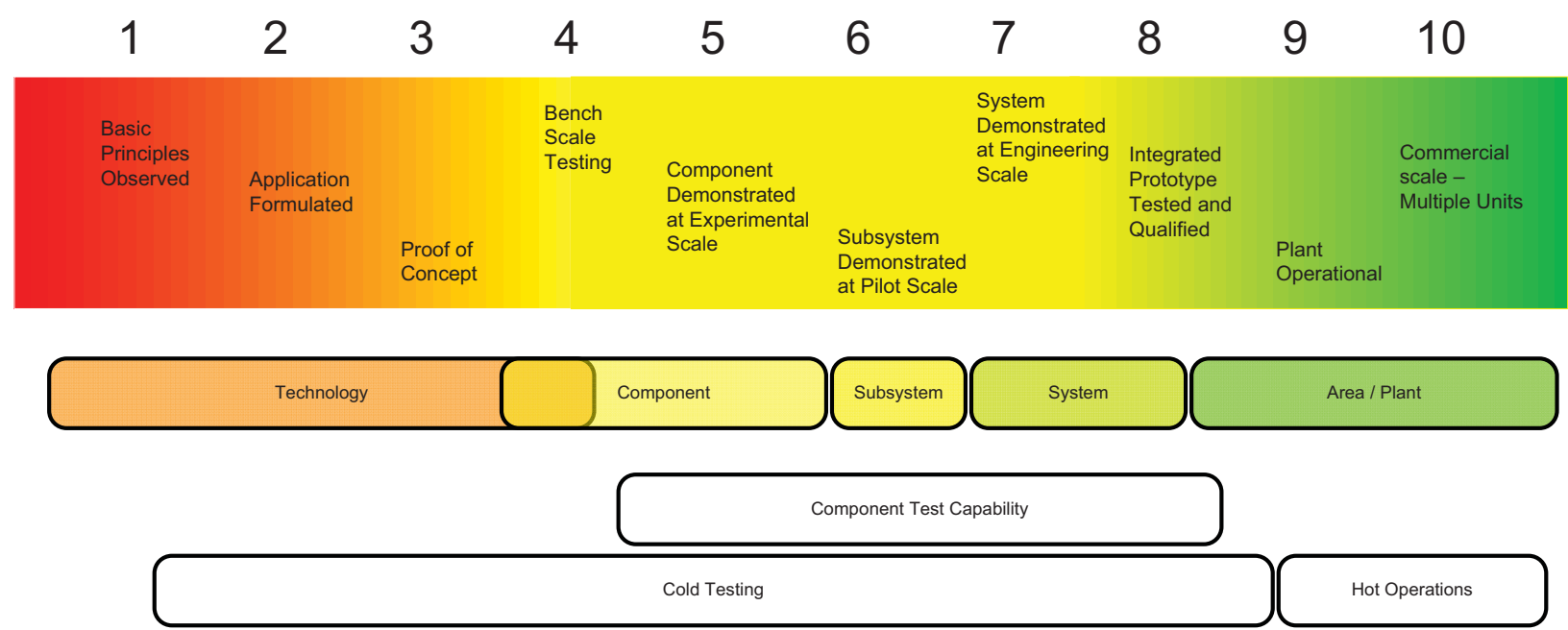

Figure ES-1. Technology Readiness Levels

Understanding the TRL of the NGNP's critical PASSCs creates a starting point for developing the steps needed to further mature the technologies and demonstrate reliable performance of components or systems. These steps are consolidated into TDRMs, which provide the framework to systematically perform decision analysis, reduce risk, and mature technologies early in the project, and thus avoid cost overruns and schedule delays late in the project.

\section{Technology Development Roadmaps}

With the baseline PASSCs and their associated TRLs defined, a TDRM is developed to guide the needed maturation, as shown in Figure ES-2. As the technology achieves the performance criteria required for advancing technology readiness, the uncertainty associated with the successful implementation of that technology is reduced. In this fashion, risk is reduced as technology readiness levels increase. An early step in technology maturation is to select between competing technologies. In technology down selection, decision discriminators are developed as the important parameters that a successful technology would have to satisfy to assist NGNP in meeting its mission. This list of parameters is then consolidated into key selection discriminators that focus the data collection on the parameters important to the NGNP, namely those that distinguish the benefits of one technology from another. Typically, technologies or components must be matured to a TRL of 5 to proceed with down selection when the technologies are sufficiently understood and the risks of making the wrong choices are minimized. The tasks required for technology down selection include studies, tests, evaluations, modeling, simulations, qualitative analyses, and quantitative analyses. 


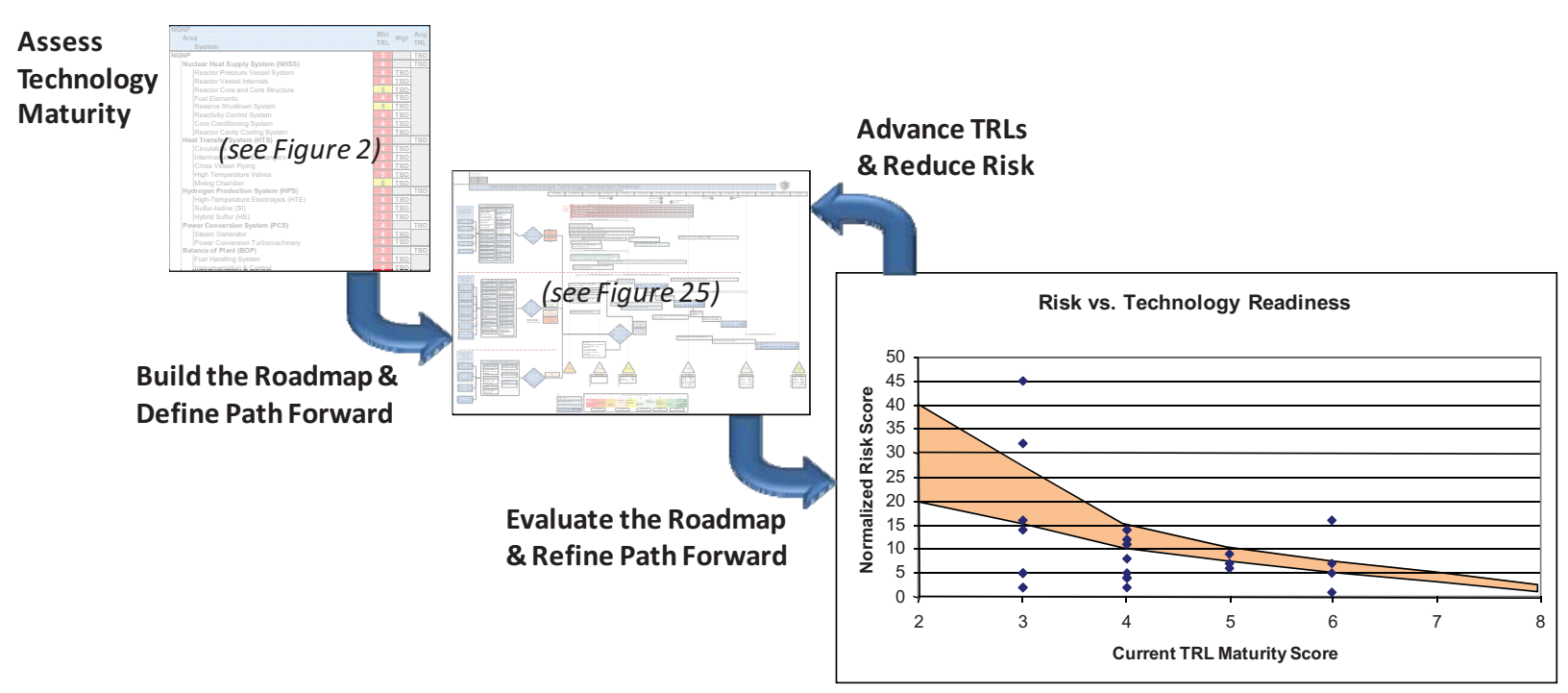

Figure ES-2. Executing the Roadmap increases Readiness while Reducing Risk.

The TDRM process focuses the research and development (R\&D) efforts and engineering studies on the known risks to advancing the selected technology and satisfying the increasingly demanding and scaled up tests. In the NGNP application, TDRMs provide the required structure and are the primary means to systematically perform risk-informed decision making, risk reduction, technology down selection, and technology qualification and maturation in a cost effective and timely manner.

Additionally, TDRMs serve to coordinate engineering, R\&D, and licensing efforts. The steps in the process include Structure Identification, Technology Readiness Assessment, Technology Selection, Technology Maturation, and Test Plan Development. Technology roadmaps for critical NGNP PASSCs were developed to:

- Set the vision for maturing technologies to the required TRL

- Identify the key selection discriminators and drive the needed actions to down select technologies and designs

- Ensure technology readiness is demonstrated through testing, modeling, simulations, piloting, and prototyping

- Provide early identification and resolution of technical risks

- Avoid late project technical challenges, which manifest themselves as cost overruns and schedule delays

- Develop the test plans to provide demonstrable evidence of the technology maturation required for codification and qualification.

Test Plans are established for the critical PASSCs, including high-temperature heat applications. These test plans are specific to the supplier identified critical PASSC and proposed research; modeling; and laboratory, bench-scale, experimental, pilot-scale, integrated, and engineering-scale testing required to advance the technology from its current readiness level through the next and subsequent levels to a TRL level of 8 . Included in the test plans are the test objective, the duration of the test, the scale of the test, and the proposed location. Additionally, the items to be tested, the features to be tested, the test approach, the pass/fail criteria, safety considerations, and test deliverables are included, where possible. Some of the test plans developed for $950^{\circ} \mathrm{C}$ ROT were modified for $750-800^{\circ} \mathrm{C}$ ROT. Other test plans are 
largely applicable to the $750-800^{\circ} \mathrm{C}$ ROT, but will need to be slightly modified to reflect the change in some test due to temperature reductions.

\section{Summary Roadmaps for NGNP Areas}

The near-term tasks required to mature a technology from its current readiness level to the next level are captured by area in the summary roadmaps for each of the consolidated critical PASSCs (see Figures ES-3 through ES-6). For some critical PASSCs, the advancement to the next TRL will allow for down selection between competing technologies. For other PASSCs, this TRL advancement is designed to occur in a timely fashion to support conceptual, preliminary, and final design; Combined License Application submittals, and safety basis development. 


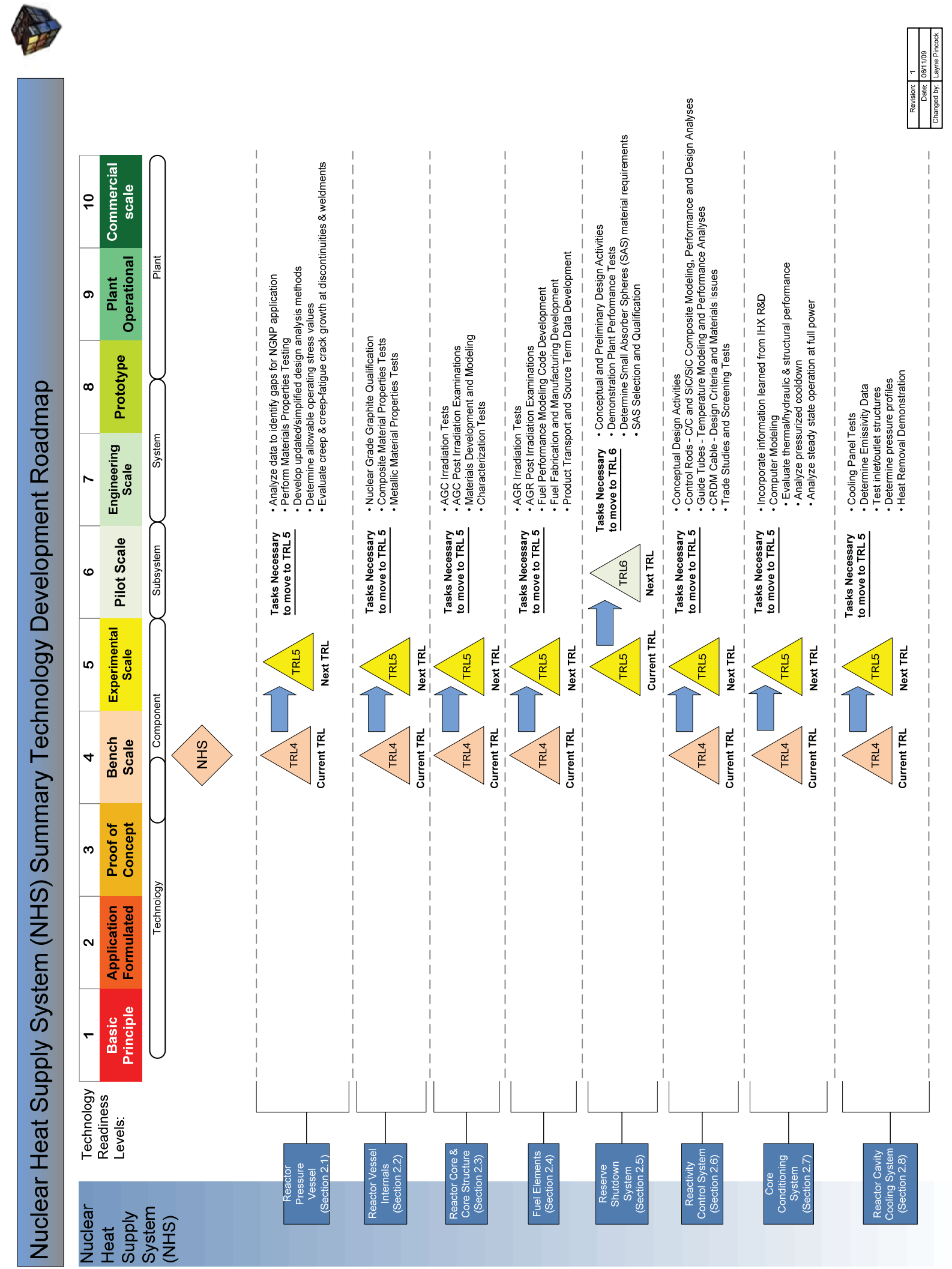

Figure ES-3. Nuclear Heat Supply System Summary Roadmap for $750-800^{\circ} \mathrm{C}$ ROT 


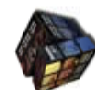

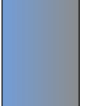

\%
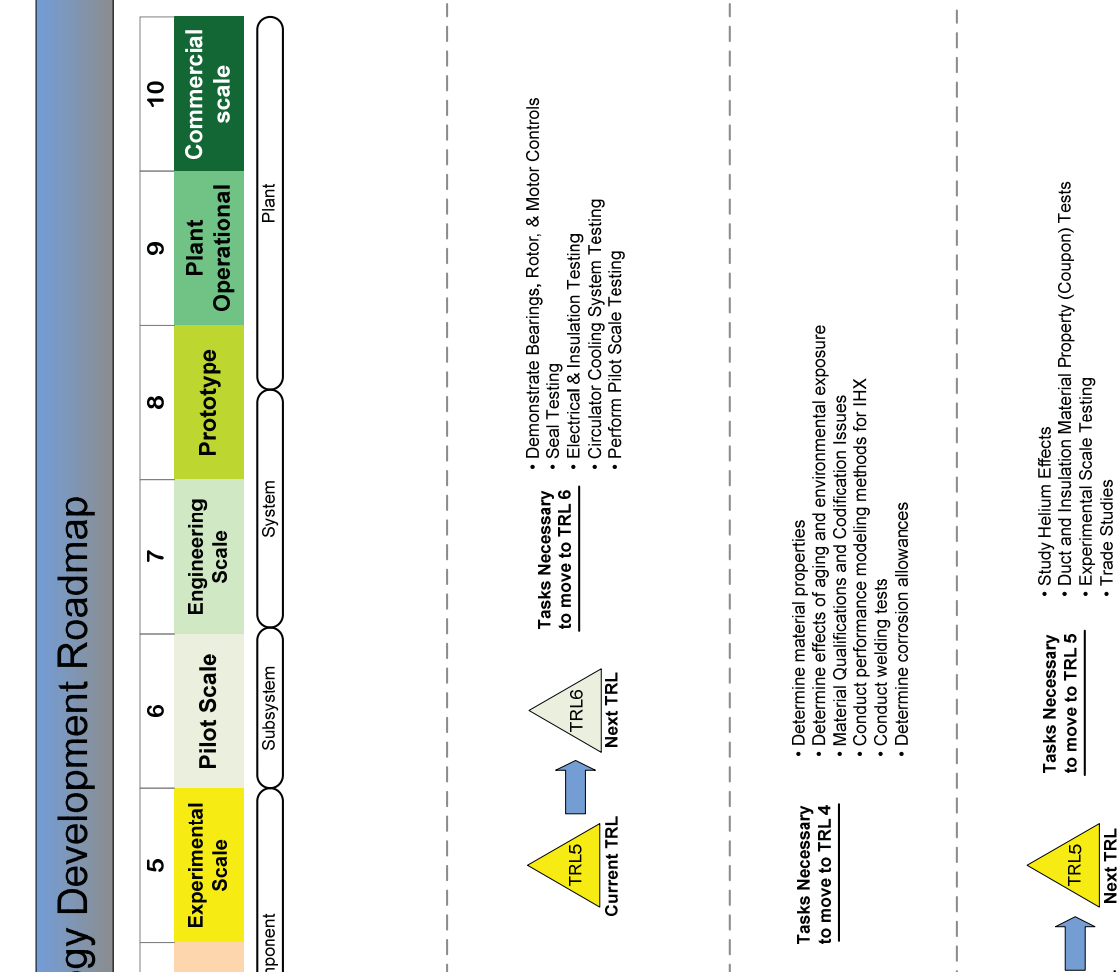

$\frac{\infty}{\mathbb{8}}$
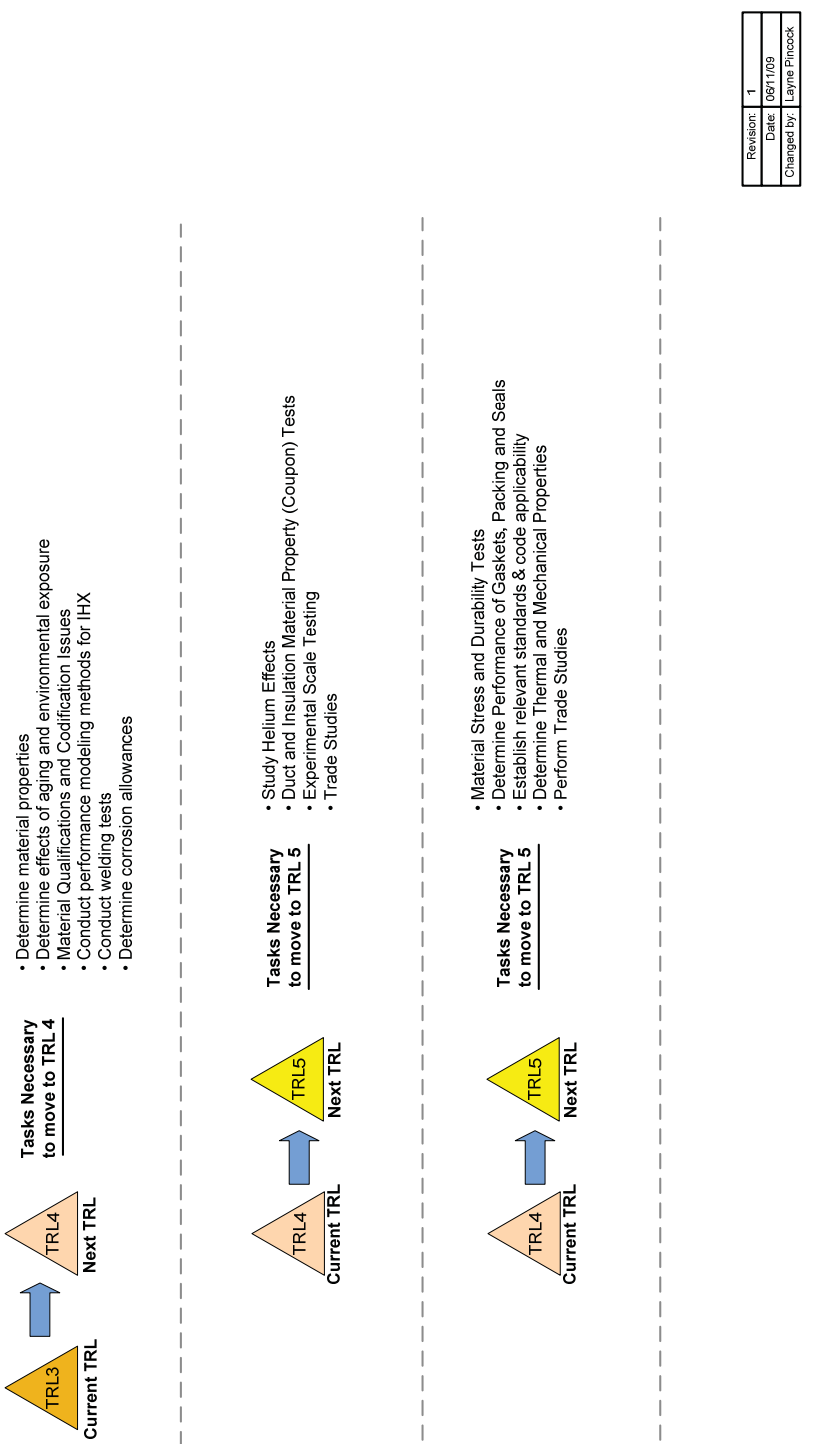


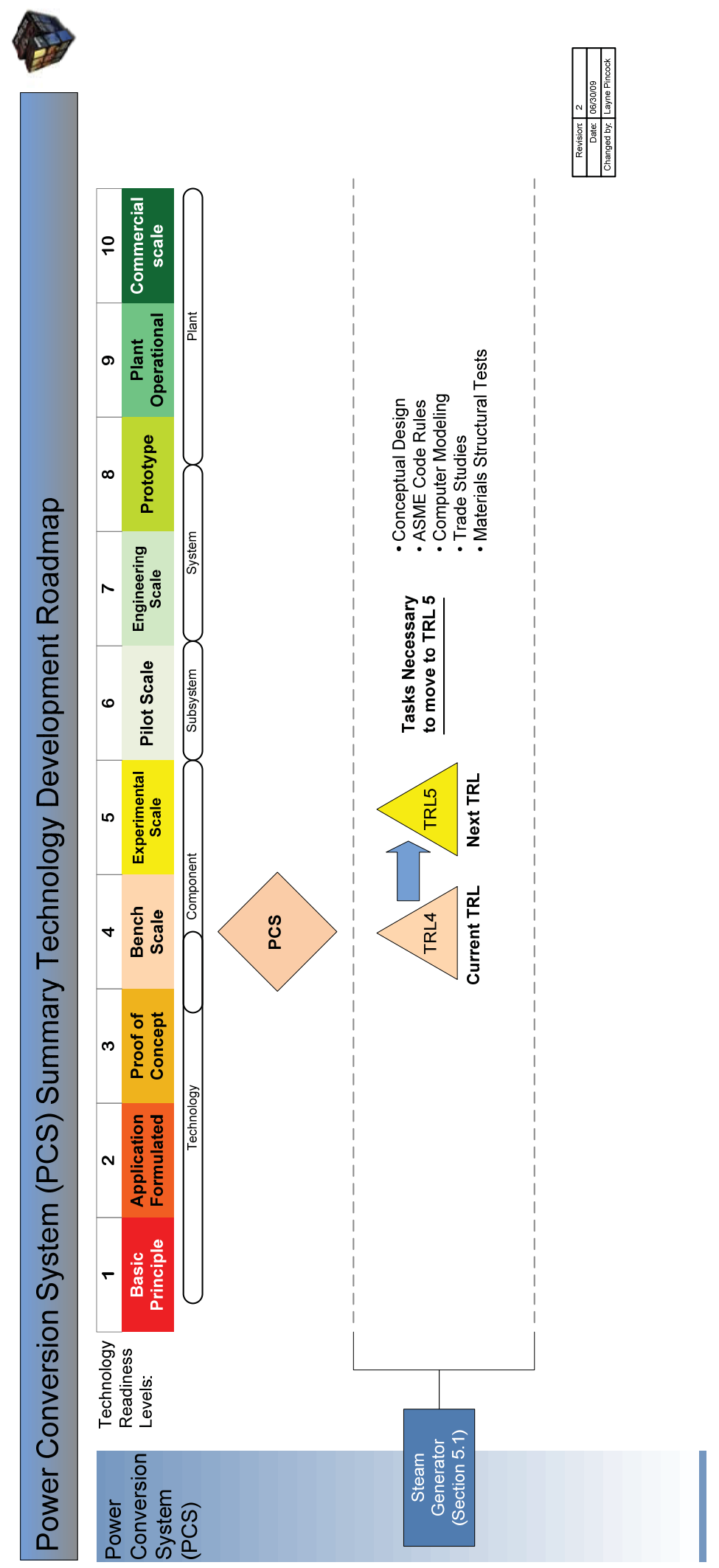

Figure ES-5. Power Conversion System Summary Roadmap for $750-800^{\circ} \mathrm{C}$ ROT 


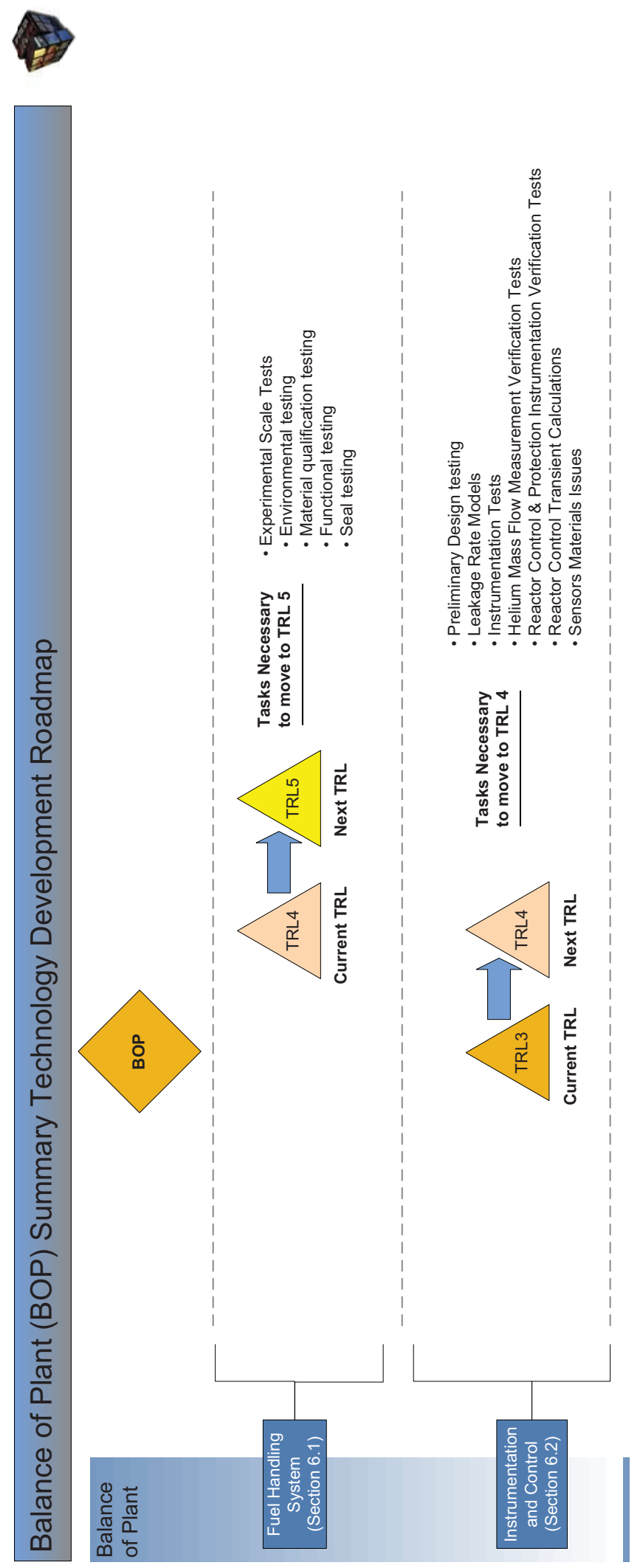

Figure ES-6. BOP Summary Roadmap for $750-800^{\circ} \mathrm{C}$ ROT 


\section{Conclusions}

Conclusions and needed actions discovered during the Technology Readiness Assessment and the creation of TDRMs are as follows:

1. Conclusion: The NGNP technology readiness level is inherently higher for an ROT of $750-800^{\circ} \mathrm{C}$ versus $950^{\circ} \mathrm{C}$. However, due to the significant number of discrete steps with each TRL advancement, these differences are not all reflected in the raw TRL scores. Instead, the differences are reflected in the reduced difficulty in achieving the next TRL rating at 750$800^{\circ} \mathrm{C}$ versus $950^{\circ} \mathrm{C}$.

Action: At an ROT of $750-800^{\circ} \mathrm{C}$ versus $950^{\circ} \mathrm{C}$, expedite the near-term TDRM tasks to meet schedule.

2. Conclusion: Two PASSCs are no longer considered critical by the suppliers due to the reduction in $\mathrm{ROT}$ to $750-\mathbf{8 0 0}^{\circ} \mathrm{C}$. The mixing chamber, proposed by Westinghouse, and the Power Conversion System for direct combined cycle, proposed by General Atomics, were removed from the critical list.

Action: Focus resources on the remaining critical PASSCs.

3. Conclusion: Differences exist between the PASSCs determined to be critical by each supplier. Some of the designs proposed by the suppliers are at differing levels of technical maturity. Hence, one supplier might consider a system to be more mature and not satisfy the definition for a critical system. For example, the Core Conditioning System is not considered critical by all suppliers.

Action: Use the technical maturity of the proposed designs as one criterion in evaluating and down selecting the design used in the NGNP, such as in the due diligence reviews.

4. Conclusion: Differences exist between the NGNP Project and the suppliers on the current TRL of each critical PASSC and on the steps needed for technology maturation. For example, when materials issues are yet to be resolved, NGNP has not granted a TRL higher than 4.

Action: Resolve the differences in TRL assessment by convening an independent TRL validation board and generate a set of validated NGNP TRLs.

5. Conclusion: Most NGNP Critical PASSCs are currently at a low level of technical maturity. The minimum PASSC TRL is a 3 . This lack of maturity is primarily due to the fact that materials issues and the lack of demonstrated component operability.

Action: Expedite the work called on in the TDRM to increase technology readiness.

6. Conclusion: Major decisions must be made at key points in the project life cycle to select technologies and design strategies that reduce risk and enhance the opportunity for project success. The major decision options and technology hurdles will be addressed throughout the TDRM process as a basis for conceptual, preliminary, and final design, and for updating the integrated project schedule.

Action: Work the TDRM process, including the down selection of technologies based on identified decision discriminators, to provide the technology readiness input needed to make design decisions. Accelerate key risk-reducing tasks to inform decisions.

7. Conclusion: A component test capability is required to reduce the risk and fully mature critical PASSCs prior to insertion in the NGNP. Based on reviews of the available 
international test capabilities/facilities, the reactor suppliers have identified 90 tests to be performed in a component test capability to adequately mature the technologies and components prior to insertion in the NGNP.

Action: Develop a component test capability needed to conduct supplier-identified tests. 


\section{CONTENTS}

EXECUTIVE SUMMARY 1

ACRONYMS

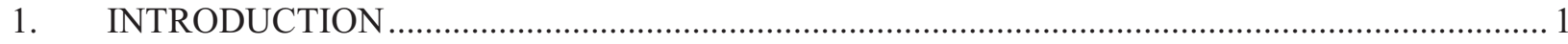

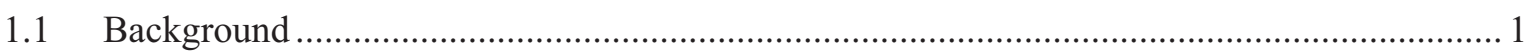

1.1.1 Technology Readiness Levels for Critical Structures, Systems, and

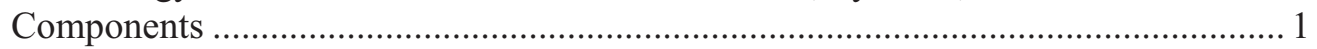

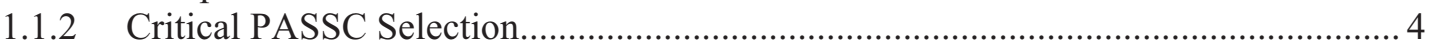

1.1.3 Technology Development Roadmaps for Critical Structures, Systems, and

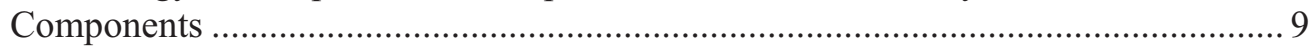

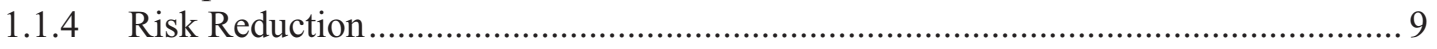

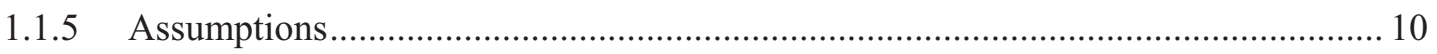

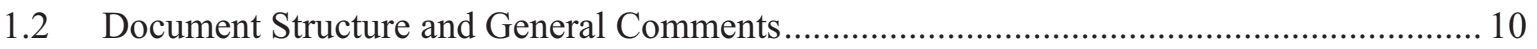

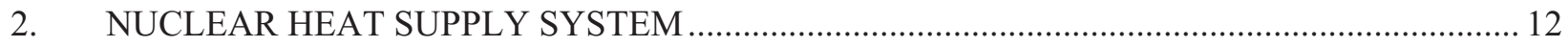

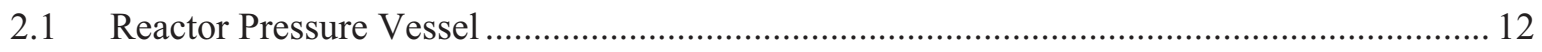

2.1.1 Reactor Pressure Vessel Design Description ........................................................... 12

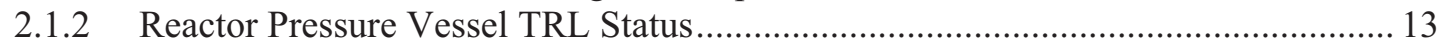

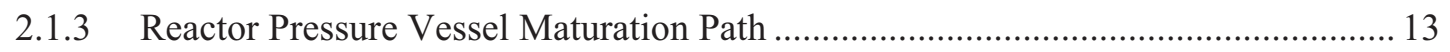

2.1.4 Consolidated INL Technology Development Roadmap ........................................ 14

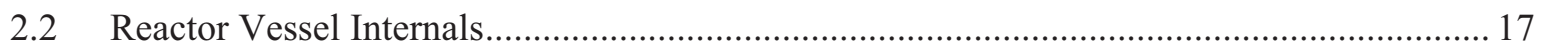

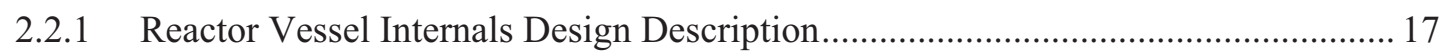

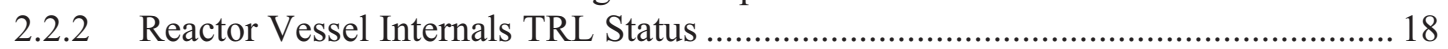

2.2.3 Reactor Vessel Internals Maturation Path............................................................. 19

2.2.4 Consolidated INL Technology Development Roadmap ........................................... 20

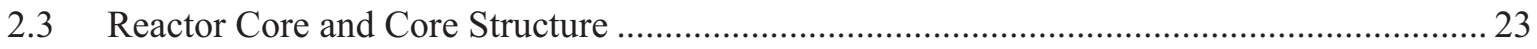

2.3.1 Reactor Core and Core Structure Design Description ............................................ 23

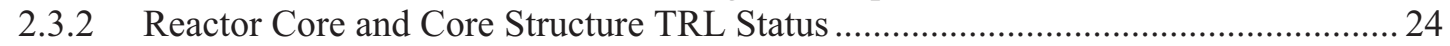

2.3.3 Reactor Core and Core Structure Maturation Path ...................................................25

2.3.4 Consolidated INL Technology Development Roadmap ..........................................25

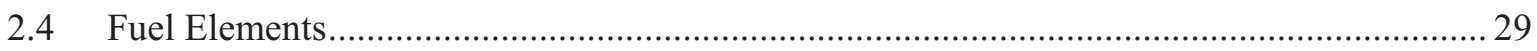

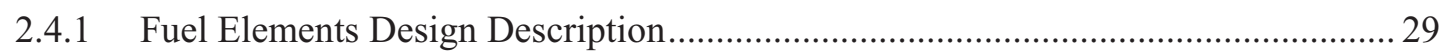

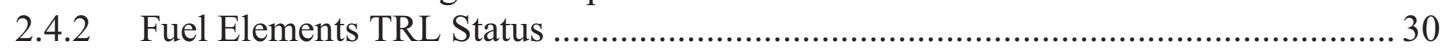

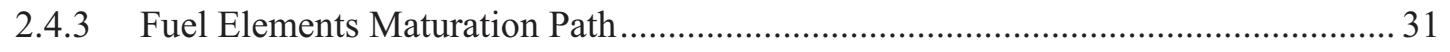

2.4.4 Consolidated INL Technology Development Roadmap ......................................... 32

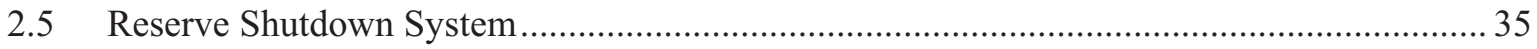

2.5.1 Reserve Shutdown System Design Description ...................................................... 35

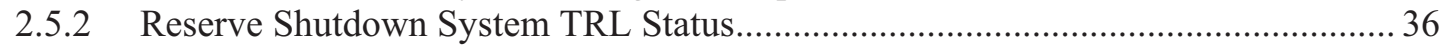

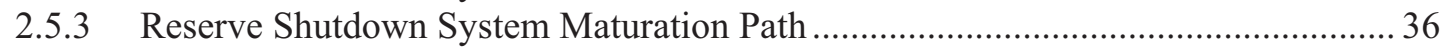

2.5.4 Consolidated INL Technology Development Roadmap ........................................ 36

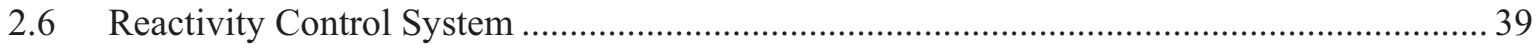

2.6.1 Reactivity Control System Design Description ..................................................... 39

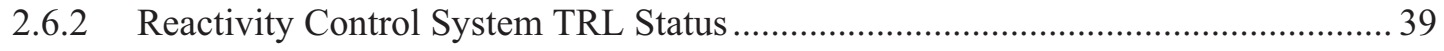

2.6.3 Reactivity Control System Maturation Path ..................................................... 40 
2.6.4 Consolidated INL Technology Development Roadmap .......................................... 40

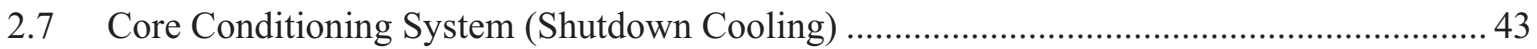

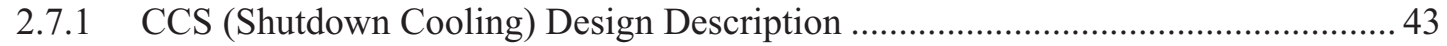

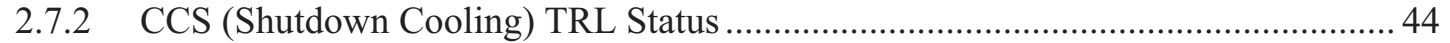

2.7.3 CCS (Shutdown Cooling) Maturation Path.................................................................. 44

2.7.4 Consolidated INL Technology Development Roadmap ............................................ 44

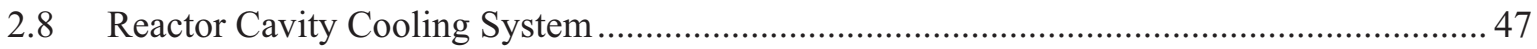

2.8.1 Reactor Cavity Cooling System Design Description ............................................... 47

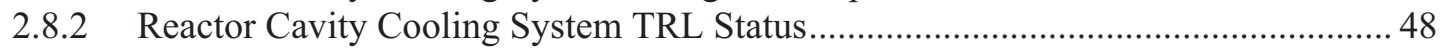

2.8.3 Reactor Cavity Cooling System Maturation Path ................................................... 49

2.8.4 Consolidated INL Technology Development Roadmap ......................................... 49

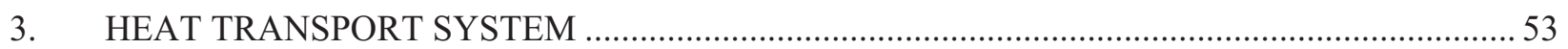

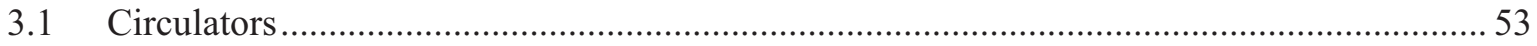

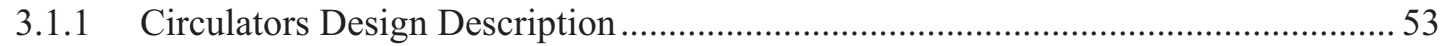

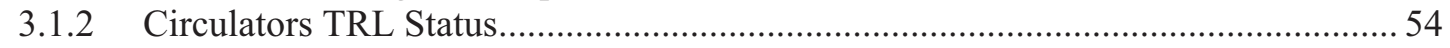

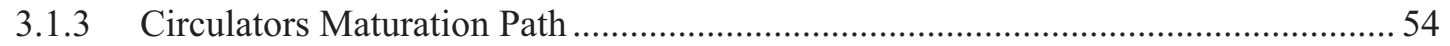

3.1.4 Consolidated INL Technology Development Roadmap .......................................... 55

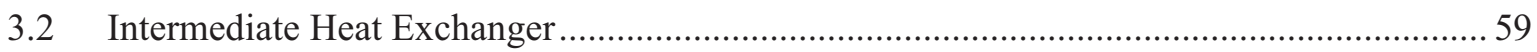

3.2.1 Intermediate Heat Exchanger Design Description ...................................................59

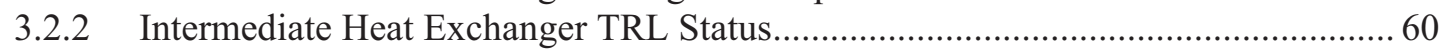

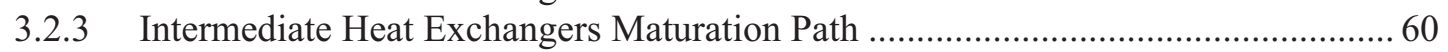

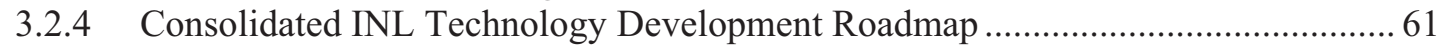

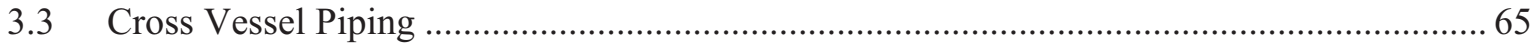

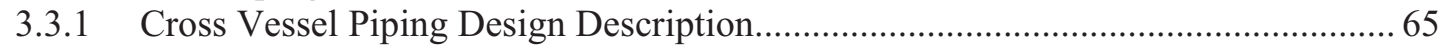

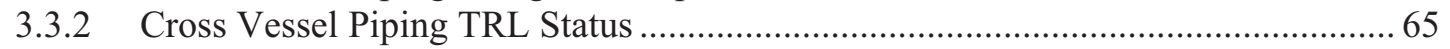

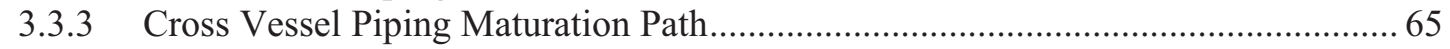

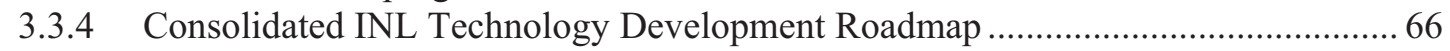

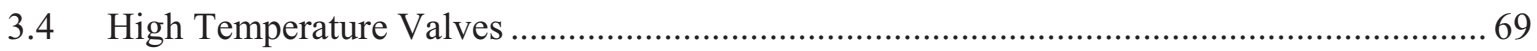

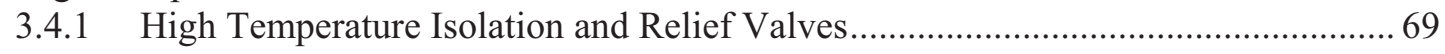

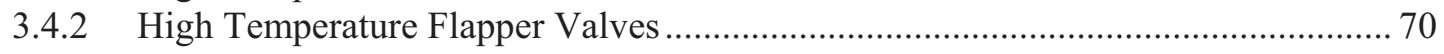

3.4.3 Consolidated INL Technology Development Roadmap ......................................... 71

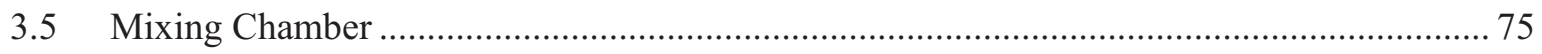

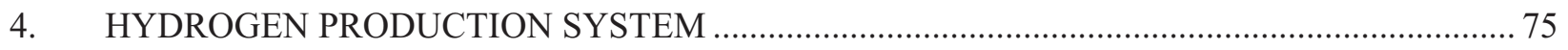

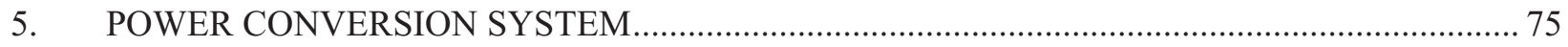

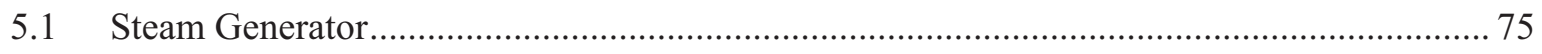

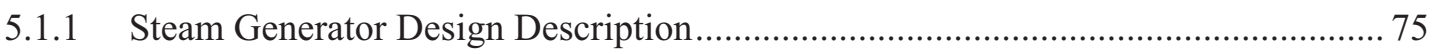

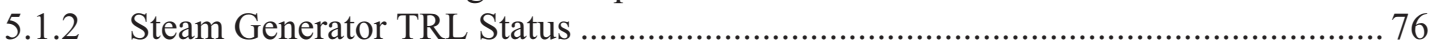

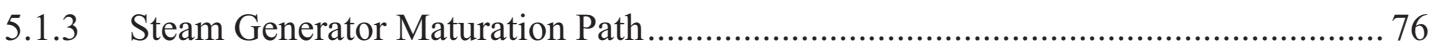

5.1.4 Consolidated INL Technology Development Roadmaps......................................... 76

5.2 PCS Equipment for Direct Combined Cycle .................................................................. 79

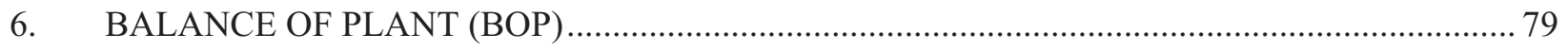

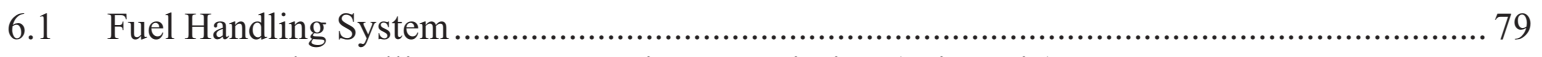

6.1.1 Fuel Handling System Design Description (Prismatic) ......................................... 79

6.1.2 Fuel Handling System Design Description (Pebble Bed) ......................................... 81 
6.1.3 Consolidated INL Technology Development Roadmap ........................................ 84

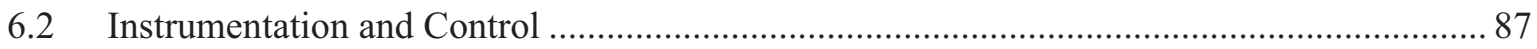

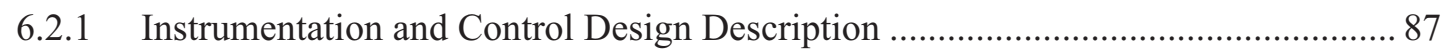

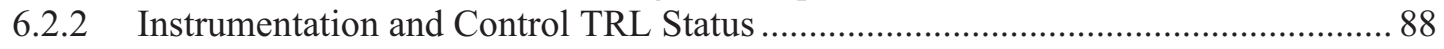

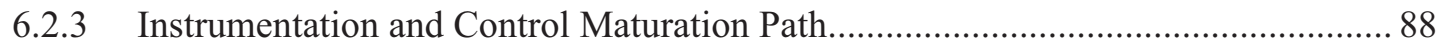

6.2.4 Consolidated INL Technology Development Roadmap ........................................... 88

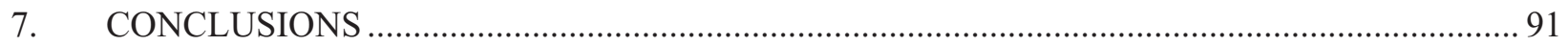

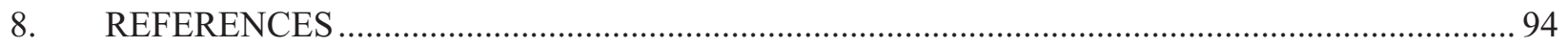

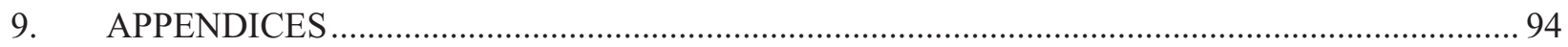

Appendix A Supplier Reports, Large Consolidated Roadmaps, and TRL Rating Sheets for 750$800^{\circ} \mathrm{C}$ ROT

\section{FIGURES}

Figure ES-1. Technology Readiness Levels 4

Figure ES-2. Executing the Roadmap increases Readiness while Reducing Risk.....................................5

Figure ES-3. Nuclear Heat Supply System Summary Roadmap for $750-800^{\circ} \mathrm{C}$ ROT …......................... 7

Figure ES-4. Heat Transport System Summary Roadmap for $750-800^{\circ} \mathrm{C}$ ROT ...................................... 8

Figure ES-5. Power Conversion System Summary Roadmap for 750-800 ${ }^{\circ} \mathrm{C}$ ROT …............................. 9

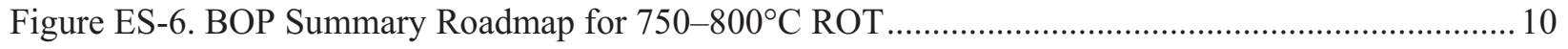

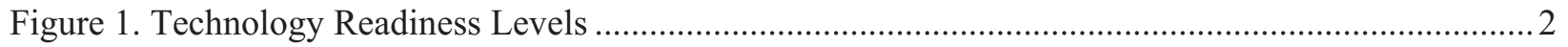

Figure 2. NGNP TRL Consolidation of Critical PASSCs for $750^{\circ} \mathrm{C}-800^{\circ} \mathrm{C}$ ROT …........................... 4

Figure 3. Schematic of AREVA Reference Plant Design for TDRM Process .......................................... 5

Figure 4. General Atomics NGNP Configuration for Technology Development Roadmapping ................ 6

Figure 5. PBMR NGNP Demonstration Plant Process Flow Diagram - H2 Production $\left(950^{\circ} \mathrm{C}\right)$............... 7

Figure 6. Executing the Roadmap increases Readiness while Reducing Risk......................................... 10

Figure 7. Typical Reactor Vessel \& Support System ……................................................................... 12

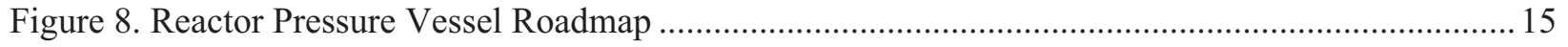

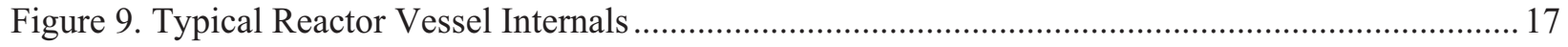

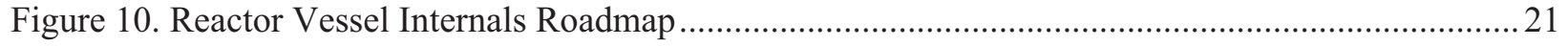

Figure 11. Representative Annular Prismatic Core Design ................................................................. 23

Figure 12. Reactor Core and Core Structure Roadmap..................................................................... 27

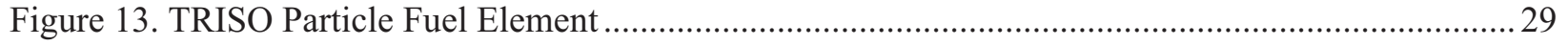

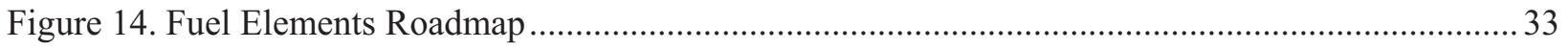

Figure 15. Representative Reserve Shutdown System Schematic Layout..............................................35 


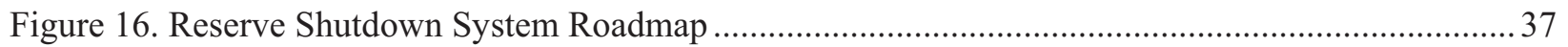

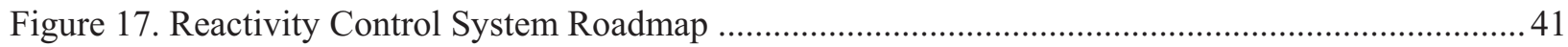

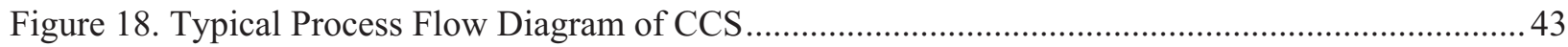

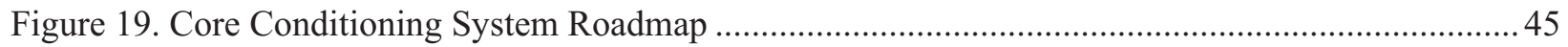

Figure 20. Representative RCCS Layout provided by AREVA …....................................................... 47

Figure 21. General arrangement of RCCS components (provided by AREVA) ..................................... 48

Figure 22. Reactor Cavity Cooling System Roadmap ......................................................................... 51

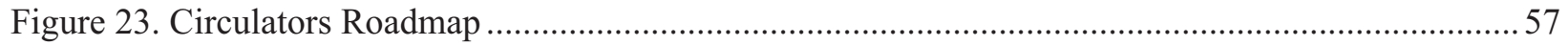

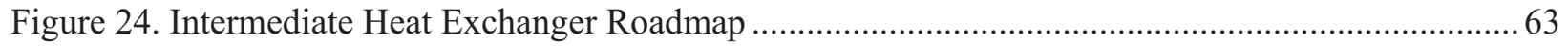

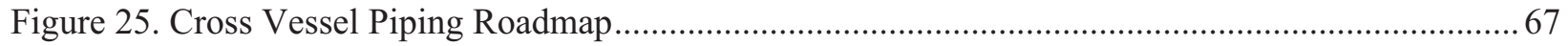

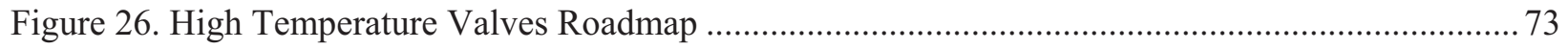

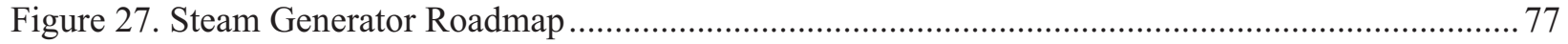

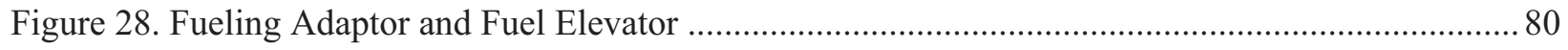

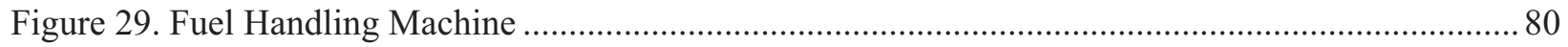

Figure 30. Typical Layout of the Prismatic Fuel Handling and Storage System...................................8 82

Figure 31: The simplified process flow diagram of the Prismatic FHSS ................................................. 83

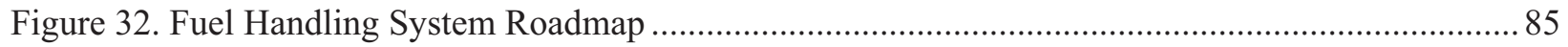

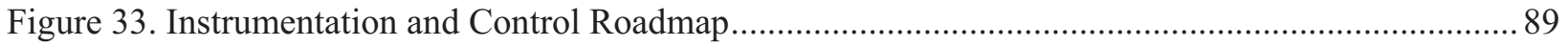

\section{TABLES}

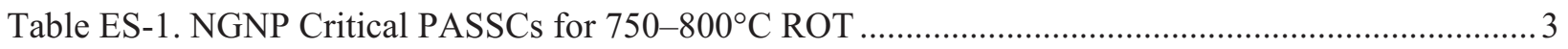

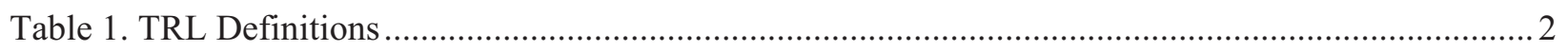

Table 2. Supplier-Identified Critical PASSCs for $750-800^{\circ} \mathrm{C}$ ROT................................................... 8

Table 3. Reactor Pressure Vessel Summary TRL Table ...................................................................... 13

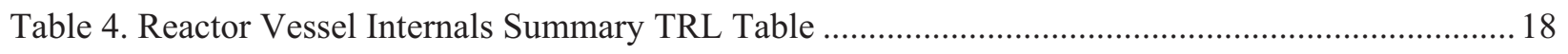

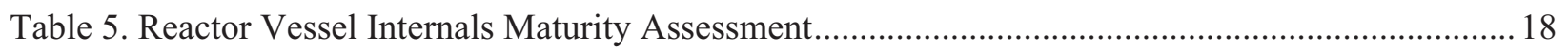

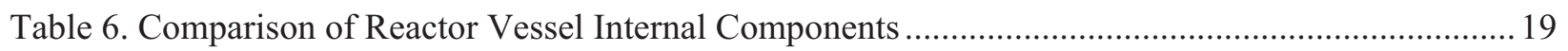

Table 7. Reactor Core and Core Structure Summary TRL Table .............................................................. 25

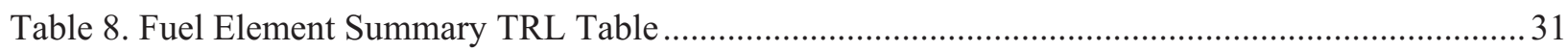

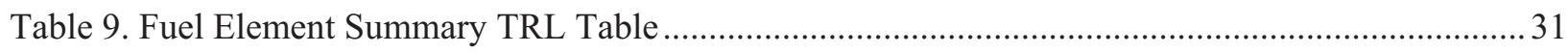

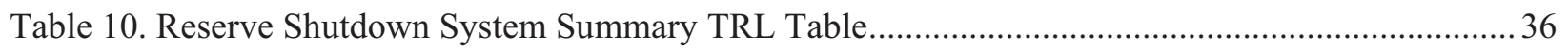

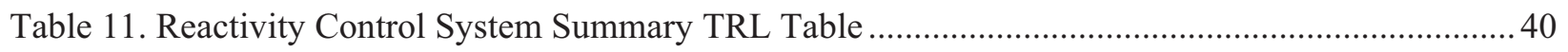

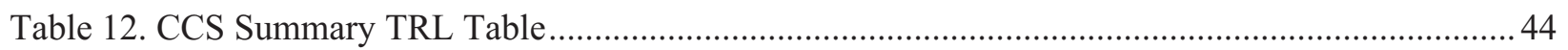

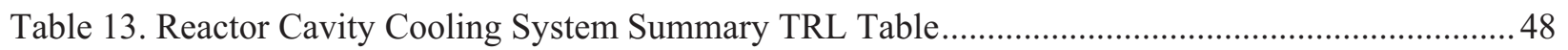




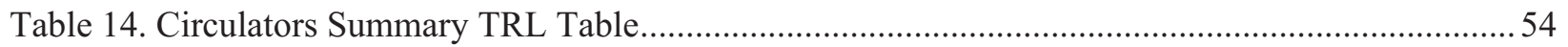

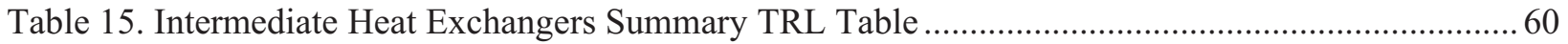

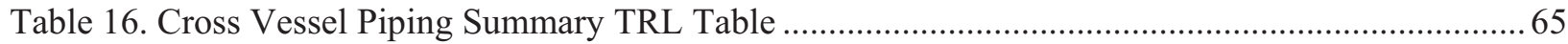

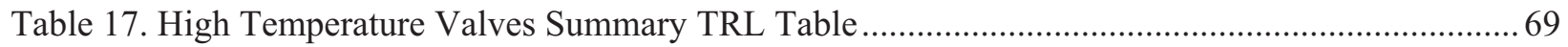

Table 18. High Temperature Valves Summary TRL Table .................................................................. 71

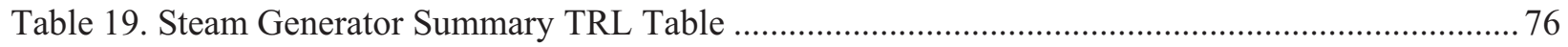

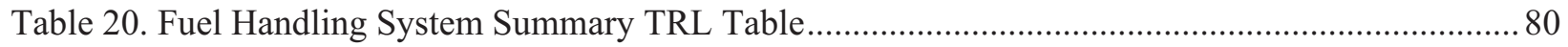

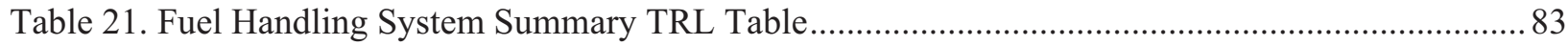

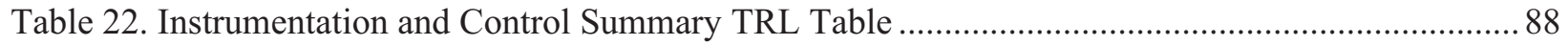

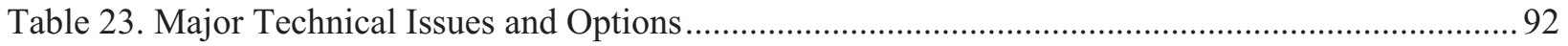

Table 24. Tests Requiring Component Test Capability......................................................................... 93 
This page intentionally left blank. 


\section{ACRONYMS}

AGC

AGR

$\mathrm{AOO}$

ASME

AVR

BOP

$\mathrm{C} / \mathrm{C}$

CCS

CRDM

CTC

CVP

DBA

DOD

DPP

FHM

FHS

FIMA

GWd/MTHM

GT-MHR

HPS

HyS

HTE

HTGR

HTS

HTTR

$\mathrm{I} \& \mathrm{C}$

IHX

INL

LWR

MHTGR

$\mathrm{MWd} / \mathrm{tU}$

NASA

NGNP
Advanced Graphite Capsule

Advanced Gas Reactor

Anticipated Operational Occurrence

American Society of Mechanical Engineers

Arbeitsgemeinschaft Versuchsreaktor (Germany)

Balance of Plant

Carbon/Carbon (composite)

Core Conditioning System

Control Rod Drive Mechanism

Component Test Capability

Cross Vessel Piping

Design Basis Accident

U.S. Department of Defense

Demonstration Pilot Plant

Fuel Handling Machine

Fuel Handling System

fissions per initial metal atom

Gigawatt days/Metric Tons Heavy Metal

Gas Turbine-Modular Helium Reactor

Hydrogen Production System

Hybrid Sulfur

High Temperature Electrolysis

High Temperature Gas-Cooled Reactor

Heat Transport System

High Temperature Test Reactor (Japan)

Instrumentation and Controls

Intermediate Heat Exchanger

Idaho National Laboratory

Light Water Reactor

Modular High-Temperature Gas-cooled Reactor

Megawatt days/Thermal Unit

National Aeronautic and Space Administration

Next Generation Nuclear Plant 
NHS Nuclear Heat Supply System

NPR New Production Reactor

PASSC Plant, Areas, Systems, Subsystems, and Components

PBMR Pebble-Bed Modular Reactor

PCS Power Conversion System

PHTS Primary Heat Transport System

PIE Post-Irradiation Examination

R\&D Research and Development

RAMI Reliability, Availability, Maintainability, and Inspectabilty

RCCS Reactor Cavity Cooling System

RCS Reactivity Control System

RPV Reactor Pressure Vessel

RSA Republic of South Africa

RSS Reserve Shutdown System

RVI Reactor Vessel Internals

SAR Safety Analysis Report

SCHE Shutdown Cooling Heat Exchanger

SHTS Secondary Heat Transport System

SI Sulfur-Iodine

$\mathrm{SiC} / \mathrm{SiC} \quad$ Silicon-Carbide/Silicon-Carbide (composite)

SRM System Requirements Manual

$\mathrm{SSC}$

System, Subsystem/Structure, Component

TBD To Be Determined

TDRM Technology Development Roadmap

THTR Thorium Hocktemperatur Reaktor (Germany)

TRISO tri-isotropic (particles)

TRL Technology Readiness Level

VCS Vessel Cooling System

VHTR Very High Temperature Reactor 


\section{Next Generation Nuclear Plant Project Technology Development Roadmaps: The Technical Path Forward for $750-800^{\circ} \mathrm{C}$ Reactor Outlet Temperature}

\section{INTRODUCTION}

Industry experience repeatedly demonstrates the consequences of proceeding with projects using technologies that are not sufficiently mature. The U.S. General Accounting Office noted that these consequences manifest themselves as cost overruns and schedule delays late in the project life cycle [GAO 2007]. To avoid these undesirable consequences, the Next Generation Nuclear Plant (NGNP) project initiated effort to assess technology readiness of critical Plant, Areas, Systems, Subsystems, and Components (PASSCs) and identify the steps required to ensure sufficient maturity prior to inclusion into the NGNP design.

This document presents the NGNP Critical PASSCs and defines their technical maturation path through Technology Development Roadmaps (TDRMs) and their associated Technology Readiness Levels (TRLs). As the critical PASSCs advance through increasing levels of technical maturity, project risk is reduced and the likelihood of within-budget and on-schedule completion is enhanced. The current supplier-generated TRLs and TDRMs for a $750-800^{\circ} \mathrm{C}$ reactor outlet temperature (ROT) specific to each supplier are collected in Appendix A.

\subsection{Background}

\subsubsection{Technology Readiness Levels for Critical Structures, Systems, and Components}

The Technology Readiness Assessment process originates with NASA and the U.S. Department of Defense (DOD) and evaluates the deployment readiness of a technology and its readiness to function in an integrated environment. The NGNP uses TRLs with a tailored scale of 1 to 10, compared to the standard 1 to 9 scale used by NASA and DOD. The additional rating allows the NGNP to assess readiness for full commercialization following the construction and successful operation of the NGNP.

Technology Readiness Levels are an input to inform NGNP project management of the readiness of a particular technology, component, or system. For TRLs 1-5, assessment typically occurs on an individual technology or component with a calculated roll up TRL for the associated area, systems, and subsystems. As the technology or component progress to further levels of maturity, integrated testing occurs and allows TRL assessments directly against subsystems and systems. The integrated testing or modeling occurs at increasingly larger scales and in increasingly relevant environments, thus achieving higher TRL ratings. Abbreviated TRL definitions are shown in Figure 1. 

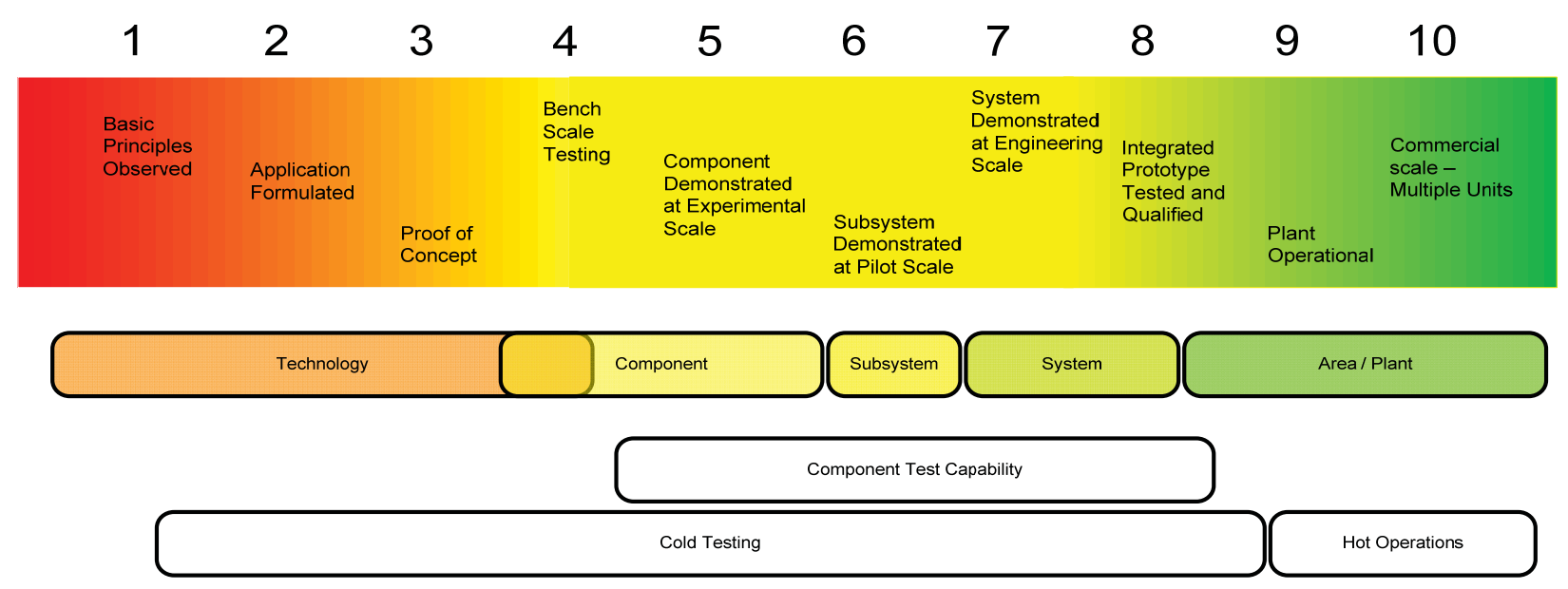

Figure 1. Technology Readiness Levels

Expanded definitions of the TRLs are provided in Table 1.

Table 1. TRL Definitions

\begin{tabular}{|c|c|c|}
\hline $\begin{array}{c}\text { Rating } \\
\text { Level }\end{array}$ & Technology Readiness Level Definition & $\begin{array}{l}\text { TRL Abbreviated } \\
\text { Definition }\end{array}$ \\
\hline 1 & $\begin{array}{l}\text { Basic principles observed and reported in white papers, industry literature, lab } \\
\text { reports, etc. Scientific research without well defined application. }\end{array}$ & Basic principles observed \\
\hline 2 & $\begin{array}{l}\text { Technology concept and application formulated. Issues related to performance } \\
\text { identified. Issues related to technology concept have been identified. Paper studies } \\
\text { indicate potentially viable system operation. }\end{array}$ & Application formulated \\
\hline 3 & $\begin{array}{l}\text { Proof-of concept: Analytical and experimental critical function and/or } \\
\text { characteristic proven in laboratory. Technology or component tested at laboratory- } \\
\text { scale to identify/screen potential viability in anticipated service. }\end{array}$ & Proof of Concept \\
\hline 4 & $\begin{array}{l}\text { Technology or Component is tested at bench-scale to demonstrate technical } \\
\text { feasibility and functionality. For analytical modeling, use generally recognized } \\
\text { benchmarked computational methods and traceable material properties. }\end{array}$ & Bench-scale testing \\
\hline 5 & $\begin{array}{l}\text { Component demonstrated at experimental scale in relevant environment. } \\
\text { Components have been defined, acceptable technologies identified and } \\
\text { technology issues quantified for the relevant environment. Demonstration } \\
\text { methods include analyses, verification, tests, and inspection. }\end{array}$ & $\begin{array}{l}\text { Component Verified at } \\
\text { Experimental Scale }\end{array}$ \\
\hline 6 & $\begin{array}{l}\text { Components have been integrated into a subsystem and demonstrated at a } \\
\text { pilot-scale in a relevant environment. }\end{array}$ & $\begin{array}{l}\text { Subsystem Verified at Pilot- } \\
\text { scale in a relevant } \\
\text { environment }\end{array}$ \\
\hline 7 & $\begin{array}{l}\text { Subsystem integrated into a system for integrated engineering-scale } \\
\text { demonstration in a relevant environment. }\end{array}$ & $\begin{array}{l}\text { System demonstration at } \\
\text { Engineering-scale }\end{array}$ \\
\hline 8 & $\begin{array}{l}\text { Integrated prototype of the system is demonstrated in its operational } \\
\text { environment with the appropriate number and duration of tests and at the required } \\
\text { levels of test rigor and quality assurance. Analyses, if used support extension of } \\
\text { demonstration to all design conditions. Analysis methods verified. Technology } \\
\text { issues resolved pending qualification (for nuclear application, if required). } \\
\text { Demonstrated readiness for hot startup }\end{array}$ & $\begin{array}{l}\text { Integrated Prototype Tested } \\
\text { and Qualified in a non- } \\
\text { radiological operating } \\
\text { environment }\end{array}$ \\
\hline 9 & $\begin{array}{l}\text { The project is in final configuration tested and demonstrated in operational } \\
\text { environment. }\end{array}$ & Plant Operational. \\
\hline 10 & $\begin{array}{l}\text { Commercial-scale demonstration is achieved. Technological risks minimized by } \\
\text { multiple units built and running through several years of service cycles. }\end{array}$ & $\begin{array}{l}\text { Commercial Scale - } \\
\text { Multiple Units }\end{array}$ \\
\hline
\end{tabular}


In January 2009, the NGNP project issued a report (INL/EXT-08-15148) entitled, Next Generation Nuclear Plant Project Technology Development Roadmaps: The Technical Path Forward. The report documents a Technology Readiness Assessment, critical PASSCs, and Technology Development Roadmaps (TDRM) to mature the technologies needed for a high-temperature gas reactor with an outlet temperature of $950^{\circ} \mathrm{C}$, as well as other requirements. The requirements and operating conditions are consistent with those found in the NGNP System Requirements Manual (SRM) [INL 2008a] and Summary of Bounding Requirements for the NGNP Demonstration Plant F\&ORs [INL 2008b].

This report is an update to the January 2009 report and baselines the critical PASSCs, Technology Readiness Levels, and the TDRMs to mature the technologies needed for a high-temperature gas reactor with an outlet temperature of $750-800^{\circ} \mathrm{C}$, as well as other requirements and operating conditions consistent with those found in the SRM, Revision 2. As such, this document establishes a baseline for the current technology readiness status and provides a path forward to achieve increasing levels of technical maturity and reduce risk. The January 2009 report and TDRMs show numerous engineering studies and design tasks initiating in March 2009. These tasks were not initiated due to funding constraints and a lack of authorization to initiate design tasks. This report shows these studies and tasks initiating in October 2009 based on the assumption that design tasks will be funded and authorized by that time.

The salient features of the pre-conceptual design requirements are as follows:

- Reactor outlet temperature (ROT) of $750-800^{\circ} \mathrm{C}$

- $\quad$ Pressure of 5-9 MPa

- Indirect Configuration using pebble bed reactor design and a secondary gas loop to supply heat. - Westinghouse

OR Indirect Configuration using a prismatic block reactor design with a secondary loop using steam as the heat transport fluid. - AREVA / General Atomics

- GenIV fuel type

- 60 year plant life.

Each supplier performed a Technology Readiness Assessment and presented evidence to justify their proposed TRL rating (see Appendix A). While many of the selected critical PASSCs differed by supplier, several PASSCs were common to all suppliers. The common critical PASSCs were rated with different TRLs by each supplier based on differing supplier designs, different supplier supported demonstrations of those designs, and different interpretations of the TRL definitions. The Idaho National Laboratory (INL) reviewed these justifications and associated paths forward and developed NGNP consolidated TRL ratings and consolidated NGNP TDRMs. These consolidated TRL ratings:

- Establish the current state of proposed technologies that are used as the starting point for TRLs

- Provide a consistent measure of readiness levels and confidence in the levels as inputs to quantifying performance, cost, and schedule risks. 
Figure 2 depicts the consolidated TRLs of the critical PASSCs. The method depicted here will be used to evaluate the technical readiness of each area and the NGNP as a whole. Once the TRLs are validated by an independent review board, the relative contribution to the weighted average will be factored into the rollup, currently depicted as TBDs. At that time, this tool will be used to evaluate (1) one proposed NGNP design against another, (2) one design associated with certain requirements versus another design associated with another set of requirements, and (3) progress over time.

\subsubsection{Critical PASSC Selection}

The NGNP can be divided into five areas: Nuclear Heat Supply System (NHS), Heat Transport System (HTS), Hydrogen Production System (HPS), Power Conversion System (PCS), and Balance of Plant (BOP). Each area is further broken down into systems, which are comprised of subsystems, which are further comprised of components. The current status of the TRLs, TDRMs, and

\begin{tabular}{|c|c|c|c|}
\hline \begin{tabular}{|l|} 
NGNP \\
$\quad$ Area \\
$\quad$ System
\end{tabular} & $\begin{array}{l}\text { Min } \\
\text { TRL }\end{array}$ & Wgt & $\begin{array}{l}\text { Avg } \\
\text { TRL }\end{array}$ \\
\hline NGNP & 3 & & TBD \\
\hline Nuclear Heat Supply System (NHSS) & 4 & TBD & TBD \\
\hline Reactor Pressure Vessel & 4 & TBD & \\
\hline Reactor Vessel Internals & 4 & TBD & \\
\hline Reactor Core and Core Structure & 4 & TBD & \\
\hline Fuel Elements & 4 & TBD & \\
\hline Reserve Shutdown System & 5 & TBD & \\
\hline Reactivity Control System & 4 & TBD & \\
\hline Core Conditioning System & 4 & TBD & \\
\hline Reactor Cavity Cooling System & 4 & TBD & \\
\hline Heat Transfer System (HTS) & 3 & & TBD \\
\hline Circulators & 5 & TBD & \\
\hline Intermediate Heat Exchangers & 3 & TBD & \\
\hline Cross Vessel Piping & 4 & TBD & \\
\hline High Temperature Valves - Flapper & 6 & TBD & \\
\hline High Temperature Valves - Iso, Relief & 4 & TBD & \\
\hline Power Conversion System (PCS) & 4 & & TBD \\
\hline Steam Generator & 4 & TBD & \\
\hline Balance of Plant (BOP) & 3 & & TBD \\
\hline Fuel Handling System - Prismatic & 4 & TBD & \\
\hline Fuel Handling System - Pebble Bed & 5 & TBD & \\
\hline Instrumentation \& Control & 3 & TBD & \\
\hline
\end{tabular}

Figure 2. NGNP TRL Consolidation of Critical PASSCs for $750^{\circ} \mathrm{C}-800^{\circ} \mathrm{C}$ ROT Test Plans for the critical PASSCs forming these five areas is the focus of this document. Although hydrogen production remains a critical PASSC, the hydrogen production system (HPS) TDRM was not updated pending a technology down selection. Upon down selection, a consolidated HPS TDRM for $750-800^{\circ} \mathrm{C}$ ROT will be generated to reflect the programs path forward.

Critical PASSCs are defined as those components that are not commercially available or have not been proven in relevant industry environments, at appropriate scale, or fully integrated with other components. Given the five areas for the NGNP, each supplier recommended 14-16 critical PASSCs required to perform the desired functions and meet the requirements specified by the project. The contractor-recommended PASSCs and Idaho National Laboratory (INL) prismatic fuel were consolidated into the 15 NGNP critical PASSCs. Each of the supplier selected designs is summarized below:

\section{AREVA}

The AREVA design uses a High Temperature Gas-Cooled Reactor (HTGR) as the NGNP that is envisioned as providing an $\mathrm{ROT}$ of $750^{\circ} \mathrm{C}$ and a conventional steam cycle. The plant configuration uses a prismatic block core and has two primary coolant loops, two steam generators, and one turbine generator. The steam produced by the steam generators provides energy to the turbine generator and one or more steam reboilers. The steam reboilers provide process steam to industrial processes through a tertiary process steam loop. The secondary side configuration is not fully defined at this point in conceptual design (see Figure 3). 


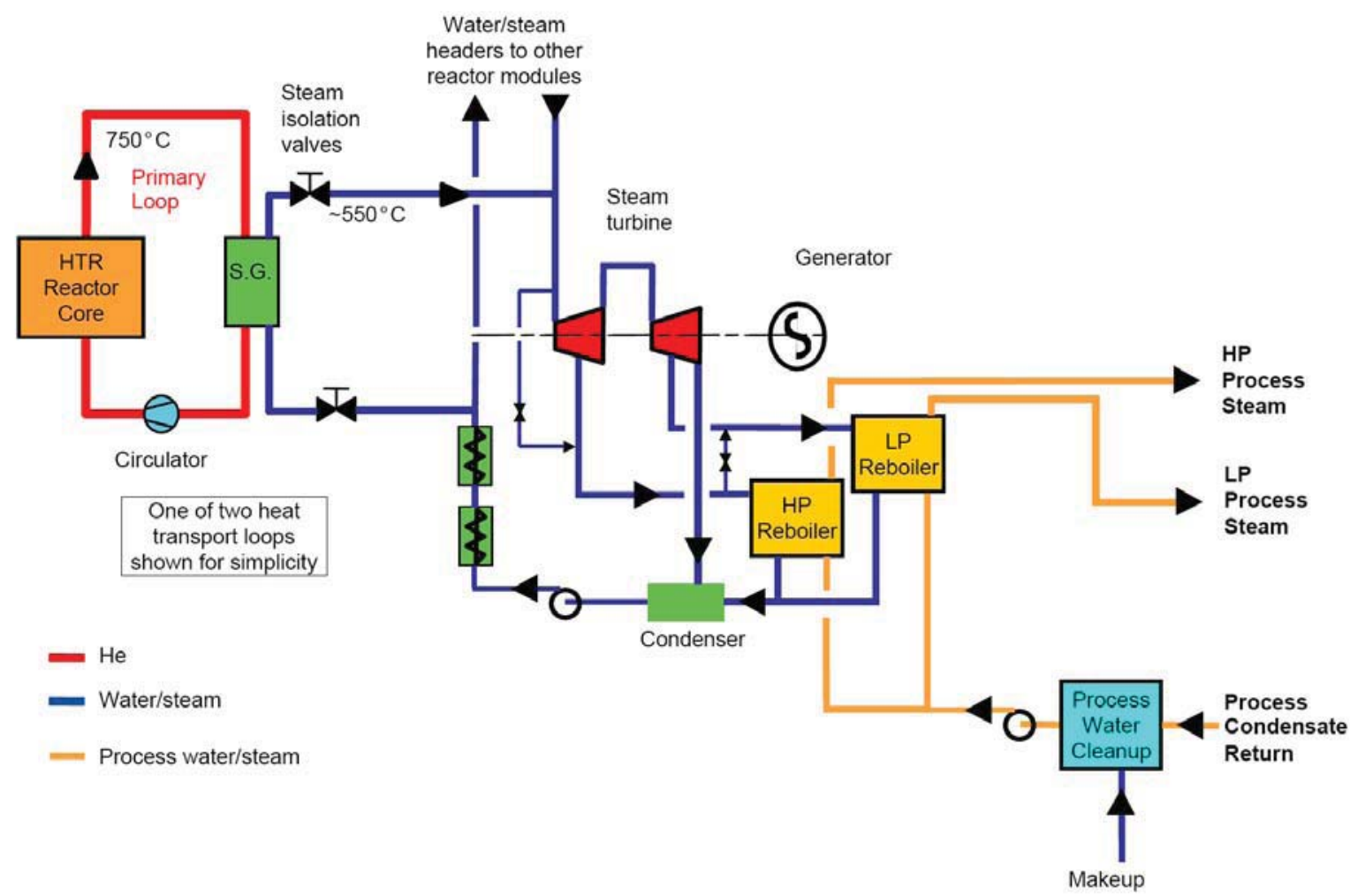

Figure 3. Schematic of AREVA Reference Plant Design for TDRM Process

\section{General Atomics}

General Atomics based their TDRM effort on the NGNP configuration shown in Figure 4, which is based on the decision by the NGNP Project to analyze a lower ROT in the range of $750^{\circ} \mathrm{C}-800^{\circ} \mathrm{C}$. As reflected by Figure 4, it is currently anticipated that the NGNP will be used to co-generate electricity and process heat in the form of steam, and that the steam will be provided to the end-user's facility via a tertiary loop. Heat will be transferred from an appropriate location (or locations) in the power conversion loop to the tertiary loop via a steam-to-steam heat exchanger. A steam-to-steam heat exchanger may also be needed in the power conversion loop to reheat the steam exiting the highpressure turbine as a means of improving power conversion cycle efficiency and reducing steam wetness at the back end of the cycle. This plant configuration is consistent with the high-level requirements specified in the latest revision of the NGNP Systems Requirements Manual [SRM 2009]. 


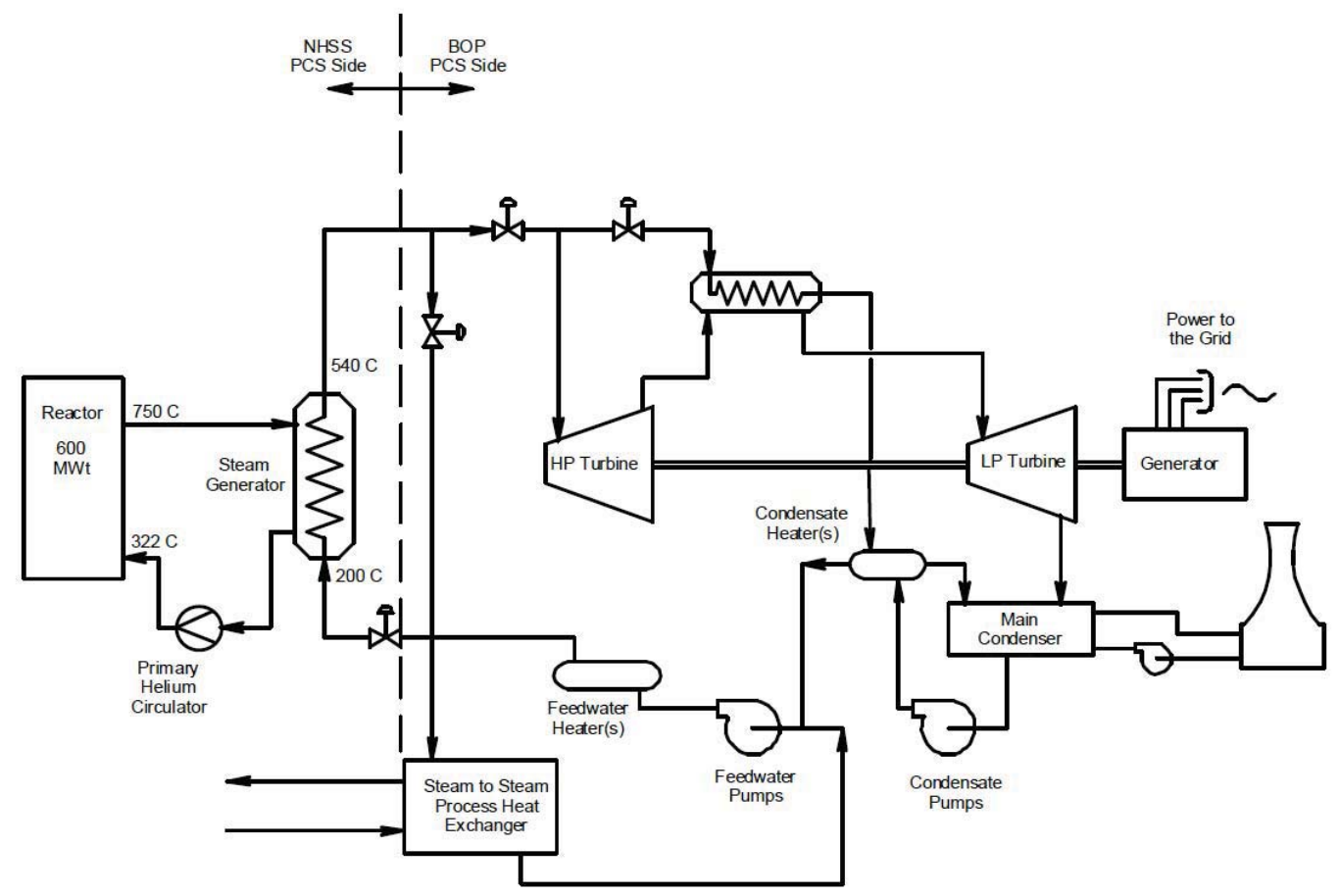

Figure 4. General Atomics NGNP Configuration for Technology Development Roadmapping

In the absence of a conceptual design, the following assumptions were made with respect to the NGNP design to provide a basis for this TDRM effort. These assumptions are based on the various NGNP conceptual design studies that have been performed to date by the General Atomics team.

- The working fluid for the primary heat transport loops will be helium, and for the secondary heat transport loop it will be steam.

- All vessels will be made out of LWR steel (i.e., SA-508/533). A vessel cooling system will not be necessary to control the reactor pressure vessel (RPV) maximum temperatures below ASME code limits for SA-508/533.

\section{Westinghouse}

Westinghouse proposed a pebble-bed reactor with primary and secondary helium loops coupled to a $750^{\circ} \mathrm{C}$ ROT. The schematic in Figure 5 presents one option for a steam production plant, and this option will be used as the $750^{\circ} \mathrm{C}$ reference for the purposes of this report. In this option, the Process Coupling Heat Exchanger (PCHX) is removed from the Secondary Heat Transport System (SHTS) and a single Intermediated Heat Exchanger (IHX) is retained. The steam could be used for electricity production, process steam, or cogeneration. This configuration represents the minimum departure from the PBMR NGNP Preconceptual Design and would provide enveloping development requirements for $750^{\circ} \mathrm{C}$ applications. It is potentially representative of applications, such as oil sands, in which extreme water quality requirements or other considerations (e.g., tritium migration) would dictate the use of an IHX. In other applications, it may be possible to eliminate the IHX and relocate the steam generator to the Primary Heat Transport System (PHTS). The actual configuration of a $750^{\circ} \mathrm{C}$ application remains subject to trade studies that would be done during conceptual design. 


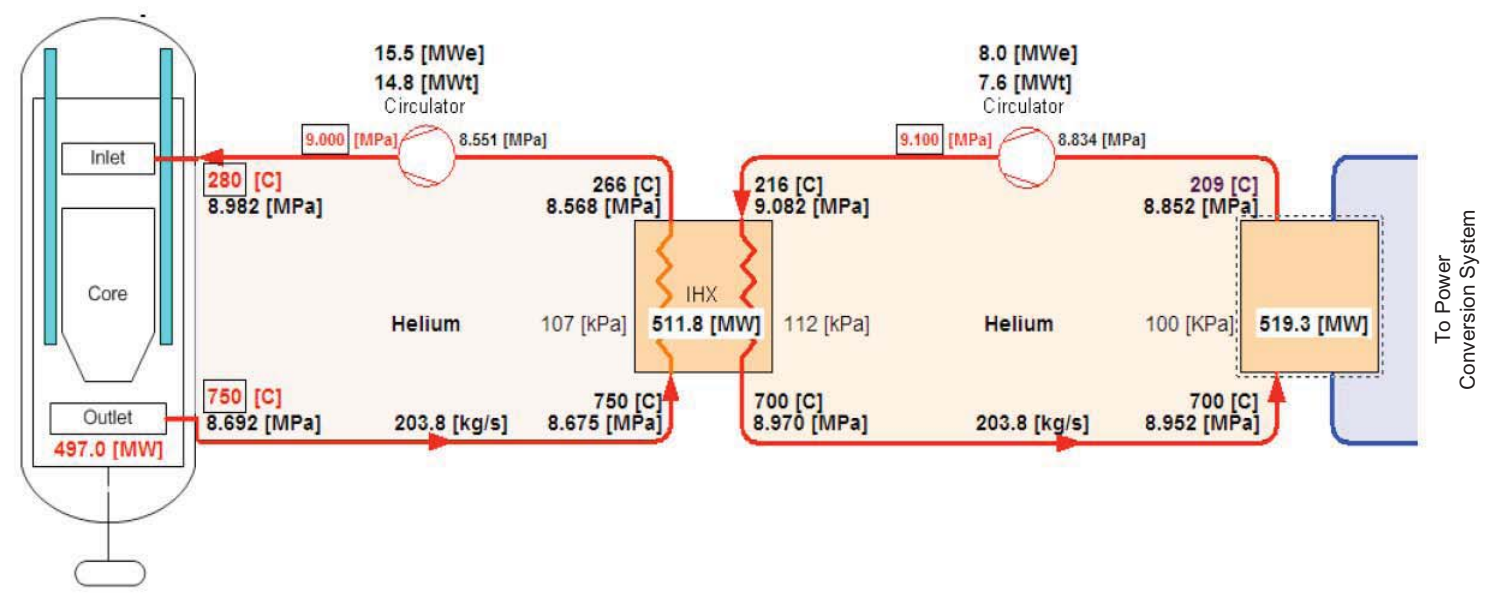

Figure 5. PBMR NGNP Demonstration Plant Process Flow Diagram - H2 Production $\left(950^{\circ} \mathrm{C}\right)$

Table 2 provides a mapping between the NGNP consolidated critical PASSCs and supplier-identified critical PASSCs. The table consists of five primary columns, representing the consolidated NGNP critical PASSCs, the AREVA critical PASSCs, the General Atomics critical PASSCs, the Westinghouse Electric Company critical PASSCs, and the INL Fuel Element and HPS PASSCs. The sub-columns to the left of the PASSC names identify the section number of the supplier report wherein the technology readiness assessment details are provided. In the case of NGNP consolidated PASSCs, the number represents the section in this document. Blank cells in the table represent an absence of supplier-identified PASSCs corresponding to the NGNP consolidated PASSCs. PASSCs are organized according to the five NGNP areas: Nuclear Heat Supply System (NHS), Heat Transport System (HTS), HPS, Power Conversion System (PCS), and Balance of Plant (BOP). One addition to the table not used in the rest of the document is Other Development Issues. This is presented to provide a place holder for additional PASSCs that suppliers deemed important, but not critical, in the TDRM work and activities associated with the scope of work tasked to them. As the design matures and requirements change, additional PASSCs may be added to those already identified in this report. 
Table 2. Supplier-Identified Critical PASSCs for $750-800^{\circ} \mathrm{C}$ ROT.

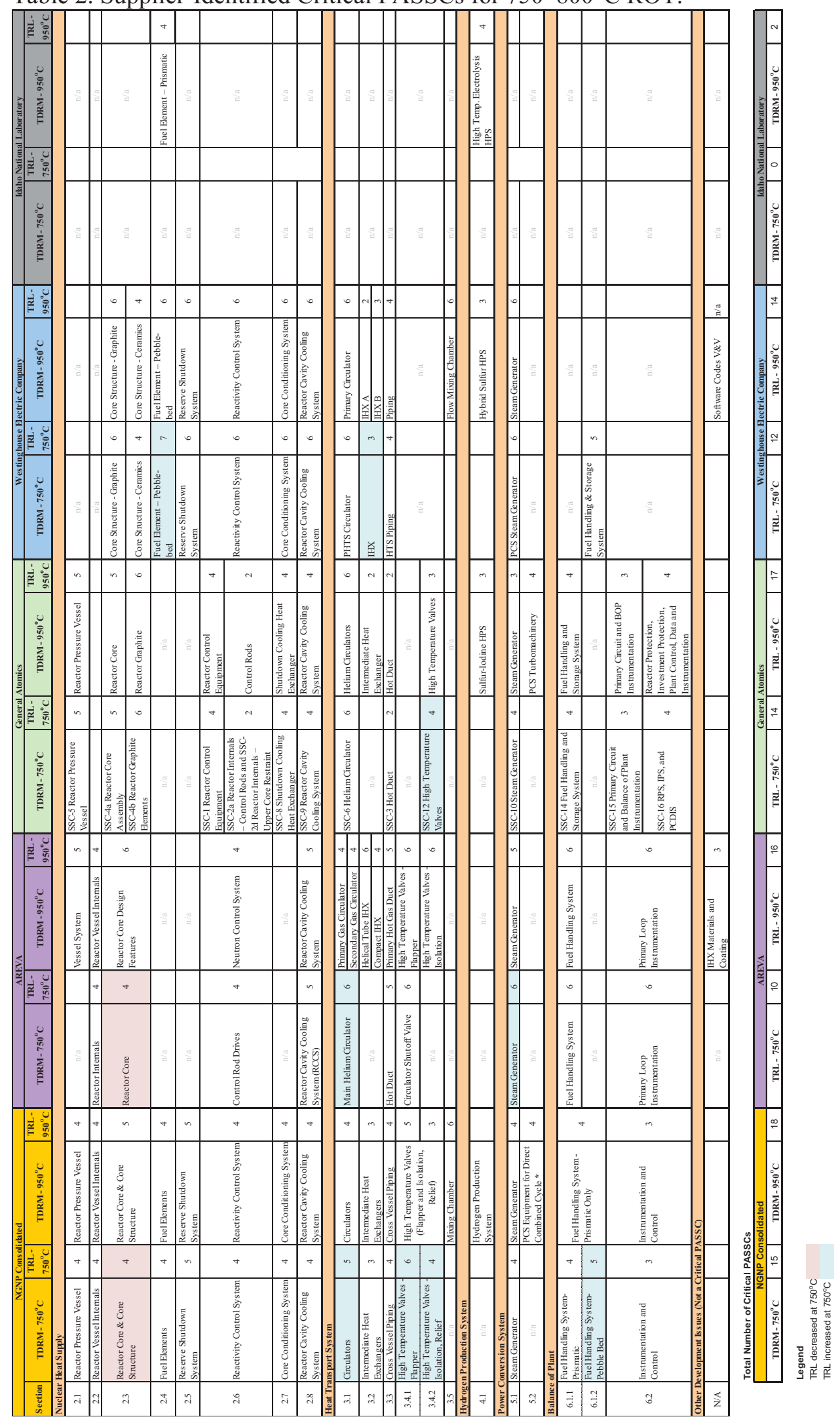




\subsubsection{Technology Development Roadmaps for Critical Structures, Systems, and Components}

In the NGNP application, TDRMs provide the framework and structure required to systematically perform decision analysis, reduce risk, and mature technologies in a cost effective and timely manner. The process includes Physical (PASSC) Structure Identification, Technology Readiness Assessment, Technology Selection, and Technology Maturation.

A TDRM documents the tasks needed to obtain information in key discriminating criteria to support technology down selection, and the tasks and tests required to sufficiently mature the technology and enhance project performance. The set of TDRMs along with their associated documentation will represent the path forward for the NGNP project to complete its mission, which consists of the research, development, design, construction, and operation of a prototype plant. Performance criteria are shown on the TDRM as a basis for TRL advancement. Where specific values are not known, TBDs are used. This document contains the TDRMs necessary to facilitate risk-informed decision making, technology down selection, management of technical uncertainty, and technology qualification and maturation for critical PASSCs, while also serving to coordinate engineering, research and development (R\&D), and licensing efforts and mitigate risks early in the NGNP project.

This process provides the following benefits to the NGNP project:

- Sets the vision for and drives the needed actions to down select technologies and designs

- Identifies project objectives and helps focus resources on critical technologies that are needed to meet those objectives

- Creates a shared vision of NGNP project needs based on capabilities needed now and in the future

- Provides early identification of high-risk items and allows early focused attention to enhance project cost and schedule success

- Supports R\&D, engineering, and management priorities, which inform schedule development and resource allocation

- Ensures technology readiness is demonstrated through testing, modeling, simulation, piloting, and prototyping

- Develops the test plans required to provide demonstrable evidence of the technology maturation required for codification, qualification, and licensing.

\subsubsection{Risk Reduction}

The major technical risks identified for each critical PASSC represent the overall uncertainties that must be addressed and reduced to enhance the probability of a successful NGNP. These risks are generally reduced as a technology is developed per the TDRMs. A risk that is not shown but requires addressing each of the PASSCs is one of system interconnectivity. Interconnectivity is proven and further reduced as one tests integrated and large-scale systems rather than mere components. This risk is not reduced sufficiently until the NGNP is system operability tested and successfully receives a TRL of 8 . Figure 6 shows a hypothetical risk reduction that occurs as the TDRM plan is executed and as technologies are matured through the advancing readiness levels. The majority of risk should be reduced prior to achieving a TRL of 5. To reduce cost and schedule overruns, the TDRMs are designed to reduce risk at the lowest possible TRL. 


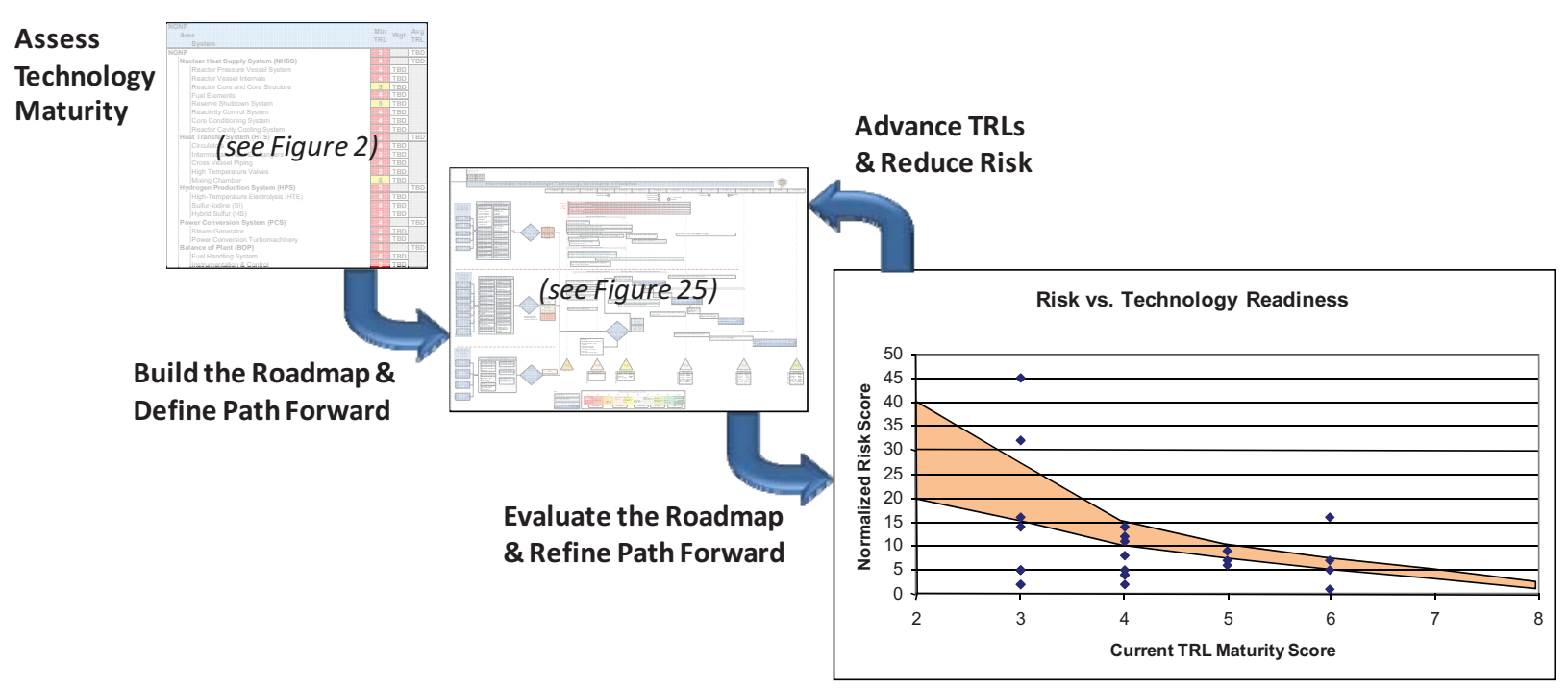

Figure 6. Executing the Roadmap increases Readiness while Reducing Risk.

\subsubsection{Assumptions}

The following assumptions are made in developing the TDRMs contained herein:

1. The reactor supplier reports (see Appendix A) will not change the content of this document when finalized.

2. A final Hydrogen Production System TDRM will be created to show selected technology(ies) and will complete the $750-800^{\circ} \mathrm{C}$ TDRMs.

3. The test plans created for the $950^{\circ} \mathrm{C}$ TDRMs (ref: January 2009 Report) have been modified for the $750-800^{\circ} \mathrm{C}$ TDRMs when they are appreciably different. Other test plans were not modified, and it is assumed the no appreciable differences exist.

4. Many design-related tasks are scheduled to initiate during the first quarter of fiscal year 2010. It is assumed that funding and authorization to begin engineering studies and design tasks will be granted by January 1, 2010.

\subsection{Document Structure and General Comments}

Sections 2 through 6 contain specific information regarding the five main NGNP areas, as follows:

- Section 2 - Nuclear Heat Supply System

- Section 3 - Heat Transport System

- Section 4 - Hydrogen Production System

- Section 5 - Power Conversion System

- Section 6 - Balance of Plant.

The subsections therein address specific PASSCs (typically at the system level) within those areas and provide the following general information: 


\section{Consolidated INL Technology Development Roadmaps}

A consolidated TDRM, produced from pertinent supplier-provided data combined with NGNP R\&D data, is provided for each critical PASSC. These TDRMs consist of $11 \times 17$ fold-out diagrams that visually depict the current TRL of critical PASSC; the steps required to advance the system to the desired end state; the schedule associated with TRL advancement activities; related design decisions, alternatives, and discriminators; and a summary of the major risks. E-sized, print-ready versions of the TDRMs are provided in Appendix A.

\section{Design Description}

Functional descriptions are provided for each of the supplier-identified critical PASSCs. Each description discusses the functions performed; potential design options, if any; and discriminators to aid selection between alternative designs. Identified discriminators have not yet been weighted to reflect their relative impact on design decisions, nor have performance measures and other metrics been assigned. These parameters and additional discriminators, if needed, will be identified through future design efforts. Details on supplier-proposed design solutions can be found in Appendix A.

\section{Technology Readiness Level Status}

Technology Readiness Level ratings, as provided by each supplier, are presented in tabular format alongside an NGNP assessment of the associated PASSC. Occasionally, a particular supplier's TRL assessment is shown as "Not Provided" to indicate that either the supplier did not provide a design alternative for the PASSC or that they consider an existing design alternative as already having a TRL rating of 6 or greater. Consolidated NGNP TRLs are based on currently available information and will be updated. At that time, TRLs will be weighted according to the relative importance of the PASSC to determine an overall TRL rating for the NGNP.

\section{Maturation Path}

The maturation path describes key tasks and tests required to advance only the 15 critical NGNP PASSCs to their desired end states. 


\section{NUCLEAR HEAT SUPPLY SYSTEM}

\subsection{Reactor Pressure Vessel}

The Reactor Pressure Vessel (RPV) houses the reactor, the reactor internals, and the reactor support structure.

\subsubsection{Reactor Pressure Vessel Design Description}

The RPV provides containment and structure for the reactor components, including the Reactor Core and the control rods, capable of withstanding the temperatures that are generated by the reaction heat.Figure 7 represents a typical reactor vessel and support system.

\subsubsection{Functions Performed}

The functions performed by the RPV System are:

- House and support the components of the Reactor Core, Reactor Internals, and Reactor Support Structure

- Maintain positioning relative to the control rods

- Contain the primary coolant inventory within a leaktight pressure boundary

- Maintain the integrity of the coolant pressure boundary.

\subsubsection{Design Options}

The RPV represents a fairly mature technology. The design of the RPV will be impacted somewhat by the design of the reactor core (e.g., pebble-bed or prismatic), but the primary development issues are the choice of material.

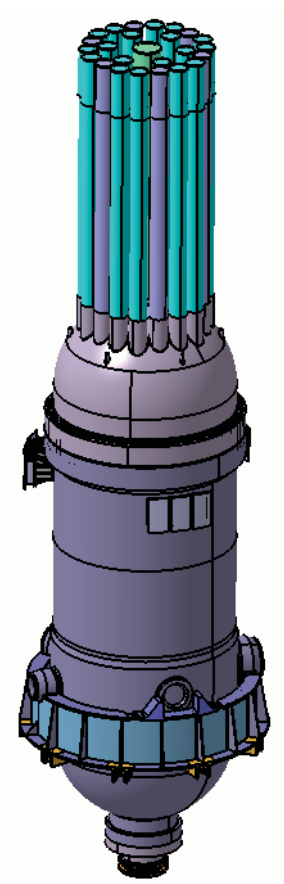

Figure 7. Typical Reactor Vessel \& Support System

General Atomics recommends using SA-508/533. However, limited data are available on the longterm thermal and environmental aging effects in an impure helium environment. In particular, creep deformation has been identified as a potential concern over a 60 -year design life of normal operations at $350^{\circ} \mathrm{C}$. With an ROT of $750^{\circ} \mathrm{C}$ and an inlet of about $320^{\circ} \mathrm{C}$, a vessel cooling system (VCS) may not be required to keep the vessel within ASME code limits for SA-508/533 steel.

Westinghouse does not consider the RPV to be a critical system, with regard to NGNP, based on an assumption that testing planned for a similar vessel associated with the Pebble-Bed Modular Reactor (PBMR) Demonstration Pilot Plant (DPP) will sufficiently advance the technology to an acceptable readiness level. This assumption represents an NGNP risk should the DPP fail to perform and advance the technology.

AREVA does not consider the RPV to be a critical system at an ROT of $750^{\circ} \mathrm{C}$ because SA508/533 steel can be used, just as is currently being used on LWR. 


\subsubsection{Design Discriminators}

The design discriminators for the RPV include:

- Material properties - The ability of the material to perform acceptably at NGNP conditions (i.e., maintain acceptable mechanical properties over the life of the plant without unacceptable dimensional requirements). Material that does not require cooling is preferred.

- Availability - The capability, capacity, and willingness of potential suppliers to supply the material or an SSC in the required configuration at the required time.

- Development Schedule - The amount of time required to complete all tasks to achieve a TRL of 7 .

- Qualification Schedule - The ability to qualify the vessel material on a schedule consistent with the needs of the NGNP project.

- Cost - The cost of the vessel system and required supporting systems plus the operating cost, including inspections.

\subsubsection{Reactor Pressure Vessel TRL Status}

Since the RPV design concept has been formulated, experimental proof-of-concept demonstrated, and the component demonstrated in a typical, relevant environment, the RPV currently has a TRL rating of 4. This rating is based on the absence of crucial data on materials to include long-term aging and corrosion effects, which need to be collected and analyzed before a TRL of 5 can be granted (see Table 3).

Table 3. Reactor Pressure Vessel Summary TRL Table

\begin{tabular}{|c|c|c|c|c|}
\hline & AREVA & General Atomics & Westinghouse & NGNP \\
\hline TRL & Not provided & 5 & Not provided & 4 \\
\hline
\end{tabular}

The primary technology development issue with the RPV is the choice of material. TRL assessment of SA-508/533 material is based on the experience of using it in current generation LWR RPVs and codification of this material in Section III of the ASME code.

\subsubsection{Reactor Pressure Vessel Maturation Path}

For an RPV with SA-508/533 material, a TRL of 5 will be achieved as material issues of aging and environmental effects are addressed.

To mature the RPV design from a TRL of 5 to a TRL of 6 , the following tasks are necessary:

- Design requirements for the RPV system have been defined

- Necessary testing program for SA-508/533 has been defined and performed

- Data needed to support final design of the RPV and to support NGNP licensing has been obtained.

To mature the RPV design from a TRL of 6 to a TRL of 7, the following tasks are necessary:

- Prepare procurement specifications

- Develop the detailed design of the RPV system 
- Refine the RPV computer model

- Perform analyses to verify that maximum vessel temperatures will be within ASME code limits for SA-508/533 with adequate margin

- Eliminate concerns about creep effects over 60 years.

To achieve a TRL of 8, an integrated system containing the RPV will need to be demonstrated in an operational environment. Testing in the final NGNP configuration including normal and abnormal operating conditions will need to be completed, and this component will need to be proven through multiple cycles of hot operations.

\subsubsection{Consolidated INL Technology Development Roadmap}

A consolidated TDRM, produced from pertinent supplier RPV TDRM data combined with NGNP R\&D data, is shown in Figure 8. 


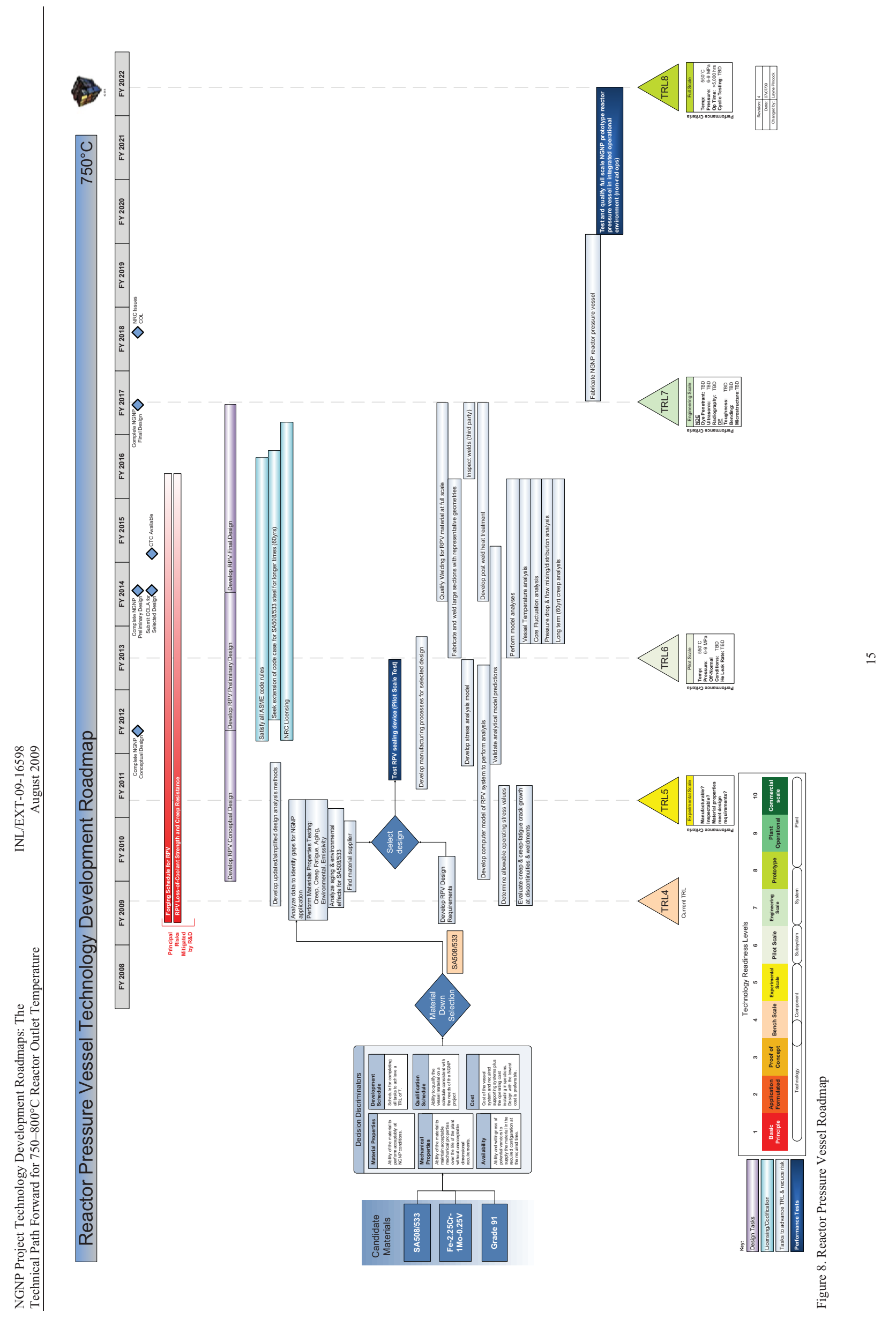




\subsection{Reactor Vessel Internals}

The Reactor Vessel Internals (RVI) provide the mechanical, thermal, and radiological interfaces between the Reactor Core and the RPV.

\subsubsection{Reactor Vessel Internals Design Description}

The RVI consists of a combination of floorings, plenums, reflectors, shrouds, restraints, and supports that maintain the reactor core geometry within the RPV, provide thermal and radiological shielding, and transport heat. Figure 9 depicts a typical RVI.

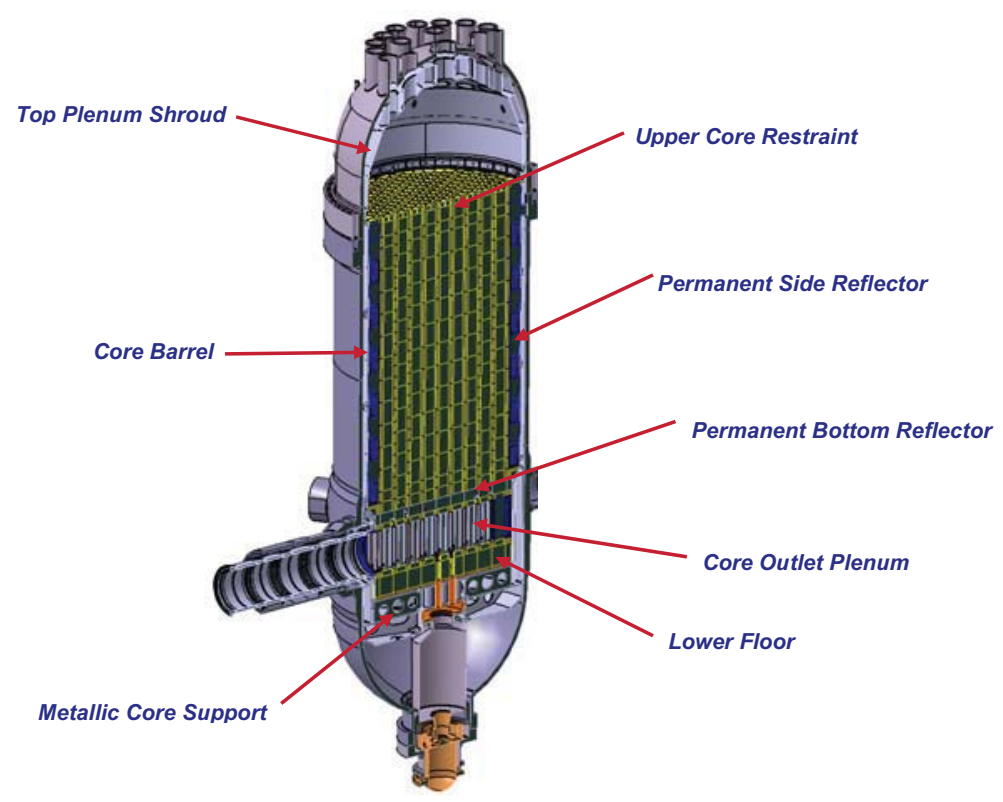

Figure 9. Typical Reactor Vessel Internals

\subsubsection{Functions Performed}

The functions performed by the RVI are as follows:

- Provide the mechanical or structural interface between the Reactor Core and the RPV to maintain reactor core geometry

- Provide heat transfer, during conduction cool down, by routing helium between the Reactor Core and the Primary Heat Transport and Shutdown Cooling Systems

- Provide thermal and radiological shielding of the reactor vessel

- Conserve neutrons during power production.

\subsubsection{Design Options}

The RVI components can be divided into three groups: metallic components, graphite components, and composite components. The metallic components are a mature technology, requiring little or no technology development prior to use. The graphite components require qualification of a new graphite source to replace the $\mathrm{H} 451$ graphite used in older gas-cooled reactors, such as Fort St. Vrain. The composite components will require significant development prior to use. 


\subsubsection{Design Discriminators}

The design discriminators for the RVI include:

- Thermal aging

- Environment - corrosion

- Neutron Irradiation Embrittlement

- Codification of material.

\subsubsection{Reactor Vessel Internals TRL Status}

Since the analytical and experimental proof-of-concept exists and the technology has been demonstrated in a bench-scale environment, the status of the current technology for the RVI is TRL 4.

Table 4. Reactor Vessel Internals Summary TRL Table

\begin{tabular}{|c|c|c|c|c|}
\hline & AREVA & General Atomics & Westinghouse & NGNP \\
\hline TRL & 4 & Not provided & Not provided & 4 \\
\hline
\end{tabular}

The RVI technology development includes the selection of a material design for the Lower Floor Blocks, qualification of a new graphite supply to replace the historical H451 graphite grade, and selection and qualification of a composite design for those components that require such material (see Table 5). Data and analyses are needed in the areas of corrosion of carbon/carbon $(\mathrm{C} / \mathrm{C})$ composites in an impure helium environment. Corrosion data to validate the life of $\mathrm{C} / \mathrm{C}$ composite materials in the NGNP reactor environment is also necessary for maturation.

Table 5. Reactor Vessel Internals Maturity Assessment

\begin{tabular}{|l|l|l|}
\hline \multicolumn{1}{|c|}{ Component } & \multicolumn{1}{|c|}{ Materials } & \multicolumn{1}{c|}{ Maturity Assessment } \\
\hline Top Plenum Shroud & Metallic/Ceramic & $\begin{array}{l}\text { Mature technology - no } \\
\text { development required }\end{array}$ \\
\hline Upper Core Restraint & Composite or Metallic & $\begin{array}{l}\text { Mature if metallic - Alloy 800H } \\
\text { Significant development required } \\
\text { for composite }\end{array}$ \\
\hline Permanent Side Reflector & Graphite & $\begin{array}{l}\text { Mature Technology - requires new } \\
\text { graphite qualification }\end{array}$ \\
\hline Permanent Bottom Reflector & Graphite & $\begin{array}{l}\text { Mature Technology - requires new } \\
\text { graphite qualification }\end{array}$ \\
\hline Core Outlet Plenum & Graphite & $\begin{array}{l}\text { Mature Technology - requires new } \\
\text { graphite qualification }\end{array}$ \\
\hline Lower Floor & Composite or Graphite & $\begin{array}{l}\text { Significant Development required } \\
\text { for composite material } \\
\text { Graphite qualification required for } \\
\text { graphite material }\end{array}$ \\
\hline Metallic Core Support & Metallic & $\begin{array}{l}\text { Mature technology - no } \\
\text { development required }\end{array}$ \\
\hline Core Barrel & Metallic & $\begin{array}{l}\text { Mature technology - no } \\
\text { development required }\end{array}$ \\
\hline
\end{tabular}


Composites are anticipated to play a large role in future gas reactors as implied in Table 6 and as a result of a recent engineering study completed by General Atomics on composites (issued June 09).

Table 6. Comparison of Reactor Vessel Internal Components

\begin{tabular}{|c|c|c|c|}
\hline Component & $\begin{array}{c}\text { Applicable } \\
\text { Temperature Range }\end{array}$ & $\begin{array}{c}\text { Interim Material Prior } \\
\text { to Composite } \\
\text { Qualification }\end{array}$ & $\begin{array}{c}\text { Long-term Suggested } \\
\text { Material }\end{array}$ \\
\hline $\begin{array}{l}\text { Control Rod Structural } \\
\text { Elements }\end{array}$ & $700 \mathrm{C} \leq$ Tout $\leq 950 \mathrm{C}$ & Hastelloy XR & $\mathrm{SiC}-\mathrm{SiC}$ \\
\hline $\begin{array}{l}\text { Control Rod \& Reserve } \\
\text { Shutdown Material Guide } \\
\text { Tubes }\end{array}$ & Tout $\leq 800 \mathrm{C}$ & Hastelloy X & $\begin{array}{l}\mathrm{C}-\mathrm{C} \text { or } \mathrm{SiC}-\mathrm{SiC} \\
\text { Composite }\end{array}$ \\
\hline $\begin{array}{l}\text { Upper Core Restraint } \\
\text { Elements }\end{array}$ & $700 \mathrm{C} \leq$ Tout $950 \mathrm{C}$ & Hastelloy X & SiC-SiC Composite \\
\hline $\begin{array}{l}\text { Upper Plenum Shroud } \\
\text { Thermal Barrier }\end{array}$ & Tout $\leq 950 \mathrm{C}$ & & Hastelloy X \\
\hline $\begin{array}{l}\text { Permanent Side Reflector } \\
\text { Seal Sleeves }\end{array}$ & & & $\begin{array}{l}\text { Graphite (No change } \\
\text { from original study) }\end{array}$ \\
\hline $\begin{array}{l}\text { Metallic Core Support } \\
\text { Load Bering Insulators }\end{array}$ & & & $\begin{array}{l}\text { Monolithic Ceramic (No } \\
\text { change from original } \\
\text { study) }\end{array}$ \\
\hline Hot Duct Thermal Barrier & $\begin{array}{l}\text { At or below Tout }=700 \mathrm{C} \\
750 \mathrm{C} \leq \text { Tout } \leq 850 \mathrm{C} \\
\text { Tout } \geq 900 \mathrm{C}\end{array}$ & & $\begin{array}{l}\text { Alloy } 800 \mathrm{H} \\
\text { Hastelloy X } \\
\text { Sic-Sic Composite }\end{array}$ \\
\hline $\begin{array}{l}\text { Lower Plenum Sidewall } \\
\text { Thermal Barrier }\end{array}$ & $\begin{array}{l}\text { Tout } \leq 800 \mathrm{C} \\
850 \mathrm{C} \leq \text { Tout } \leq 950 \mathrm{C}\end{array}$ & & $\begin{array}{l}\text { Alloy } 800 \mathrm{H} \\
\text { Hastelloy X }\end{array}$ \\
\hline $\begin{array}{l}\text { Shutdown Cooling System } \\
\text { Gas Entrance Tubes }\end{array}$ & $\begin{array}{l}\text { Tout } \leq 800 \mathrm{C} \\
850 \mathrm{C} \leq \text { Tout } \leq 950 \mathrm{C}\end{array}$ & & $\begin{array}{l}\text { Alloy } 800 \mathrm{H} \\
\text { Hastelloy X }\end{array}$ \\
\hline $\begin{array}{l}\text { Shutdown Cooling System } \\
\text { Heat Exchanger Thermal } \\
\text { Barrier }\end{array}$ & $\begin{array}{l}\text { Cooled by reactor inlet } \\
\text { helium during operation; } \\
\text { no heat up during } \\
\text { conduction cool down } \\
\text { (CCD) }\end{array}$ & & Alloy $800 \mathrm{H}$ \\
\hline
\end{tabular}

The material properties values for the selected graphite and composite materials will be required to qualify for use in the NGNP. Physical, thermal, and mechanical properties will need to be determined as a function of temperature and neutron fluency over the ranges expected in the NGNP plant. The composite material will also need to be codified prior to use. Details of the tests required to obtain this data and the actions necessary for codification are provided in Appendix A.

\subsubsection{Reactor Vessel Internals Maturation Path}

To mature the RVI design to a TRL of 5, the qualification of nuclear grade graphite will need to be complete and the development and initial material properties of composite materials will need to be complete. 
To mature the RVI design from a TRL of 5 to a TRL of 6 , the final or near-to-final designs of all RVI components that are to be composed of composite or ceramic materials should be produced. ASTM standards should be completed by issuance of TRL 6, and some of the ASME codes should be approved.

To mature the RVI design from a TRL of 6 to a TRL of 7, the upper core restraint blocks and lower floor blocks should be tested and the key thermal hydraulic parameters for conduction cool down modeling should be determined. These tests are at pilot-scale, with preparations being formulated for engineering-scale tests.

To achieve a TRL of 8 , an integrated system containing the RVI will need to be demonstrated in an operational environment. Testing in the final NGNP configuration, including normal and abnormal operating conditions, will need to be completed, and this component will need to be proven through multiple cycles of hot operations.

\subsubsection{Consolidated INL Technology Development Roadmap}

A consolidated TDRM, produced from pertinent supplier Reactor Vessel TDRM data combined with NGNP R\&D data, is shown in Figure 10. 


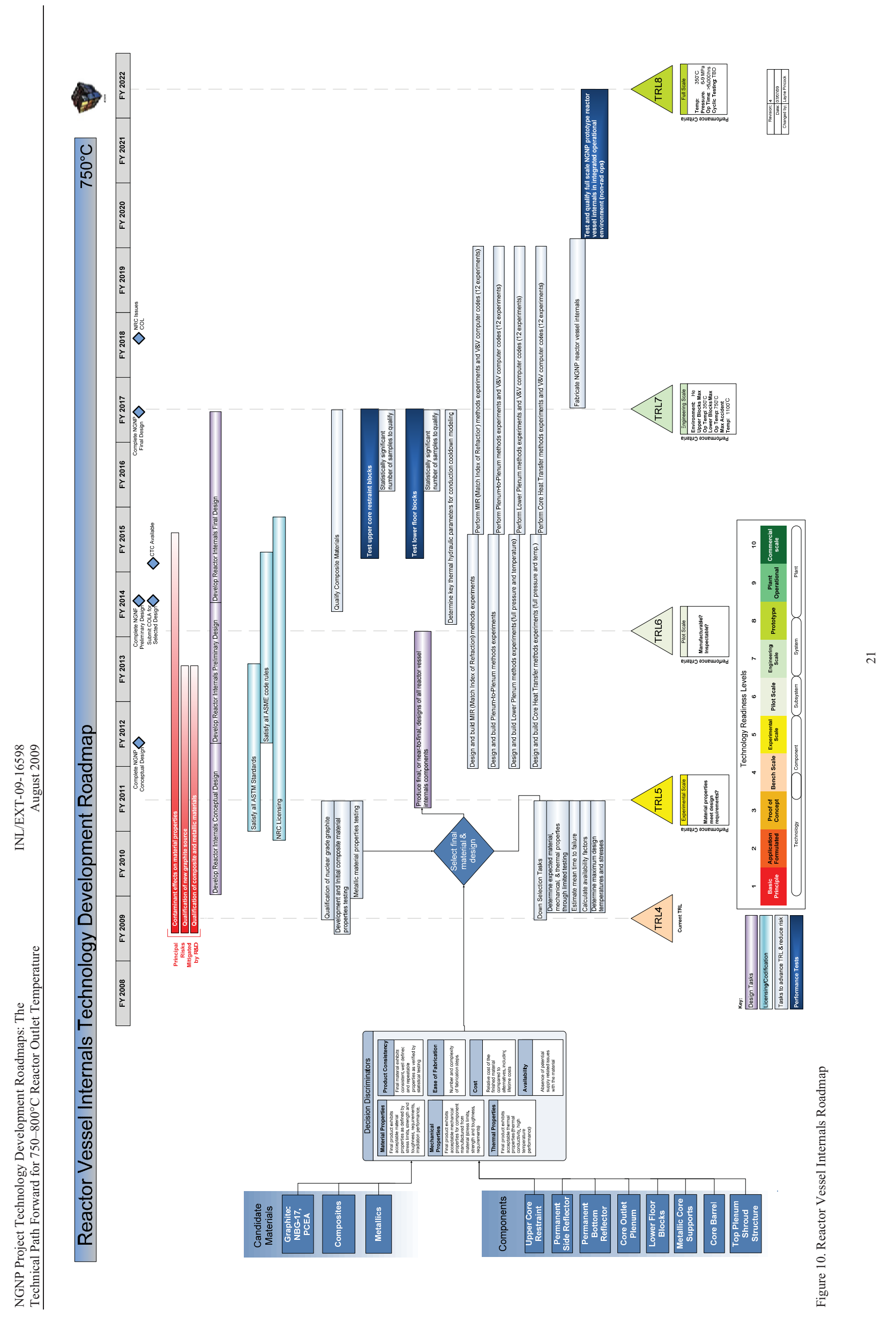




\subsection{Reactor Core and Core Structure}

The Reactor Core and Core Structure are the heart of the reactor. Within it, the thermonuclear reaction (e.g., generation of heat through nuclear fission) occurs and is contained and controlled.

\subsubsection{Reactor Core and Core Structure Design Description}

The Reactor Core and Core Structure refer to the reactor core and its support structure. The reactor core provides the housing for the fissile fuel material, moderator material, control rods, and reflectors. The fuel material is the source of heat while undergoing the fission reaction. The moderator material may be fixed in place or placed in the moveable control rods, and moderates or controls the sustained fission reaction. The reflectors provide containment and assist in sustaining the reaction. Figure 11 depicts a representative annular prismatic reactor core design showing these components. The core structure also provides channels for the flow of helium coolant for heat exchange.
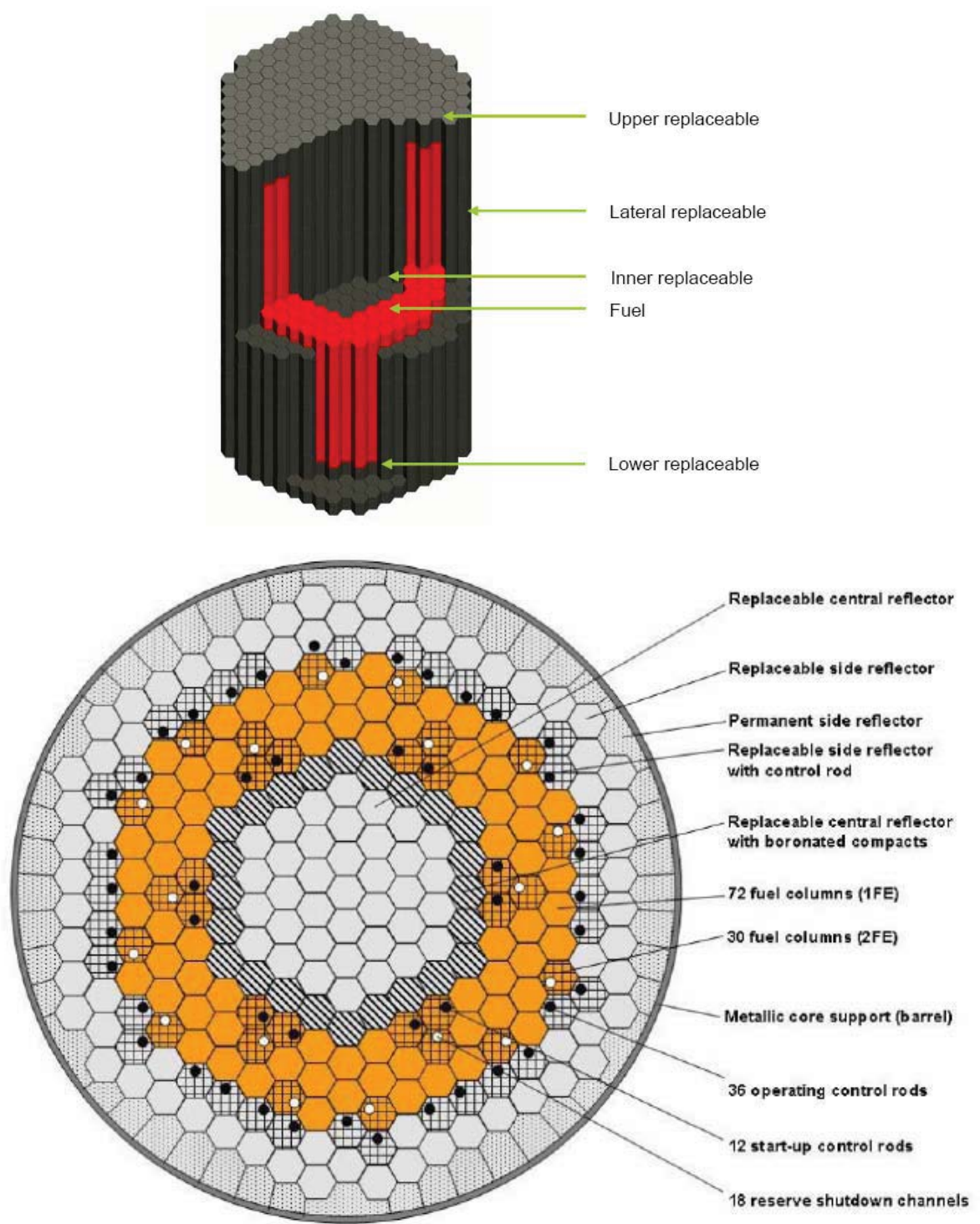

Figure 11. Representative Annular Prismatic Core Design 


\subsubsection{Functions Performed}

The functions performed by the Reactor Core are as follows:

- Start the reaction

- Generate high-temperature heat using nuclear fission

- Transfer the heat to the helium coolant

- Control radiation from the core

- Sustain the fission reaction through neutron reflection in the core

- Maintain flow passage configuration

- Limit the temperatures and the fast neutron fluence.

Many additional lower level functions can be found in Appendix A.

\subsubsection{Design Options}

Two general reactor core designs have been suggested. AREVA and General Atomics both propose a prismatic design, while Westinghouse proposes a pebble-bed design. The prismatic design employs prismatic or hexagonal columnar blocks consisting of fuel, moderator, or reflector material placed in a columnar array. Control rods, containing additional moderator material, are inserted into tubes within the columnar blocks to control the reaction in the fuel. In the pebble-bed design, the fuel elements are spheres rather than prismatic columnar blocks.

One potential challenge with the prismatic design is machining the fuel, coolant, and neutron absorber holes with acceptable tolerances at a reasonable throughput rate. Also, an annular prismatic core has never been operationally demonstrated.

For both designs, commercial availability of acceptable grades of graphite is an issue since some previously used and proven materials are no longer commercially available. New nuclear-grade graphites are being developed and qualified, including PCEA, NBG-17, and NBG-18. Development of the fuel and fuel compacts is also currently being addressed.

\subsubsection{Design Discriminators}

The major design discriminators for the Reactor Core include: cost; schedule, for both development and material qualification; and material performance in the physical, thermal, and radiation environment, including heat capacity and dimensional changes. Additional design discriminators might include: material purity, fabricability, development risk, licensing, reliability, maintainability, and availability.

\subsubsection{Reactor Core and Core Structure TRL Status}

There is high confidence that the annular core with prismatic blocks design will meet all requirements for safety, licensing, and operation at NGNP operating parameters. Some existing data needs to be collected to aid the design of the NGNP. If such data is unavailable to the reactor core designer during the design phase, then additional test work may be identified to fill data gaps. A rating of TRL 4 is given to the Reactor Core and Core Structure based on the current state of technology development (see Table 7). 
Table 7. Reactor Core and Core Structure Summary TRL Table

\begin{tabular}{|c|c|c|c|c|}
\hline & AREVA & General Atomics & Westinghouse & NGNP \\
\hline TRL & 4 & 5 & 4 & 4 \\
\hline
\end{tabular}

\subsubsection{Reactor Core and Core Structure Maturation Path}

At this stage, the following development needs are considered to be necessary.

- Structural performance of core blocks - Demonstrate that the blocks will not be damaged during loading and unloading maneuvers and that the alignment pins will survive stressed induced from seismic loads.

- Bypass flow - The bypass flow is a key parameter and is a complex value to determine. Bypass through the gaps between block columns and in the horizontal gap between the blocks within a column must be characterized. This must be done at cold and hot conditions with blocks that simulate both unirradiated and irradiated conditions.

- Thermo-mechanical performance - The stresses that the blocks will experience due to thermo-mechanical stresses may be close to the structural limits of the graphite material. Testing is needed to quantify the stresses that will be generated in the block during operation.

To mature to a TRL of 5, material properties values for the selected graphites will be required to qualify for use in the NGNP. Physical, thermal, and mechanical properties will need to be determined as a function of temperature and neutron fluence over the ranges expected in the NGNP plant. The composite material will also need to be codified prior to use in the Reactor Core and Core Structure.

To mature the Reactor Core and Core Structure design from a TRL of a 5 to a TRL of a 6 , the high dose irradiations and tensile creep tests will be underway, and the Advanced Graphite Capsule (AGC)-3 irradiation test and baseline characterization tests will be complete.

To mature the Reactor Core and Core Structure design from a TRL of a 6 to a TRL of a 7, bypass flow testing, thermo-mechanical testing, and structural integrity testing must be complete. In addition, the ASME code case review and approval and the reactor core components and subsystem testing and modeling must be complete. After the requisite design data have been obtained for mock-up testing involving multiple graphite components and requisite design data have been obtained for the new graphite, other data will be acquired to advance to TRL 7.

To achieve a TRL of 8 , an integrated system containing the Reactor Core and Core Structure will need to be demonstrated in an operational environment; testing in the final NGNP configuration, including normal, off-normal, and abnormal operating conditions will need to be completed; and the component will need to be proven through multiple cycles of hot operations. Assuming no new technology development is required for the Reactor Core and Core Structure, this critical system will advance to a TRL of 8 during commissioning in the NGNP.

\subsubsection{Consolidated INL Technology Development Roadmap}

A consolidated TDRM, produced from pertinent supplier Reactor Core and Core Structure TDRM data combined with NGNP R\&D data, is shown in Figure 12. 
This page intentionally left blank. 


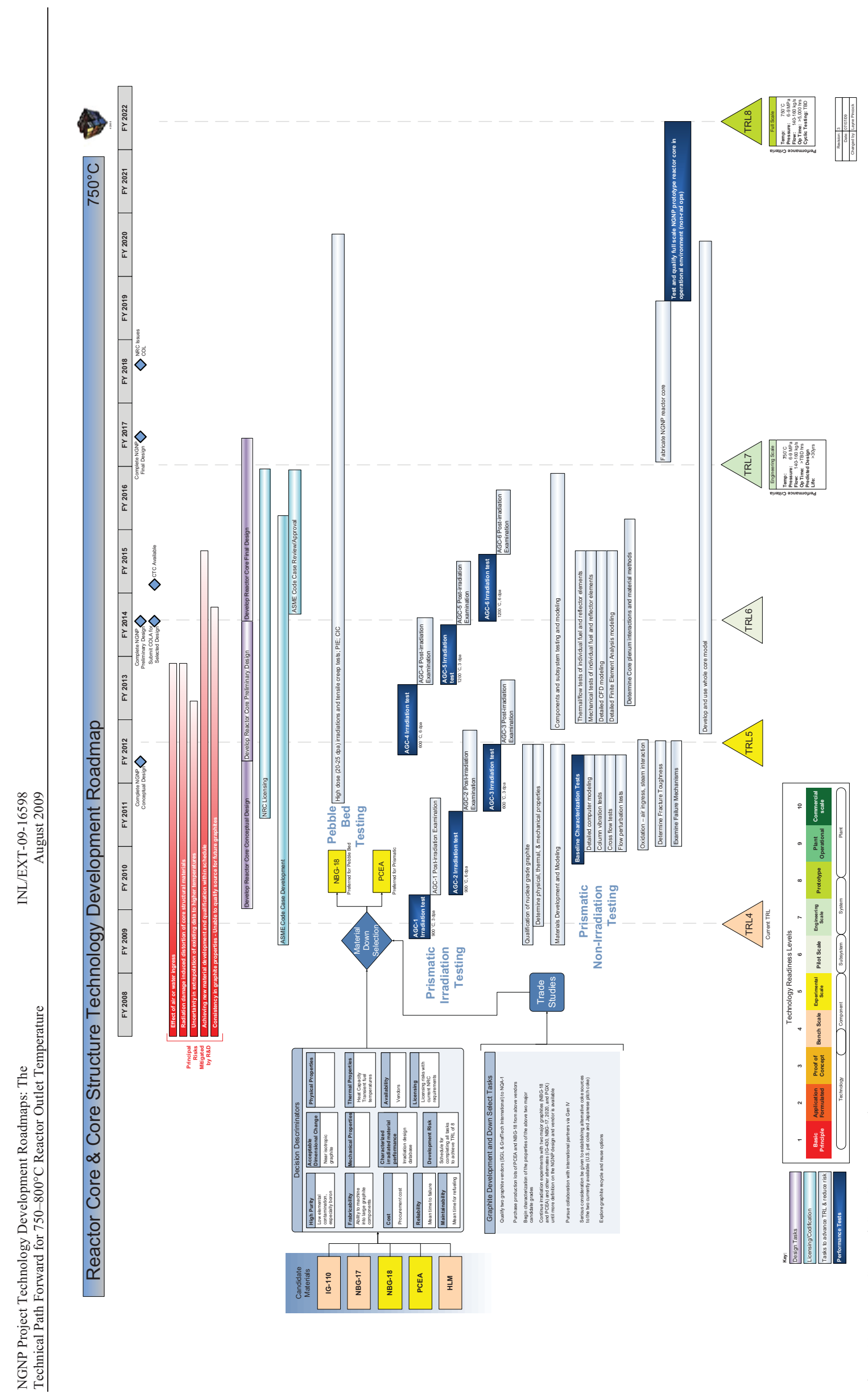

ה 


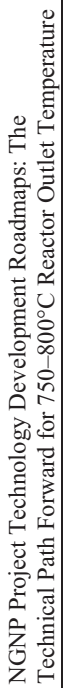




\subsection{Fuel Elements}

The Fuel Elements consist of a fissile material kernel coated with various layers of refractory materials. The design offers high flexibility in terms of geometric parameters, arrangement of layers, and choice of materials.

\subsubsection{Fuel Elements Design Description}

The fuel elements are comprised of tri-isotropic (TRISO) particles containing low enriched uranium kernels embedded in a pressed graphite matrix, as shown in Figure 13. This fuel has shown very low particle failure when restrictive parameters are imposed consistent with fuel irradiation and heat up testing (e.g., burnups, fluences, and maximum temperatures). The outstanding high-temperature performance has been established by years of irradiation and testing experience where a very small fraction of particle failure and/or fission product release occurred under simulated accident conditions.

A major goal of the Advanced Gas Reactor (AGR) Fuel Development and Qualification Program is to establish coated particle fuel fabrication technology in the United States for the Very High Temperature Reactor (VHTR) that is capable of producing fuel at a quality level at least as good as produced by German fuel technology. The AGR is used as a basis for the TRLs for the NGNP Fuel Elements.

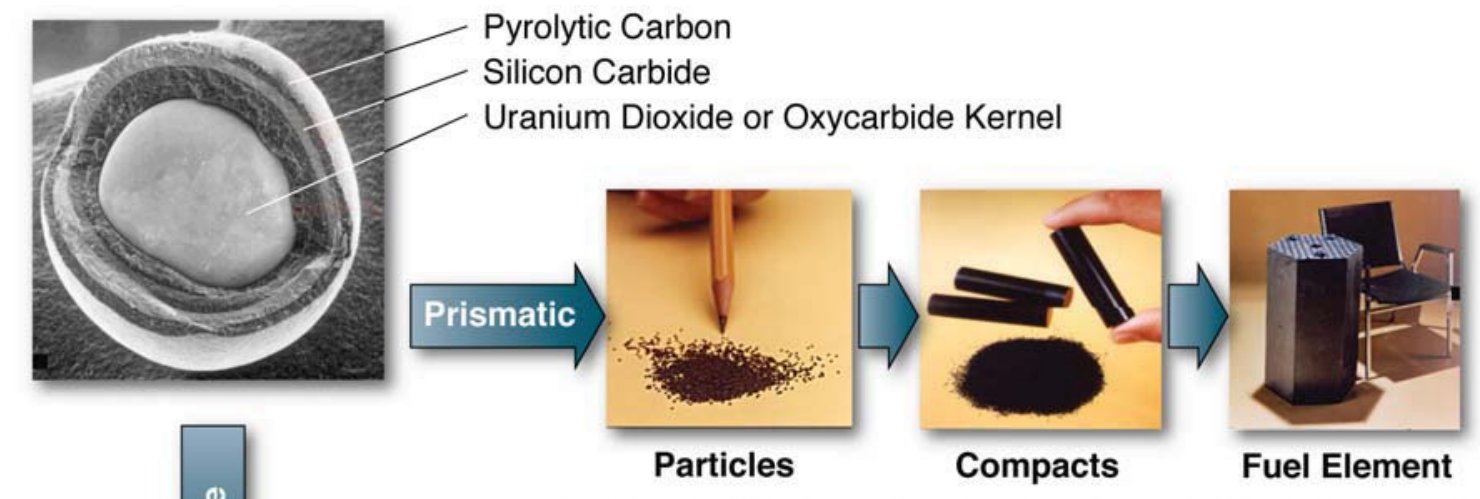

TRISO-coated fuel particles (left) are formed into fuel compacts (center) and inserted into graphite fuel elements (right) for the prismatic reactor

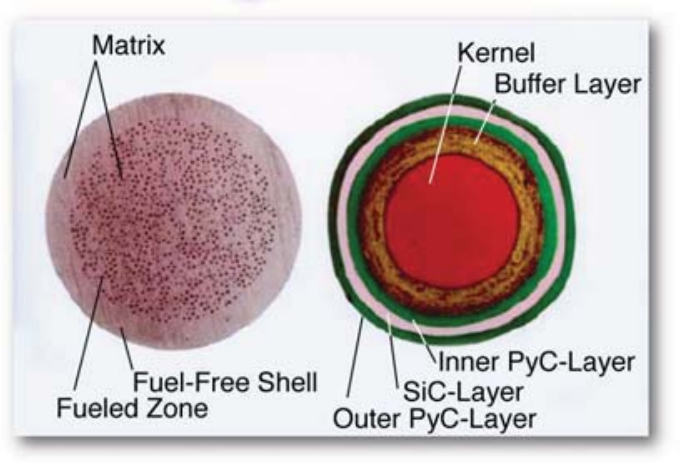

TRISO-coated fuel particles are formed into fuel spheres for pebble bed reactor

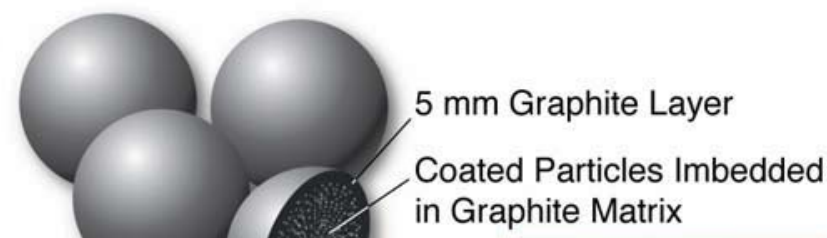

Fuel Sphere Dia $60 \mathrm{~mm}$

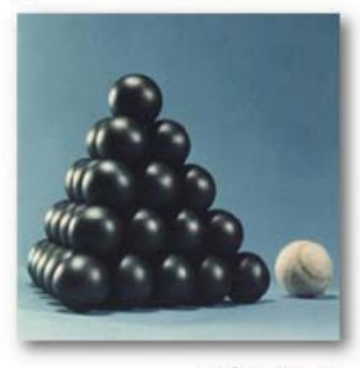

08-GA50711-01

Figure 13. TRISO Particle Fuel Element 


\subsubsection{Functions Performed}

The function performed by the Fuel Elements is to provide fissile fuel material for the fission reaction.

\subsubsection{Design Options}

The design specifications for the NGNP are not yet well-defined, but the maximum burn up envisioned in a VHTR is in the range $150-200 \mathrm{GWd} / \mathrm{MTHM}$, or $16.4-21.8 \%$ fissions per initial metal atom (FIMA). The composition of the fuel kernel and the fuel element geometry are open items. Although the Germans have demonstrated excellent performance of SiC TRISO-coated $\mathrm{UO}_{2}$ particle fuel up to about $10 \%$ FIMA and $1150^{\circ} \mathrm{C}, \mathrm{UO}_{2}$ fuel is known to have limitations because of $\mathrm{CO}$ formation and kernel migration at the high burn ups, power densities, temperatures, and temperature gradients that may be needed in the NGNP design. With UCO fuel, the kernel composition is engineered to prevent CO formation and kernel migration, which are key threats to fuel integrity at higher burn ups, temperatures, and temperature gradients. Furthermore, the excellent performance of German SiC TRISO-coated UCO fuel up to 22\% FIMA (as measured by the in-pile gas release in irradiation test FRJ-P24) gives added confidence that high-quality SiC TRISO-coated UCO fuel can be made and its performance statistically demonstrated. Thus, SiC TRISO-coated UCO has been chosen as the baseline fuel to be fabricated and tested in this program. A prismatic fuel element design has been chosen to be consistent with past fuel fabrication experience in the United States and to be complementary to the ongoing pebble-bed R\&D elsewhere in the world. If a pebble-bed design should be developed for the NGNP, the UCO fuel could be compacted into spherical elements to fit this design. Similarly, if ongoing R\&D in China, Europe, Japan, or South Africa should indicate that $\mathrm{UO}_{2}$ fuel could operate successfully at sufficiently extended burn ups, the program could be modified to test this fuel to NGNP conditions.

\subsubsection{Design Discriminators}

The design discriminators for the Fuel Elements include:

- Robustness

- Performance

- Manufacturability

- Qualification and Licensing.

\subsubsection{Fuel Elements TRL Status}

Both prismatic and pebble-bed fuel elements are currently rated as TRL 4 (see Table 8). Advancements of fuel elements readiness level depend greatly upon the AGR tests being performed, or planned to be performed, at the INL. Both AREVA and General Atomics are relying on the development of prismatic fuel elements at the INL as part of their design; hence, no TRL rating is provided by those suppliers. Based on review of the Westinghouse NGNP Technology Development Road Mapping Report (see Appendix A), the NGNP project grants a TRL of 4 for the Fuel Elements.

While the past fuel maturity of pebble-bed fuel elements through historic high-temperature reactors is recognized, there are too many uncertain and un-tested parameters with the current generation of fuel to grant the supplier suggested rating of TRL 7. The NGNP feels there is inadequate demonstration with the current generation of fuel and that demonstration via fabrication quality control, fuel irradiation, postirradiation examination (PIE), and safety testing be completed before advancement to TRL 5 can be granted. 
Table 8. Fuel Element Summary TRL Table

\begin{tabular}{|c|c|c|c|c|}
\hline & AREVA & General Atomics & Westinghouse & NGNP \\
\hline TRL & Not provided & Not provided & 7 & 4 \\
\hline
\end{tabular}

\subsubsection{Fuel Elements Maturation Path}

The Fuel Elements TDRM illustrates the two paths necessary to advance fuel technology development. Because of the unique fuel characteristics of both reactor cores types, prismatic and pebblebed, path forwards are on different maturation paths regarding timing and unique fuel characteristics. Fuel fabrication for each of the AGR experiments varies, depending on the timing of the experiment and the input previous AGR experiments provide as feedback for enhancing fuel fabrication.

\subsubsection{Prismatic Fuel Elements Maturation Path}

The path forward for the prismatic fuel maturation is described in the Table 9. Each of the AGR experiments includes a series of progressive activities necessary to fabricate and qualify fuels and to provide data for source term and safety analysis activities.

Table 9. Fuel Element Summary TRL Table

\begin{tabular}{|c|c|c|c|c|}
\hline & $\begin{array}{c}\text { TRL 4 to 5 } \\
\text { (Laboratory-scale) }\end{array}$ & $\begin{array}{c}\text { TRL 5 to 6 } \\
\text { (Pilot-scale) }\end{array}$ & $\begin{array}{c}\text { TRL 6 to 7 } \\
\text { (Engineering-scale) }\end{array}$ & $\begin{array}{c}\text { TRL 7 to 8 } \\
\text { (Plant/Prototype- } \\
\text { scale) }\end{array}$ \\
\hline Fabrication & $\begin{array}{c}\text { AGR-1 fuel } \\
\text { fabrication }\end{array}$ & $\begin{array}{c}\text { AGR-2 fuel } \\
\text { fabrication }\end{array}$ & $\begin{array}{c}\text { AGR-5/6 fuel } \\
\text { fabrication }\end{array}$ & $\begin{array}{c}\text { AGR 9 fuel } \\
\text { fabrication }\end{array}$ \\
\hline Fuel Qualification & $\begin{array}{c}\text { AGR-1 irradiation, } \\
\text { PIE, and safety } \\
\text { testing }\end{array}$ & $\begin{array}{c}\text { AGR-2 irradiation, } \\
\text { PIE, and safety } \\
\text { testing }\end{array}$ & $\begin{array}{c}\text { AGR-5/6 irradiation, } \\
\text { PIE, and safety } \\
\text { testing }\end{array}$ & $\begin{array}{c}\text { AGR-9 irradiation, } \\
\text { PIE, and safety } \\
\text { testing }\end{array}$ \\
\hline $\begin{array}{c}\text { Source Term \& } \\
\text { SAR }\end{array}$ & (historical database) & $\begin{array}{c}\text { AGR-3/4 out-of-pile } \\
\text { loop }\end{array}$ & $\begin{array}{c}\text { AGR-7/8 integrated } \\
\text { in-pile loop }\end{array}$ & \\
\hline
\end{tabular}

Overarching activities include fuel performance modeling code development and fission product transport and source term data development. Final TRL advancement will require final NGNP design, fabrication of the NGNP, and non-radiological operational tests and qualification.

\subsubsection{Pebble-bed Fuel Elements Maturation Path}

Pebble-bed fuel elements require a series of tasks and tests to advance them to a TRL of 4 to a TRL of 6. These tasks start with pre-irradiation characterization of PBMR produced fuel spheres followed by fuel sphere irradiation tests. Next, PIE needs to be performed along with heating tests (at $1600^{\circ} \mathrm{C}$ and $1800^{\circ} \mathrm{C}$ ). The irradiated samples and fuels need to be processed according to the requirements necessary for fuel matrix qualification.

Source term qualification and irradiation experiments continue for a TRL of 7 to be granted. The most pertinent task is the beginning of fuel sphere irradiation tests with parameters at $1355^{\circ} \mathrm{C}$ at a burn up of $109,000 \mathrm{MWd} / \mathrm{tU}$, along with a series of PIE and irradiation processing. Fuel graphite qualification must also begin for TRL 7 issuance. 
Completion of all of the final PIE, irradiation processes, and final fuel graphite qualification tests is necessary for the pebble-bed fuel to achieve a TRL of 8 and be considered ready for insertion into the NGNP.

\subsubsection{Consolidated INL Technology Development Roadmap}

A consolidated TDRM, produced from pertinent supplier Fuel Elements TDRM data combined with significant NGNP R\&D data, is shown in Figure 14. 


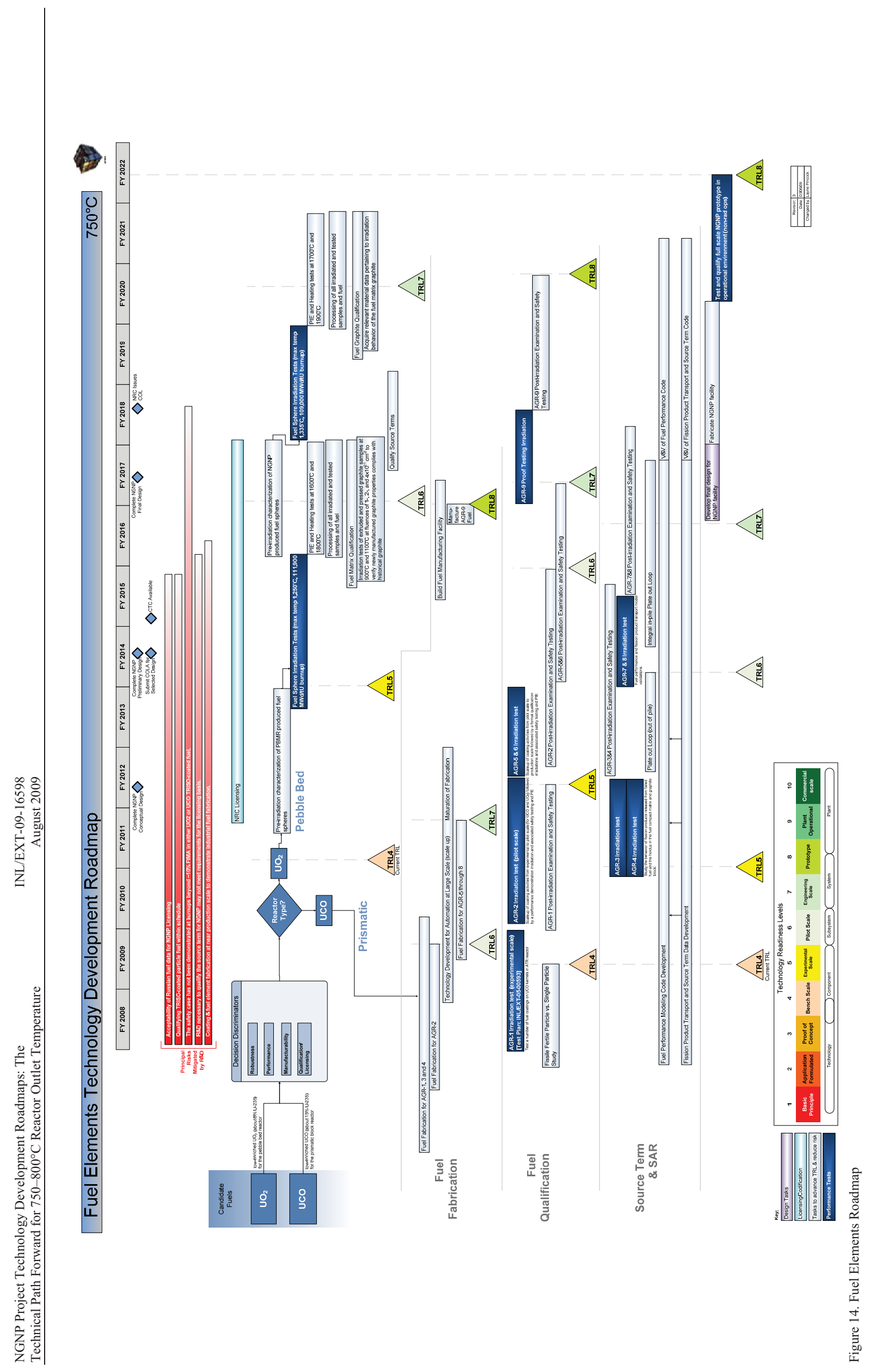




\subsection{Reserve Shutdown System}

The Reserve Shutdown System (RSS) is used to regulate the reactor, maintaining it subcritical below an average core temperature of at least $100^{\circ} \mathrm{C}$ during shutdown. Because a drastic and sharp change in temperature in the reactor may cause critical stress related problems, the RSS moderates the temperature change during shutdown. The RSS is in the pebble-bed design only.

\subsubsection{Reserve Shutdown System Design Description}

The RSS interfaces with the RPV and Reactor Core and operates at the same temperature and pressure as the reactor. The RSS typically consists of additional or reserved control rods, containing moderator or neutron absorption material, that are inserted into the core to slow down the thermonuclear reaction and bring the reactor to 'cold' conditions for maintenance operations. When engaged, the RSS maintains the reaction at a subcritical level while permitting the continued flow of helium to keep the average core temperature at $100^{\circ} \mathrm{C}$ or less. Figure 15 depicts a representative RSS.

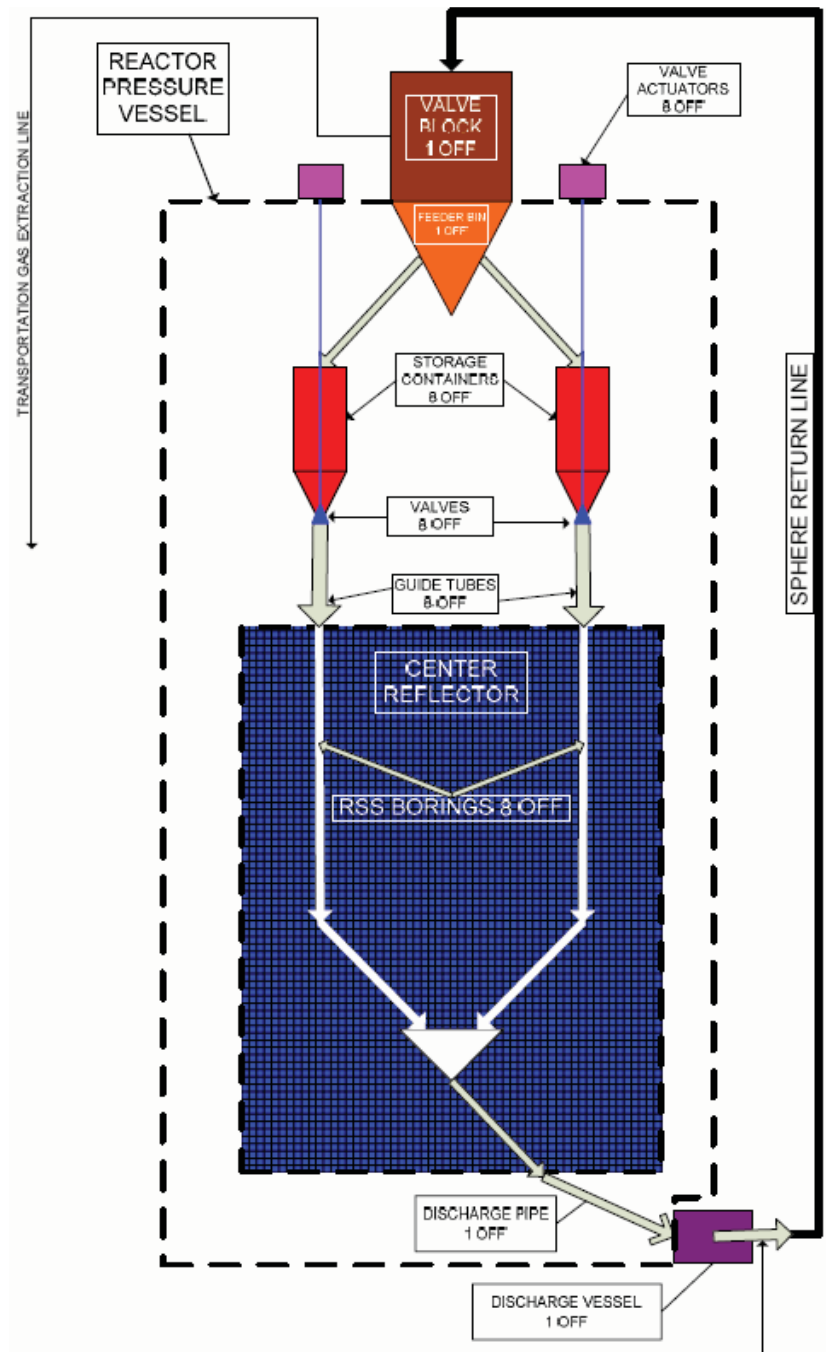

Figure 15. Representative Reserve Shutdown System Schematic Layout 


\subsubsection{Functions Performed}

At a high level, the RSS keeps the reactor subcritical and operating below an average core temperature of $100^{\circ} \mathrm{C}$ during shutdown. The RSS shuts down the reactor by neutron absorption. The RSS also maintains the RPV Pressure Boundary, where some RSS components penetrate the RPV, thus becoming part of the boundary.

\subsubsection{Design Options} RSS.

Only Westinghouse identified the RSS as a critical system. There are no alternative designs for the

\subsubsection{Design Discriminators}

Since there are no alternative designs, there are no design discriminators.

\subsubsection{Reserve Shutdown System TRL Status}

The Chinese HTR-10 $\left(700^{\circ} \mathrm{C}\right)$ is no more than $1 / 20^{\text {th }}$-scale of the NGNP experimental scale, thereby warranting a TRL of 5 (see Table 10). Additionally, the Westinghouse TDRM report identifies the following post-TRL 6 activity: "Perform analysis to determine NGNP delta and subsequent materials requirements." The testing for the DPP is expected to be completed by October 2009. This implies that for NGNP, a component (Small Absorber Spheres) may still require materials testing. Based on the above information, the RSS is rated at a TRL of 5.

Table 10. Reserve Shutdown System Summary TRL Table

\begin{tabular}{|c|c|c|c|c|}
\hline & AREVA & General Atomics & Westinghouse & NGNP \\
\hline TRL & Not Provided & Not Provided & 6 & 5 \\
\hline
\end{tabular}

\subsubsection{Reserve Shutdown System Maturation Path}

Advancement from TRL 5 to TRL 6 will require performance at a pilot-scale, with performance criteria being in a helium environment at NGNP operating temperature and pressures. Performance and functional tests need to be performed at a facility that can test the RSS at necessary performance criteria. Additionally, trade studies and Small Absorber Spheres performance activities need to be conducted prior to declaring technology viability.

Performance and functional test of the RSS need to be conducted to achieve a TRL of 7. Performance of tests will be conducted at the engineering-sale within a helium environment at a temperature range of $750-800^{\circ} \mathrm{C}$ and pressure of 5-9MPa.

TRL 8 is achieved upon full-scale testing of the RSS in the NGNP, within a non-radiological environment at a temperature range of $750-800^{\circ} \mathrm{C}$ and a pressure of 5-9 $\mathrm{MPa}$, and for a time intervals of $>5,000$ hours. This entails integrated operations for the tests.

\subsubsection{Consolidated INL Technology Development Roadmap}

A consolidated TDRM, produced from RSS TDRM data from the suppliers combined with NGNP R\&D data, is shown in Figure 16. 


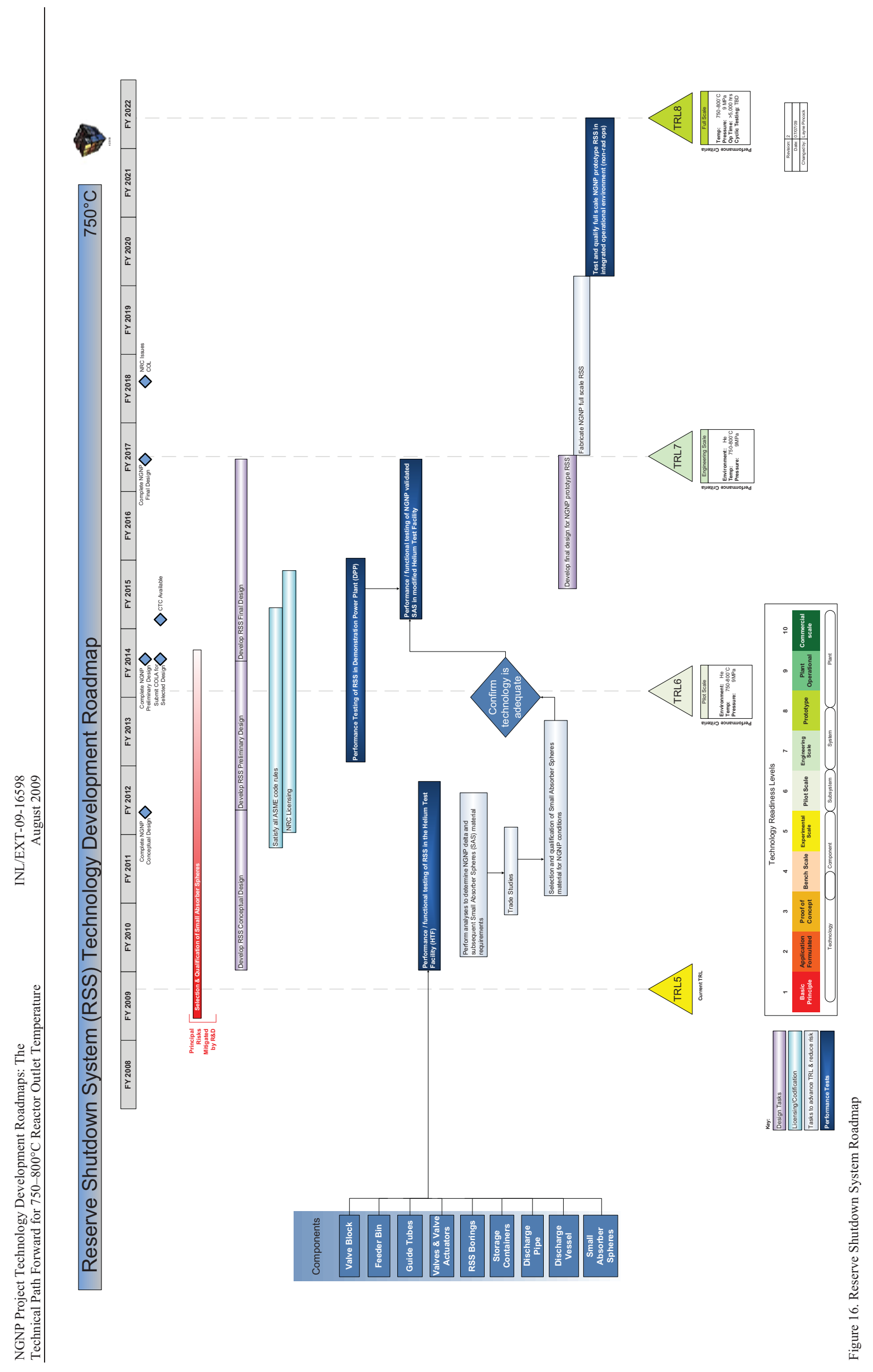




\subsection{Reactivity Control System}

The Reactivity Control System (RCS), also known as the neutron control system, is part of the Reactivity Control and Shutdown System. It controls the reactivity in the core and provides for quick shutdown, if needed.

\subsubsection{Reactivity Control System Design Description}

The RCS is used to control reactivity in the core and to quickly shutdown the reactor and keep it in a shutdown state, if necessary. This is accomplished by inserting a neutron-absorbing material into the reactor core to moderate the reaction.

The neutron-absorbing moderator, in the form of rings or annular cylinders, is encased in a sleeve or tube, and the combined sleeve and moderator comprise a control rod. The control rods are inserted into the core, and the amount of absorption is determined by the depth to which the rods are inserted. Primary components will include control rods (sleeves and moderator), guide tubes, and a drive mechanism (including cables).

\subsubsection{Functions Performed}

The RCS controls the nuclear chain reaction in the reactor core by absorbing neutrons in any operational mode.

\subsubsection{Design Options}

Design options differ in the number of startup, operating, and/or shutdown control rods, and in the materials used. All of the proposed designs are based on using boronated graphite, or boron-carbide $\left(\mathrm{B}_{4} \mathrm{C}\right)$, as the moderator, but materials for other components, such as sleeves and cables, have not yet been specified.

Due to the extremely high temperatures in the reactor core, thermal gradients across the rods may cause thermal bending. Therefore, material selection for some components will be based on thermal performance in the high-temperature environment. Candidate materials for the control rod sleeves include: Alloy $800 \mathrm{H}, \mathrm{C} / \mathrm{C}$ composites, and silicon carbide/silicon carbide ( $\mathrm{SiC} / \mathrm{SiC}$ ) composites. Candidate materials for drive mechanism cables include: Alloy 800H, PE-16, and PM2000 Oxide Dispersion Strengthened (ODS) steel.

\subsubsection{Design Discriminators}

Primary design discriminators include operating cost and material properties, as they impact the mechanical and thermal performance in the high-temperature environment. Additional discriminators, carrying less weight, include: material compatibility, environmental stability, installed equipment costs, development risk, investment risk, manufacturing maturity, licensing, reliability, maintainability, and availability.

\subsubsection{Reactivity Control System TRL Status}

The primary issue with the RCS is with the materials for high-temperature operation. If control rods are to be inserted in un-cooled channels, then extensive use of composite materials $(\mathrm{C} / \mathrm{C}, \mathrm{SiC} / \mathrm{SiC})$ will be necessary for the control rod cladding, canister joints, and control rod guide tubes. Development of these materials requires a progression from tests on fiber and matrix materials, to small sample tests, to representative geometry tests, to complete representative component tests. Table 11 summarizes the 
current TRL assessments for the RCS. General Atomics assigned a TRL of 2, AREVA assigned a TRL of 4 , and Westinghouse assigned a TRL of 6 . NGNP has evaluated the overall readiness of the RCS technology and assigned a TRL of 4 . The level of technology maturity for each of RCS components (i.e., Control Rods, Guide Tubes, and Control Rod Drive Mechanism [CRDM] Cable) is within the TRL 4 range.

Table 11. Reactivity Control System Summary TRL Table

\begin{tabular}{|c|c|c|c|c|}
\hline & AREVA & General Atomics & Westinghouse & NGNP \\
\hline TRL & 4 & 2 & 6 & 4 \\
\hline
\end{tabular}

\subsubsection{Reactivity Control System Maturation Path}

Reactivity Control System technology will achieve a TRL of 5 after a better understanding of the incore temperature and temperature distribution is achieved and after materials have been selected and experimental-scale tests have been conducted. These material tests effect all three RCS components, which need to overcome material issues and design issues before advancement to the next TRL is granted.

A TRL of 6 will be achieved once materials and assemblies have been demonstrated in pilot-scale tests. This includes systems integration, subsystems assembly, and other mechanical/design tests.

TRL 7 is achieved once interconnection and alignment tests are completed in engineering-scale. Performance criteria for engineering-scale includes a testing temperature of $750-800^{\circ} \mathrm{C}$, pressure at 5-9 $\mathrm{MPa}$, and a predicted design life of $>30$ years.

Full-scale tests are required to advanced RCS technology to a TRL of 8, which includes final testing and qualifications of the RSS in a non-radiation operational environment.

\subsubsection{Consolidated INL Technology Development Roadmap}

A consolidated TDRM, produced from supplier RCS TDRM data combined with NGNP R\&D data, is shown in Figure 17. 


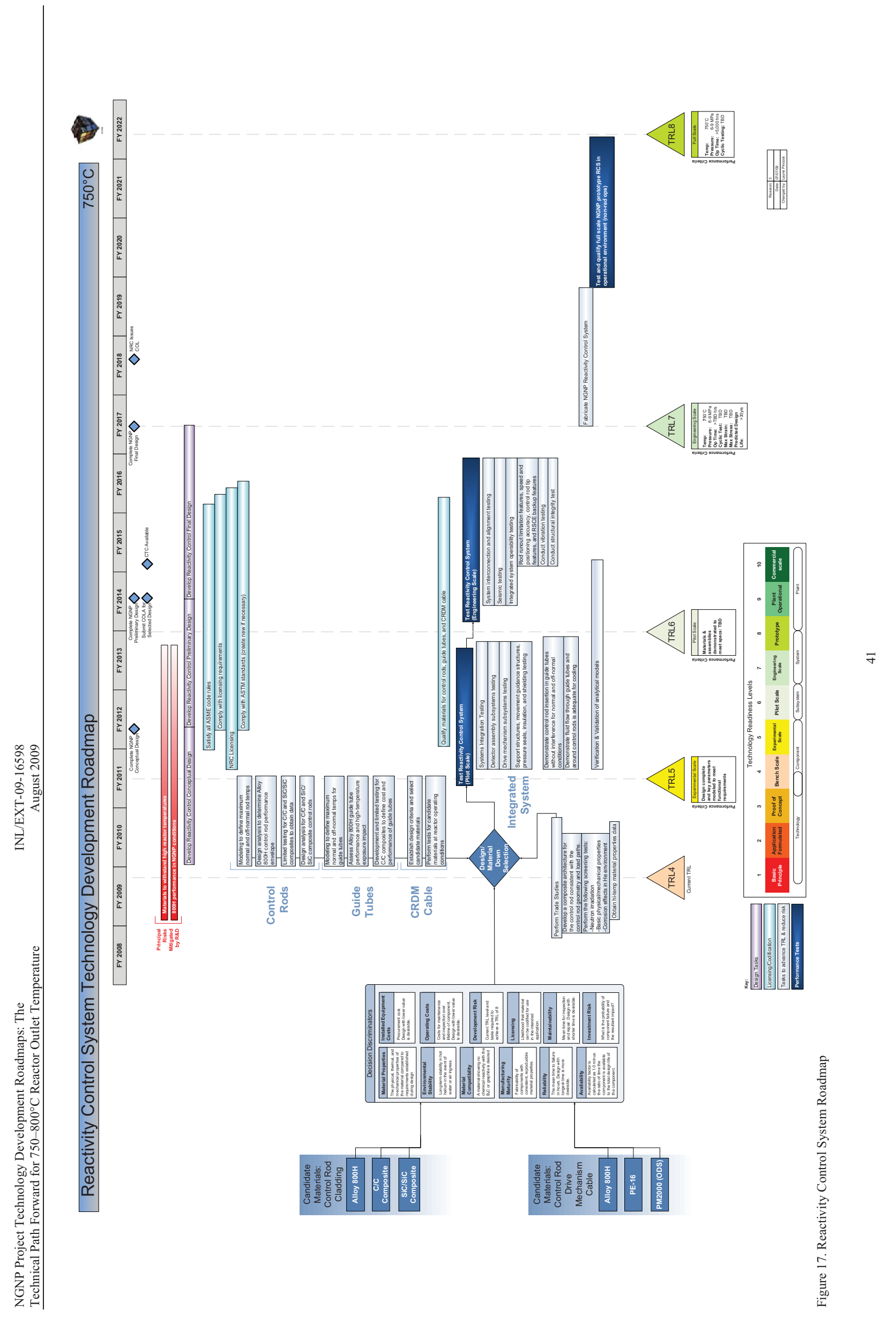




\subsection{Core Conditioning System (Shutdown Cooling)}

The Core Conditioning System (CCS) removes decay heat from the reactor when the heat exchanger is not operational. The CCS is imperative to have when maintenance and other operational situations mandate the NHS to be isolated from other NGNP areas.

\subsubsection{CCS (Shutdown Cooling) Design Description}

When the CCS is operating, hot gas is extracted from the core outlet pipe and passed through a watercooled heat exchanger, the CCS blower, and then back into the annular cooling cavity of the hot gas ducts and the core inlet pipe. A CCS by-pass control valve regulates the amount of gas directed back to the core. This way the core temperature may be controlled. The CCS consists of two identical loops, which are housed and operated separately for redundancy. A process flow diagram for a typical CCS concept is shown in Figure 18.

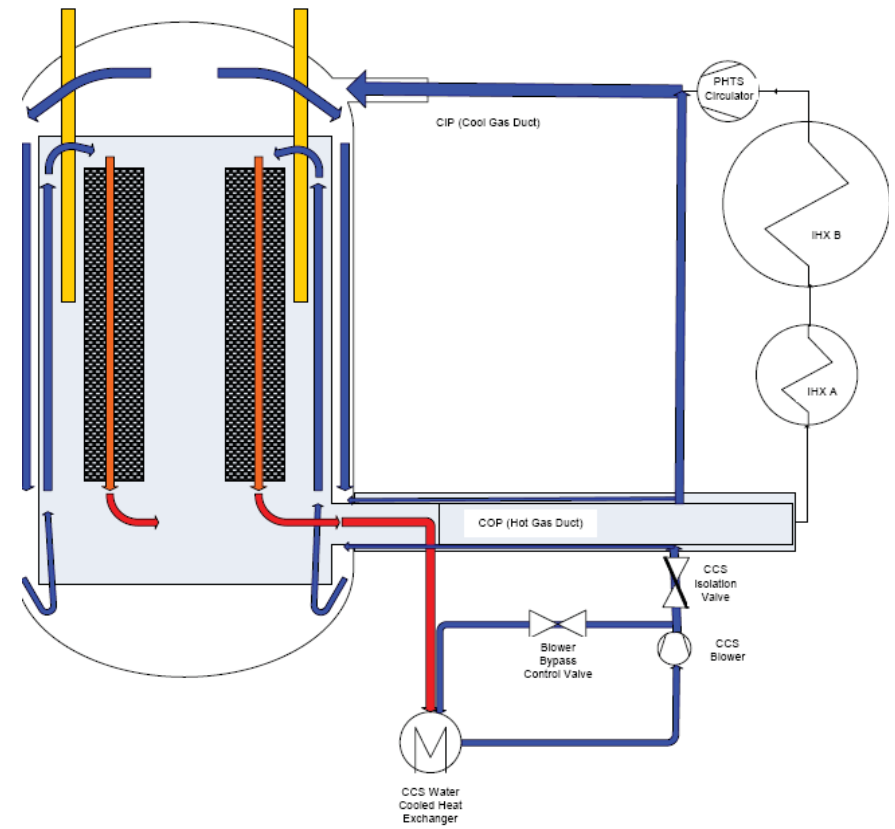

Figure 18. Typical Process Flow Diagram of CCS

\subsubsection{Functions Performed}

Some of the operational functions of the CCS include:

- Cool down the core to maintenance conditions or keep it at operating conditions should there be small leaks in the Helium Pressure Boundary

- Provide cooling flow to the reactor during maintenance.

\subsubsection{Design Options}

Design options include using a Shutdown Cooling Heat Exchanger (SCHE; General Atomics design) or a generalized CCS (Westinghouse design) in a helical tube configuration. Two areas still require down selection prior to completion of conceptual design. These are (1) selection of the shroud material from 
either Haynes 230, Alloy 800H, Inconel 617, or Hastelloy XR, contingent on input from the IHX R\&D effort; and (2) selection of the shroud insulation material from Kaowool, Alltemp, or Porous Carbon.

\subsubsection{Design Discriminators}

Major design discriminators for the CCS include: insulation efficiency, installed equipment costs, temperature capability, operating costs, mechanical performance, development risk, licensing, design lifetime, maintainability, and reliability.

\subsubsection{CCS (Shutdown Cooling) TRL Status}

The current TRL ratings of the General Atomics and Westinghouse CCSs are 4 and 6, respectively, as shown in Table 12. After evaluating the suppliers' TRL ratings and incorporating R\&D input, the NGNP assigns the CCS a TRL of 4. This critical PASSC requires tests and tasks at the late bench-scale leading to experimental-scale to demonstrate technical feasibility and functionality.

Table 12. CCS Summary TRL Table

\begin{tabular}{|c|c|c|c|c|}
\hline & AREVA & General Atomics & Westinghouse & NGNP \\
\hline TRL & Not provided & 4 & 6 & 4 \\
\hline
\end{tabular}

\subsubsection{CCS (Shutdown Cooling) Maturation Path}

Maturation tests and tasks for the CCS can be categorized into four areas: SCHE Helical Coil Tube; Tube Support Method and Wear Protection Devices; Shroud and Insulation; and Integrated System.

To advance to a TRL of 5, several key activities must be completed, including: trade studies, incorporating IHX input into CCS technology development, and computer modeling of specific criteria for the SCHE Helical Coil Tube. A key performance criterion to obtain TRL 5 is the pressurized cool down from $100 \%$ power.

To advance the CCS from TRL 5 to TRL 6, material issues need to be resolved and the components of the CCS tested, as shown on the CCS TDRM. Other tasks and tests include more detailed analysis on each of the CCS areas; important to this is the method development to be performed. Additionally, pilotscale testing begins on the SCHE, along with other tasks being performed for the Tube Support, and Shroud and Insulation development. Significant materials' testing for Shroud and Insulation begins and continues through TRL 6 .

To mature the CCS from TRL 6 to TRL 7, the CCS will be tested in a relevant environment, as shown on the TDRM. Engineering-scale testing is required, with identified performance criteria being at $800^{\circ} \mathrm{C}$ and a pressure of $9 \mathrm{MPa}$. Completion of Tube Support and Shroud and Insulation tasks grants the CCS a TRL of 7, with Final Design of the NGNP CCS being started and completed.

To mature from a TRL 7 to TRL 8, the CCS will be inserted into the NGNP for full-system operability testing. Testing and qualification of the full-scale NGNP CCS in a non-radiation operating environment grants a TRL of 8 .

\subsubsection{Consolidated INL Technology Development Roadmap}

A consolidated TDRM, produced from supplier CCS (Shutdown Cooling) TDRM data combined with NGNP R\&D data, is shown in Figure 19. 


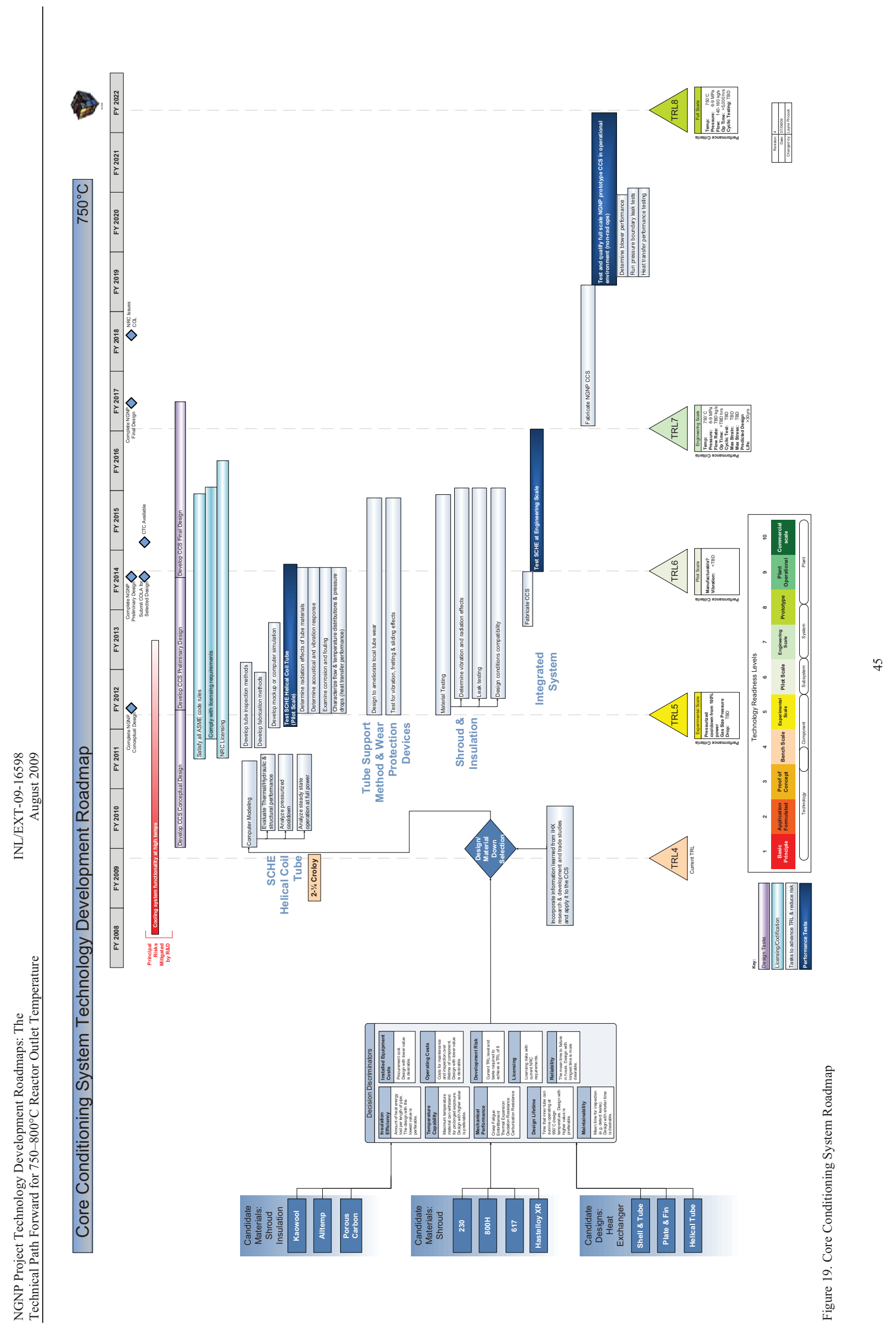




\subsection{Reactor Cavity Cooling System}

The Reactor Cavity Cooling System (RCCS) removes waste heat from the Reactor Cavity, through common heat exchange techniques, to cool the Reactor Cavity and maintain its temperature within safe operating limits.

\subsubsection{Reactor Cavity Cooling System Design Description}

The RCCS is a simple system that relies on radiation, conduction, and convection as heat transport mechanisms to transfer heat away from the Reactor Cavity in the RPV. During normal operations, the RCCS pumps and circulates water or air past the RPV. Heat is transferred to the water or air and dissipated through a heat sink or heat exchanger. The RCCS also protects the reactor cavity concrete, including RPV supports, from overheating during normal operation. Common components may include water storage, heat exchangers, pipes, and cooling panels. A representative RCCS layout is shown in Figure 20.

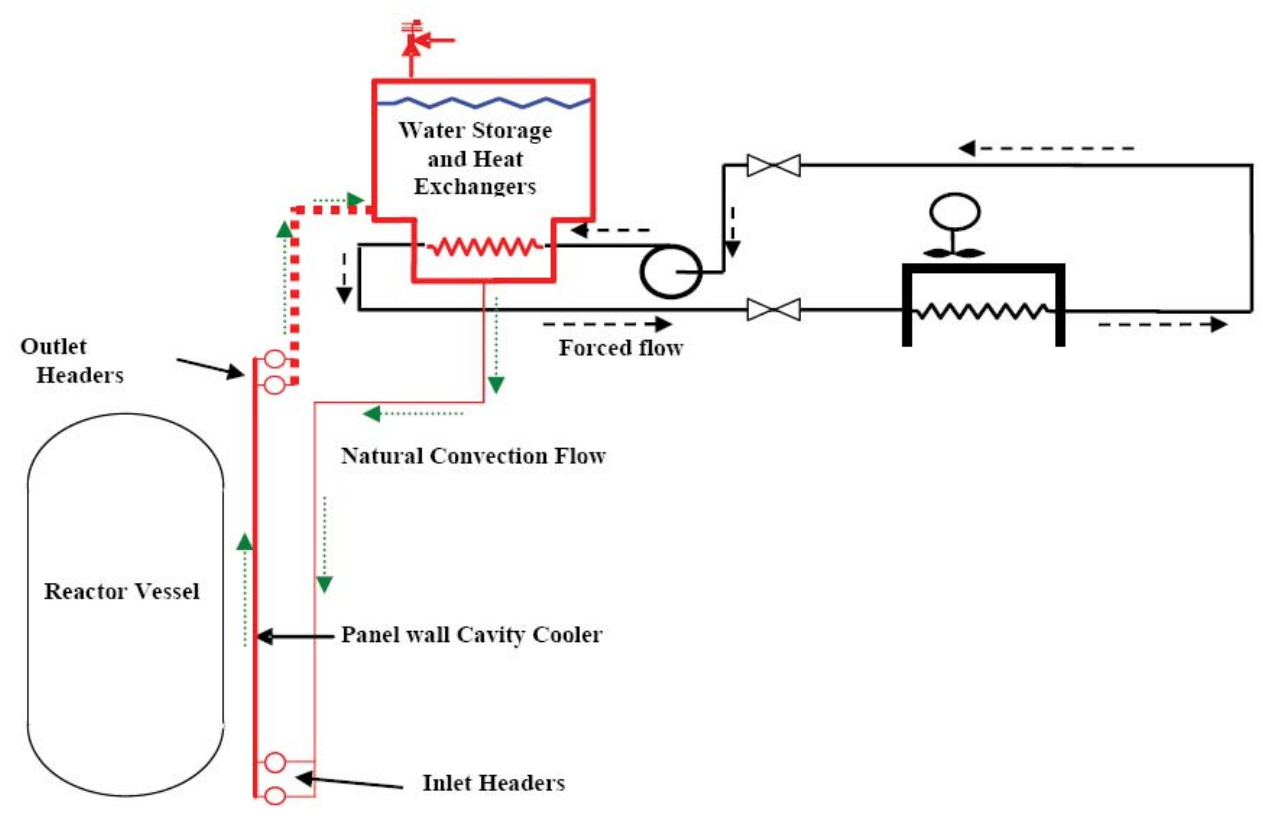

Figure 20. Representative RCCS Layout provided by AREVA

\subsubsection{Functions Performed}

The primary functions of the RCCS are:

- Remove normal operating waste heat from the Reactor Cavity

- Maintain Reactor Cavity concrete surface temperature below code limits

- Protect the RPV from overheating during normal operation

- Provide alternative means of heat removal when the Primary Heat Transport System (PHTS) and the Shutdown Cooling System are not operating. 


\subsubsection{Design Options}

Current RCCS design configurations show that AREVA and Westinghouse favor a water-cooled RCCS design over an air-cooled design. General Atomics, on the other hand, considers the possibility of using air or water as the coolant fluid.

In the Westinghouse design, redundancy is provided by feeding 72 standpipes from 18 independent tanks, as shown in Figure 21. The standpipes from the same tank are segregated to limit concentration of hot areas should one system fail. An alternative design being considered by Westinghouse, which utilizes heat pipes, is being evaluated for future plants.

Like Westinghouse, AREVA's design includes a water storage tank above the RPV. During normal shutdown, decay heat is removed through the PHTS or through the CCS. However, in the event that these paths are unavailable, decay heat is transferred by passive means from the RPV to RCCS panels.

General Atomics' configuration is a concentric cylindrical stack design with an elevated intake and exhaust. The configuration minimizes the effect of wind speeds and directions by elevating the stack intake and exhausts above the point where the local site structures have a significant effect on the wind flow boundary layer.

\subsubsection{Design Discriminators}

Major design discriminators for the RCCS include: schedule; thermal performance, particularly the ability to keep maintain RPV concrete temperature below damaging-inducing levels (RPV temperature and thermo-mechanical stress); and material performance, in terms of susceptibility to degradation in heat

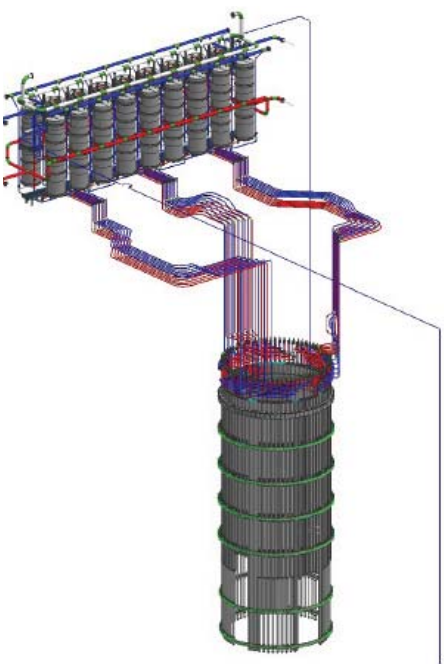

Figure 21. General arrangement of RCCS components (provided by AREVA) removal capability and in emissivity. Additional discriminators may include: cost, development risk, licensing, reliability, maintainability, and availability.

\subsubsection{Reactor Cavity Cooling System TRL Status}

A TRL of 4 is issued by the NGNP for the RCCS (see Table 13). There are significant tests and tasks to overcome before advancing to the next TRL. Generally speaking, these tasks orient around cooling panels and inlet/outlet structures work to be performed. At a TRL 4, the components of the RCCS must be tested at a bench-scale to demonstrate technical feasibility and functionality. When these material issues are overcome and information has been provided to prove feasibility of the components at a benchscale, the RCCS will advance to TRL 5.

Table 13. Reactor Cavity Cooling System Summary TRL Table

\begin{tabular}{|c|c|c|c|c|}
\hline & AREVA & General Atomics & Westinghouse & NGNP \\
\hline TRL & 5 & 4 & 6 & 4 \\
\hline
\end{tabular}




\subsubsection{Reactor Cavity Cooling System Maturation Path}

To mature the RCCS from TRL 4 to TRL 5, the components of the RCCS will be demonstrated at experimental-scale in a relevant environment. This includes the testing and evaluation of cooling panels (at pilot-scale) and the testing and evaluation of inlet/outlet structures. Emissivity and pressure are some of the parameters that must be examined. A heat removal analysis of the RCCS is also conducted for normal, off-normal, and transient conditions.

To advance the RCCS from TRL 5 to TRL 6, the components will be integrated into a subsystem and demonstrated at a pilot-scale in a relevant environment. Pilot-scale testing of cooling panels examining some specific parameters defined in the TDRM must be completed.

To mature the RCCS from TRL 6 to TRL 7, the RCCS subsystems will be integrated into an engineering-scale system and demonstrated in a relevant environment. A demonstration at this stage that shows fabricability, flow and circulation behavior, and stress in the cooling panels must be successfully completed. Tasks to be performed at this stage are shown on the TDRM.

To mature from a TRL 7 to TRL 8, the RCCS will be inserted into the NGNP for full-system operability testing. Fabrication of the NGNP RCCS must be completed before the full-scale RCCS is ready for integrated operational (non-radiation ops) testing.

\subsubsection{Consolidated INL Technology Development Roadmap}

A consolidated TDRM, produced from supplier RCCS TDRM data combined with NGNP R\&D data, is shown in Figure 22. 
This page intentionally left blank. 


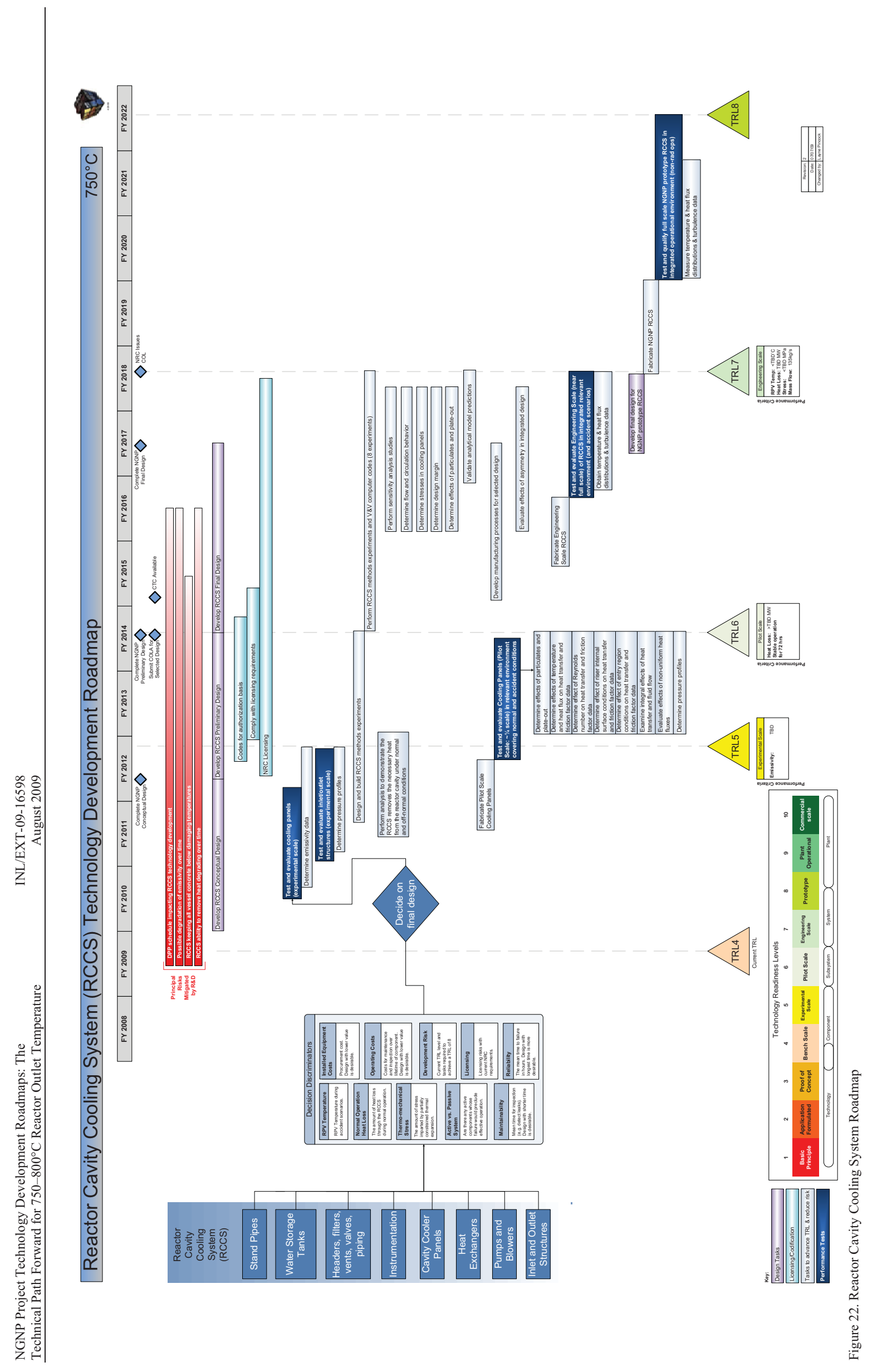




\section{HEAT TRANSPORT SYSTEM}

Section 3 provides a detailed description of the functions performed in the Heat Transport System (HTS). The key systems within the HTS are the primary loop, the secondary loop, IHX Vessel, the secondary gas circulators, the heat exchanger, the primary Hot Gas Duct, and the High-temperature Valves.

\subsection{Circulators}

The Circulators force primary helium through the reactor core and cooling loops at high temperatures to cool the system.

\subsubsection{Circulators Design Description}

The circulators are sized based on the coolant pressure drop through the reactor cooling system when the reactor is at $100 \%$ power (anticipated helium flow rate is $\sim 140$ to $200 \mathrm{~kg} / \mathrm{s}$ ). The circulators include the following components:

- Housing

- Impeller

- Diffuser

- Electric motor

- Bearings (electro-magnetic and mechanical catcher)

- Rotor

- Inverter

- Seals

\subsubsection{Functions Performed}

The high-level function performed by the circulators is to circulate helium through the primary and secondary loops. Lower-level functions include:

- Turn the rotor

- Supply power

- Convert power

- Control flow rate.

Depending on whether the design includes a submerged or external electric drive, the circulators may be required to control leakage.

\subsubsection{Design Options}

AREVA proposes two large circulators mounted in the steam generator vessels to circulate primary coolant through the steam generator and reactor core at a flow rate of $282 \mathrm{~kg} / \mathrm{sec}$. The circulator technology is mature. Helium will pass through the circulators at $320^{\circ} \mathrm{C}$ at the inlet and $325^{\circ} \mathrm{C}$ at the outlet. Due to the required flow rate at that temperature, the circulators will conservatively require a 
power rating of $4 \mathrm{MWe}$, which is considered within the state-of-the-art for gas circulators having helium immersed motors.

General Atomics identifies that The James Howden Company has designed and built 112 circulators for the commercial Advanced Gas Reactor (AGR) plants. Howden has designed a 4 MWe helium circulator to the concept stage for General Atomics. Data on helium circulators is available from component testing performed for Fort St. Vrain and the proposed Delmarva plant.

Westinghouse identified two design options. The first design is a submerged circulator with magnetic bearings and the second design is a circulator located outside the pressure boundary with oil lubricated bearing and rotating seals at pressure boundary.

\subsubsection{Design Discriminators}

The major design discriminators for the circulators include: thermal performance (i.e., can the motor be adequately cooled for the design and helium temperature), helium leakage, and bearing and seal performance. Additional design discriminators may include: manufacturability and transportability, aerodynamic efficiency, mechanical efficiency, life-cycle cost, development risk, design margin, licensing, compactness, reliability, maintainability, availability, and operations and maintenance risk. Additional information on each discriminator can be found in the TDRM (see Figure 23).

\subsubsection{Circulators TRL Status}

The current TRL rating for each supplier is shown in Table 14. The vendors state that the circulators are at a TRL of 6. However, supplier tests were identified on certain components (e.g., impeller, bearings, rotor, etc.) of the circulator, and integrated tests of their components have not been performed in the design configuration anticipated for NGNP. Helium testing is needed on motor and bearing insulation. Additionally, there are no tasks identified that verifies the circulator system performance in air is the same as Helium. Therefore, the NGNP maintains that a rating of 6 is recommended.

Table 14. Circulators Summary TRL Table

\begin{tabular}{|c|c|c|c|c|}
\hline & AREVA & General Atomics & Westinghouse & NGNP \\
\hline Circulator & 6 & 6 & 6 & 5 \\
\hline
\end{tabular}

\subsubsection{Circulators Maturation Path}

To progress to a TRL of 6 , selection of the circulator supplier will occur to build a pilot-scale circulator to demonstrate the bearings, rotor, and motor controls; test the possibility of arching in a helium environment; test the gas circulator cooling system; test seals for leakage (both oil and helium), and validate the circulator's performance. Key tests will also be performed to determine which sized circulator will be used. These include bearing, rotor, motor controls, seals, electrical, insulation, and cooling tests. Final integration of these tests will be performed at pilot-scale in ambient air conditions.

Testing of an engineering-scale circulator is required to progress to a TRL of 7 . The types of tests are like those of the pilot-scale, but in a high-temperature helium environment in a component test capability. Shaft brake testing will begin at this scale, as will preparatory work for design and fabrication of the prototype.

To achieve a TRL of 8, a full-scale NGNP circulator will be tested in the NGNP. Full-scale testing and qualifying of the circulators are performed within a non-radiological environment. 


\subsubsection{Consolidated INL Technology Development Roadmap}

A consolidated TDRM, produced from the supplier Circulators TDRM data combined with NGNP $\mathrm{R} \& \mathrm{D}$ data, is shown in Figure 23. 
This page intentionally left blank. 


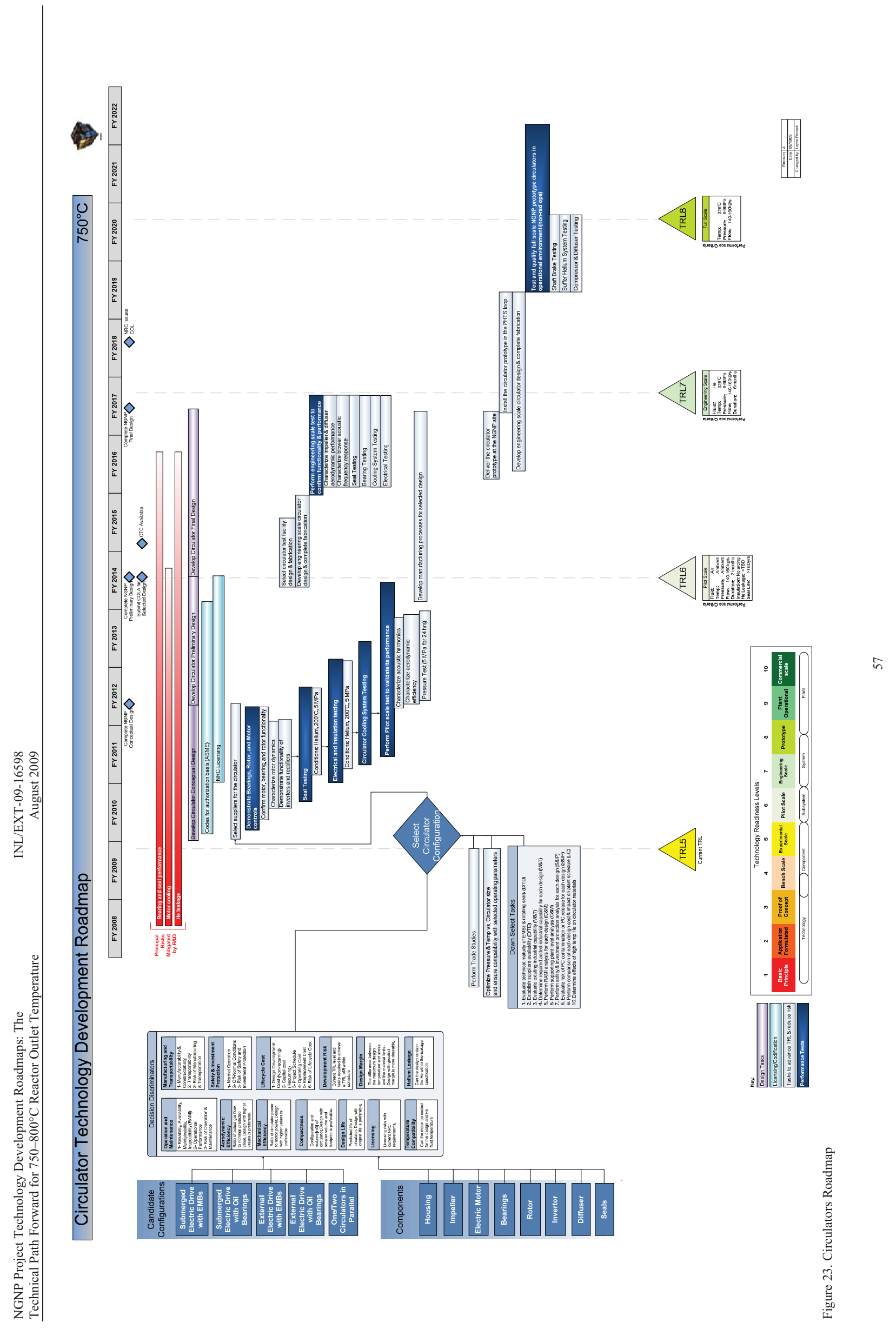




\subsection{Intermediate Heat Exchanger}

The Intermediate Heat Exchanger (IHX) accepts heat from the primary loop and transfers it to the heat transfer loop.

\subsubsection{Intermediate Heat Exchanger Design Description}

The IHX transfers heat between the PHTS and the Secondary Heat Transport System (SHTS). The PHTS is comprised of the primary piping, primary circulator, and primary helium working fluid. The SHTS is comprised of the secondary piping, secondary circulator, and secondary helium working fluid. Heat is also transferred by the IHX to downstream applications (e.g., power production [steam generation], and process heat).

The IHX is comprised of the following components:

- Heat exchanger cores and/or modules containing the heat transfer surface

- $\quad$ The IHX vessel

- Headers and/or piping that provide a transition between the heat exchanger cores and/or modules and the PHTS and SHTS piping

- Internal structures that provide for support (steady state, transients, and seismic loading) of the IHX and related internal components within the IHX vessel

- Thermal baffles and insulation.

\subsubsection{Functions Performed}

The primary functions of the IHX are to contain the primary and secondary helium coolants and to transport thermal energy, in the form of heat, from the reactor's PHTS to the SHTS working fluid. Secondary functions include: providing a pressure boundary, insulating the vessel, and preventing cross contamination (secondary to primary or vice versa).

\subsubsection{Design Options}

There are multiple options for the IHX vessel and the IHX internals. Options involve materials, fluids, structure types, and number of heat exchanges.

Four candidate materials are being considered for the pressure vessel:

- Alloy $800 \mathrm{H}$

- Alloy 230

- Alloy 617

- Hastelloy X

Seven candidate configurations exist for the heat exchanger:

- Shell and Tube

- Involute

- Capillary Tube 
- Helical Tube

- Plate and Fin

- Plate Stamped

- Printed Circuit.

The candidate currently being considered for the secondary coolant fluid is Helium.

\subsubsection{Design Discriminators}

The key material decision discriminators for the vessel include: thermal conductivity, materials database, materials lifetime, and fabrication related factors. Additional discriminators may include: maturity of material data, R\&D status, services experience, ASME code qualification, fabricability, licensing, availability, performance in an impure helium environment, and cost.

The key structural design decision discriminators for the type of heat exchanger include: localized stress/strain, erosion, and corrosion; dust susceptibility; material thickness; qualification/codification; and both equipment and operating costs. Additional discriminators may include: transient condition acceptability, receipt inspectability, tritium migration allowance, compactness, heat transfer rate (performance), repairability, and availability.

The key fluid decision discriminators include: infiltration to the primary loop in an accident scenario and ease of recovery; availability of the fluid; purification capability (i.e., removal of tritium); and cost. Additional discriminators may include inspectability and piping/valving complexity (see the TDRM in Figure 24).

\subsubsection{Intermediate Heat Exchanger TRL Status}

The current TRL status provided by Westinghouse is shown in Table 15. The rollup of the TRLs can be found for reference in Appendix A. NGNP has issued a TRL of 3 to all components associated with IHX.

Table 15. Intermediate Heat Exchangers Summary TRL Table

\begin{tabular}{|l|c|c|c|c|}
\hline & AREVA & General Atomics & Westinghouse & NGNP \\
\hline IHX & Not provided & Not provided & 3 & 3 \\
\hline
\end{tabular}

\subsubsection{Intermediate Heat Exchangers Maturation Path}

Three IHX technology development areas are illustrated in the TDRM: materials, design, and secondary fluids. Each area has a series of tasks and tests to complete to advance from one TRL to the next.

\subsubsection{IHX Materials}

A TRL of 4 is granted once material qualification/codification and constitutive modeling and analysis tasks begin.

To achieve a TRL of 5, significant IHX materials properties need to be matured and associated tasks must be completed. Overall, these maturations orient around material qualification/codification and constitutive modeling and analyses. 
TRL 6 is granted once material qualification/codification tasks are complete. Additionally, flaw assessments and lead-before-break tasks must be performed.

Extrapolation of Alloy $800 \mathrm{H}$ or Hastelloy X creep data for a 60 year life cycle must be completed to achieve a TRL of 7.

\subsubsection{IHX Designs}

Intermediate Heat Exchanger designs tasks to advance to TRL 4 include simplified design procedures, focusing various models, testing criteria, joining procedures, and corrosion allowance.

For a TRL of 5, experimental-scale testing, fabrication of the IHX at experimental-scale, and start of NRC licensing and ASME codification approvals must begin.

TRL 6 issuance requires testing and evaluation of IHX at experimental-scale. Design and fabrication of pilot heat exchangers and various in-service inspectability tasks also need to be performed so that full testing of pilot-scale heat exchangers and the final design for NGNP prototype can begin.

Technology development tasks for TRL 7 requires completion of pilot-scale IHX; design, fabrication, and testing of engineering-scale IHX. At this stage, fabrication of NGNP heat exchangers also begins.

\subsubsection{Consolidated INL Technology Development Roadmap}

A consolidated TDRM, produced from the supplier IHX TDRM data combined with NGNP R\&D data, is shown in Figure 24. 
This page intentionally left blank. 


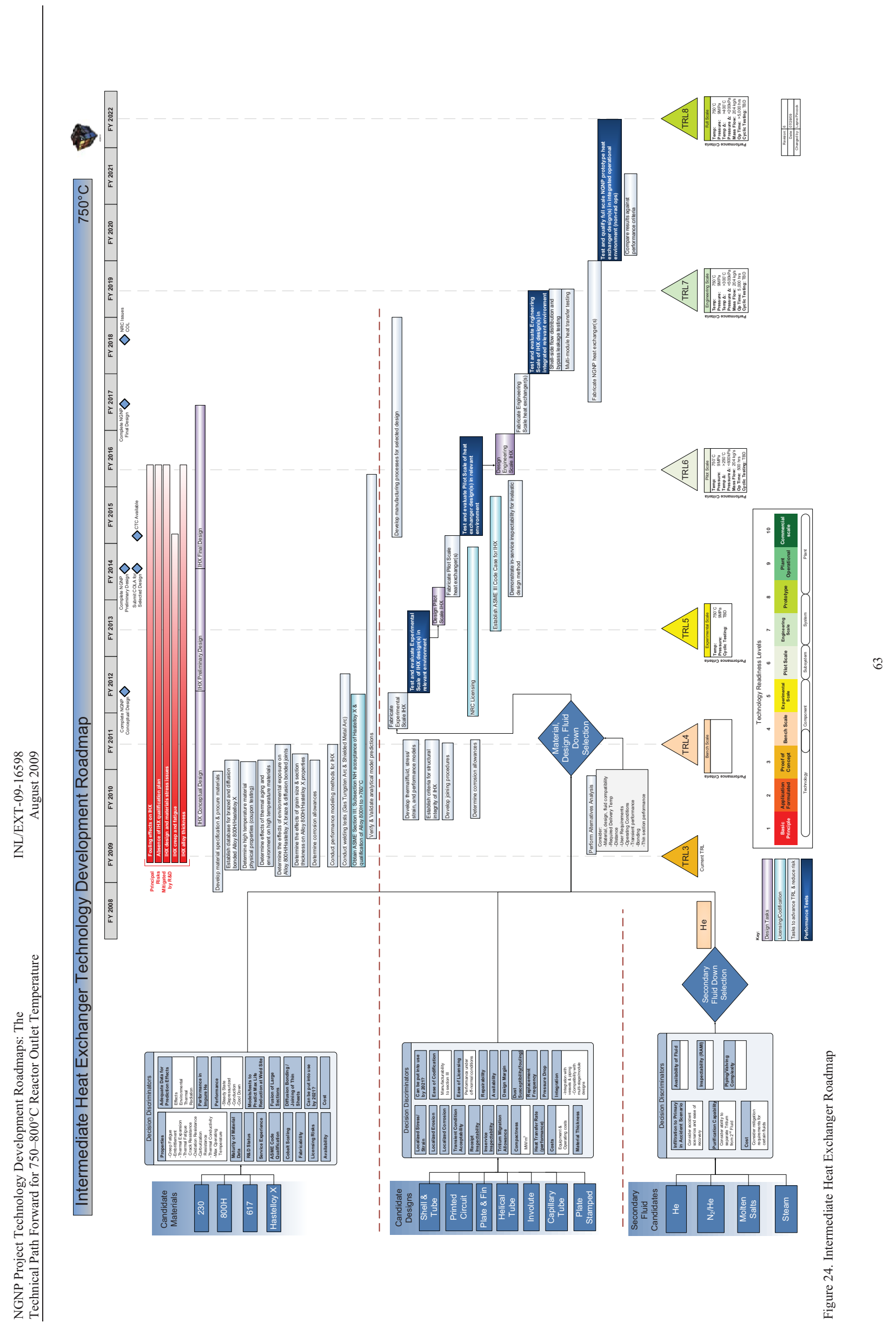




\subsection{Cross Vessel Piping}

The Cross Vessel Piping (CVP) is a piping arrangement that connects the RPV and the IHX to carry coolant fluid for heat transport.

\subsubsection{Cross Vessel Piping Design Description}

The CVP consists of four main components: the support structure, hot and cold ducts, the insulating materials, and the insulation liner. The CVP is located between the RPV and the IHX. Hot helium coolant $\left(750-800^{\circ} \mathrm{C}\right)$ is transferred via the hot duct from the core, while cold helium coolant $\left(280-340^{\circ} \mathrm{C}\right)$ is returned via the cold duct to the core.

\subsubsection{Functions Performed}

The function of the hot and cold ducts is to carry the coolant fluid between the RPV and the IHX. The function of the insulation is to reduce fluid thermal losses between the RPV and the IHX vessel. The function of the liners is to separate the cold duct from the hot duct, if they are collocated.

\subsubsection{Design Options}

The support structure material options are SA533 and 800H. The insulation material currently proposed for the DPP is fibrous aluminum; the insulation type for the NGNP has not yet been specified. The insulation material options are Kaowool, refractory, and ceramic fiber (alumina). The liner material will likely be Alloy $800 \mathrm{H}$, but Hastelloy X and other Ni-based or ceramic alloys may also be candidates. Two designs have been suggested. In one, the hot and cold ducts are spatially separated, following two different paths, and an insulation liner is not required. In the other, the hot and cold ducts are collocated and separated by an insulation liner. This design may enhance heat transfer and serve as a preheater to the fluid entering the reactor.

\subsubsection{Design Discriminators}

The design discriminators are insulation efficiency, temperature capability, design lifetime, maintainability, operating costs, development risks, licensing, and replaceability.

\subsubsection{Cross Vessel Piping TRL Status}

NGNP determined that the CVP is at a TRL 4 (see Table 16). The rollup of the TRLs from the suppliers allows for a comparison of the various reference designs. The complete supplier TRL rating sheets are contained in Appendix A.

Table 16. Cross Vessel Piping Summary TRL Table

\begin{tabular}{|c|c|c|c|c|}
\hline & AREVA & General Atomics & Westinghouse & NGNP \\
\hline TRL & 5 & 2 & 4 & 4 \\
\hline
\end{tabular}

\subsubsection{Cross Vessel Piping Maturation Path}

To mature the CVP from TRL 4 to TRL 5, a design down select must occur, and the study of the helium effects, development of a duct and insulation materials properties database, and experimental scale testing including environmental qualification of duct and insulation, initial thermal expansion analysis, initial flow and temperature analysis, hot to cold leak detection, and initial stress analysis, must take place. The design requirements must also be established during this TRL phase. 
To progress to TRL 6, ASME code approvals and licensing must be addressed, and the testing of subsystem, stress analysis and optimization, final thermal expansion analysis, and flow conditions at pilotscale needs to be performed. Other physical, design characteristics, computer model, and manufacturing processes must be developed and/or performed during advancement to TRL 6 .

To achieve a TRL of 7, an engineering-scale hot-duct and cross-vessel test needs to determine overall CVP performance. This involves integration testing of various components in relevant operational environments. Final design of the NGNP prototype is completed before the final issuance of TRL 7.

To reach a TRL of 8 , full-scale testing and qualification of the NGNP in an operational, non-radiation environment must be completed.

\subsubsection{Consolidated INL Technology Development Roadmap}

A consolidated TDRM, produced from supplier CVP TDRM data combined with NGNP R\&D data, is shown in Figure 25. 


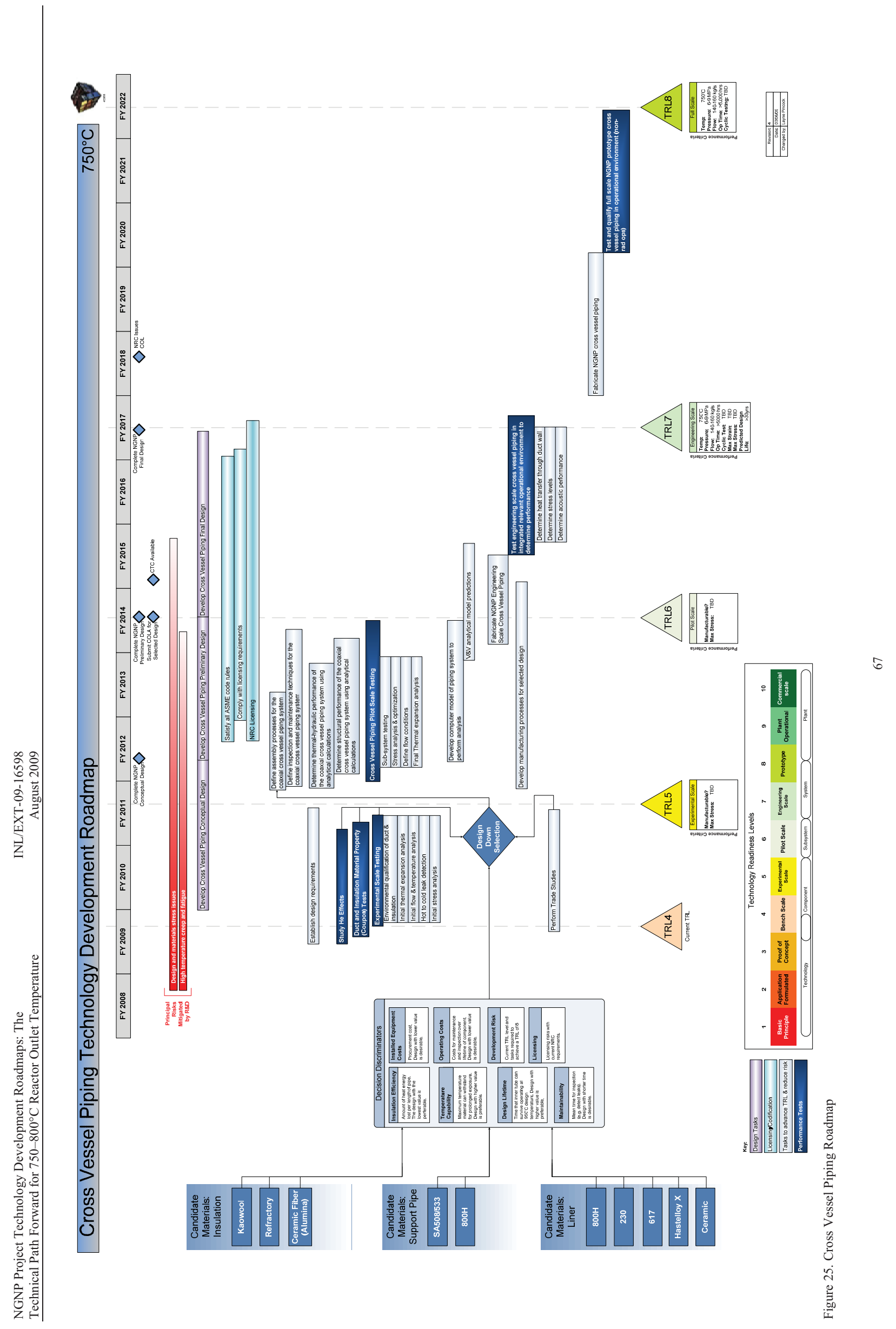




\subsection{High Temperature Valves}

The High Temperature Valves are in the secondary heat transport loop, at the inlet with the main circulator (Flapper Valves), and on the inlet to the secondary shutdown circulator piping to provide isolation and pressure relief (Isolation and Relief Valves). This section will be broken in to two main subsections. The first will address the TRL and development roadmap of the isolations and relief valves, and the second will address the flapper valve.

\subsubsection{High Temperature Isolation and Relief Valves}

\subsubsection{High Temperature Isolation and Relief Valves Design Description}

High temperature isolation valves, located in the steam circuit, enable isolation of the steam generator. Isolation valves are also present on the inlet of the branch to the power turbine and on the inlet to the reboiler used to produce process steam. The RPVis protected by a high temperature pressure actuated relief valve.

\subsection{Functions Performed}

The normal function performed by the High Temperature Valves is to direct flow. The direction of flow serves different purposes depending upon design. The High Temperature Isolation and Relief Valves are located at three different places in secondary loop and have multiple functions. The isolation valves allow normal flow and stop reverse flow at the main circulator, allow normal flow and stop reverse flow at the inlet to the secondary shutdown circulator piping, and maintain pressure in the secondary heat transport loop.

\subsection{Design Options}

Helium temperatures are assumed to be $750-800^{\circ} \mathrm{C}$ and $300-325^{\circ} \mathrm{C}$ for the hot and cold legs, respectively. A steam flow rate of $241.4 \mathrm{~kg} / \mathrm{sec}$ is produced at $541^{\circ} \mathrm{C}$ and $17.25 \mathrm{MPa}$, consistent with the CoGen plant described in the NGNP PCS alternatives report. It is also assumed that for isolation valves on the steam generator, there will be three (3) valves on the steam side of each hot and cold leg. These valves will be an integral part of the plant protective system actions for steam loop isolation events.

\subsection{Design Discriminators}

The key design discriminators are: operational efficiency, particularly in terms of parasitic pressure loss when the valve is open (lower value is preferable); and sealing efficiency, or leakage from a fully closed valve (lower value is preferable). Additional discriminators may include: compactness, design life, design margin, nuclear safety, installed equipment costs, life-cycle costs, development risk, development schedule, licensing, reliability, maintainability, and availability.

\subsubsection{High Temperature Isolation and Relief Valves TRL Status}

The rollup of the TRLs from the suppliers allows for a comparison of the various reference designs (see Table 17). The complete supplier TRL Rating sheets are contained in the Appendix A.

Table 17. High Temperature Valves Summary TRL Table

\begin{tabular}{|l|c|c|c|c|}
\hline & AREVA & General Atomics & Westinghouse & NGNP \\
\hline Isolation & Not provided & 4 & Not provided & 4 \\
\hline Relief & Not provided & 4 & Not provided & 4 \\
\hline
\end{tabular}




\subsubsection{High Temperature Isolation and Relief Valves Maturation Path}

Each of the high temperature valves are on parallel maturation paths. The isolation and relief valves, mirror each other in advancement from one TRL to the next. Trade studies need to be performed prior to any TRL advancement.

\subsection{Isolation Valves Maturation}

A TRL 5 is awarded for isolation valves once reliability, availability, maintainability, and inspectability (RAMI); modeling; analyses; and testing are performed.

Significant pilot-scale physical testing is performed for advancement to TRL 6. Models, methods, analyses, and characterization is also performed as preparation of engineering-scale valves (including start of fabrication) testing.

The completion of the integrated engineering-scale valve tests is required for TRL 7. Specific performance criteria, temperature at $750-800^{\circ} \mathrm{C}$, pressure at $5-9 \mathrm{MPa}$, flow rate of $1-\mathrm{kg} / \mathrm{s}$, and operating time of $>5,000$ hours must be demonstrated before a TRL 7 is given.

The TRL of 8 is achieved once the isolation valves for the NGNP are fabricated and the necessary testing and qualification in the NGNP prototype is completed in a non-radiological environment.

\subsection{Relief Valves Maturation}

Granting of TRL 5 is awarded for relief valves once RAMI, modeling, analyses, and testing are performed.

Significant pilot-scale physical testing is performed for advancement to TRL 6. Models, methods, analyses, and characterization is also performed as preparation of engineering-scale valves (including start of fabrication) testing.

The completion of the integrated engineering-scale valve tests is required for TRL 7. Specific performance criteria, temperature at $750-800^{\circ} \mathrm{C}$, pressure at $5-9 \mathrm{MPa}$, flow rate of $1-\mathrm{kg} / \mathrm{s}$, and operating time of $>5,000$ hours, must be demonstrated before a TRL 7 is given.

The TRL of 8 is achieved once the relief valves for the NGNP are fabricated and the necessary testing and qualification in the NGNP prototype is completed in a non-radiological environment.

\subsubsection{High Temperature Flapper Valves}

Flapper valves are located at the inlet to the circulators in the main HTS.

\subsubsection{High Temperature Flapper Valves Design Description}

Each gas circulator is equipped with a self-actuating valve set at the impeller inlet. This valve closes in the event of a malfunction or failure of the circulator or during a maintenance operation of the HTS or PCS. The primary gas circulator flapper valve prevents possible reverse flow from the reactor and core by-pass from the shutdown cooling system or the other primary cooling loop. The valve is opened by aerodynamic flow of gas over the flapper valve into the circulator inlet.

\subsection{Functions Performed}

These valves are required to remain open during plant operation and close during plant shutdown to prevent excessive backflow of coolant through the circulator(s). The valves are designed to operate 
passively using a counterweight to close the valve when flow stops and aerodynamic forces to open the valve when there is flow. The NGNP Circulator Shutoff Valve is located at the circulator inlet. The FSV Circulator Shutoff Valve is at the outlet.

\subsection{Design Options}

AREVA's design includes the flapper valves only in the primary heat transport loop. The valve is currently envisioned as a butterfly type valve, which is opened by aerodynamic flow of gas over the eccentric disk (also referred to as a "butterfly" or "flapper") which rotates on a stem. The structural design details depend on the performance requirements (pressure, seal leak tightness). An actuator may be attached to the valve stem if the valve is used as part of the automated control system.

\subsubsection{High Temperature Flapper Valves TRL Status}

A TRL of 6 is recommended by AREVA (see Table 18). The complete supplier TRL Rating sheets are contained in the Appendix A.

Table 18. High Temperature Valves Summary TRL Table

\begin{tabular}{|l|c|c|c|c|}
\hline & AREVA & General Atomics & Westinghouse & NGNP \\
\hline Flapper & 6 & Not provided & Not provided & 6 \\
\hline
\end{tabular}

\subsubsection{High Temperature Flapper Valves Maturation Path}

To advance to TRL 7, the flapper valve must be demonstrated via the engineering-scale tests within the same relevant environment as the isolation and relief valves.

TRL 8 is issued once the flapper valve is integrated into the NGNP prototype and non-radiological integration testing is completed.

\subsubsection{Consolidated INL Technology Development Roadmap}

Figure 26 is a consolidated TDRM, produced from supplier High Temperature Valves TDRM data combined with NGNP R\&D data. 
This page intentionally left blank. 


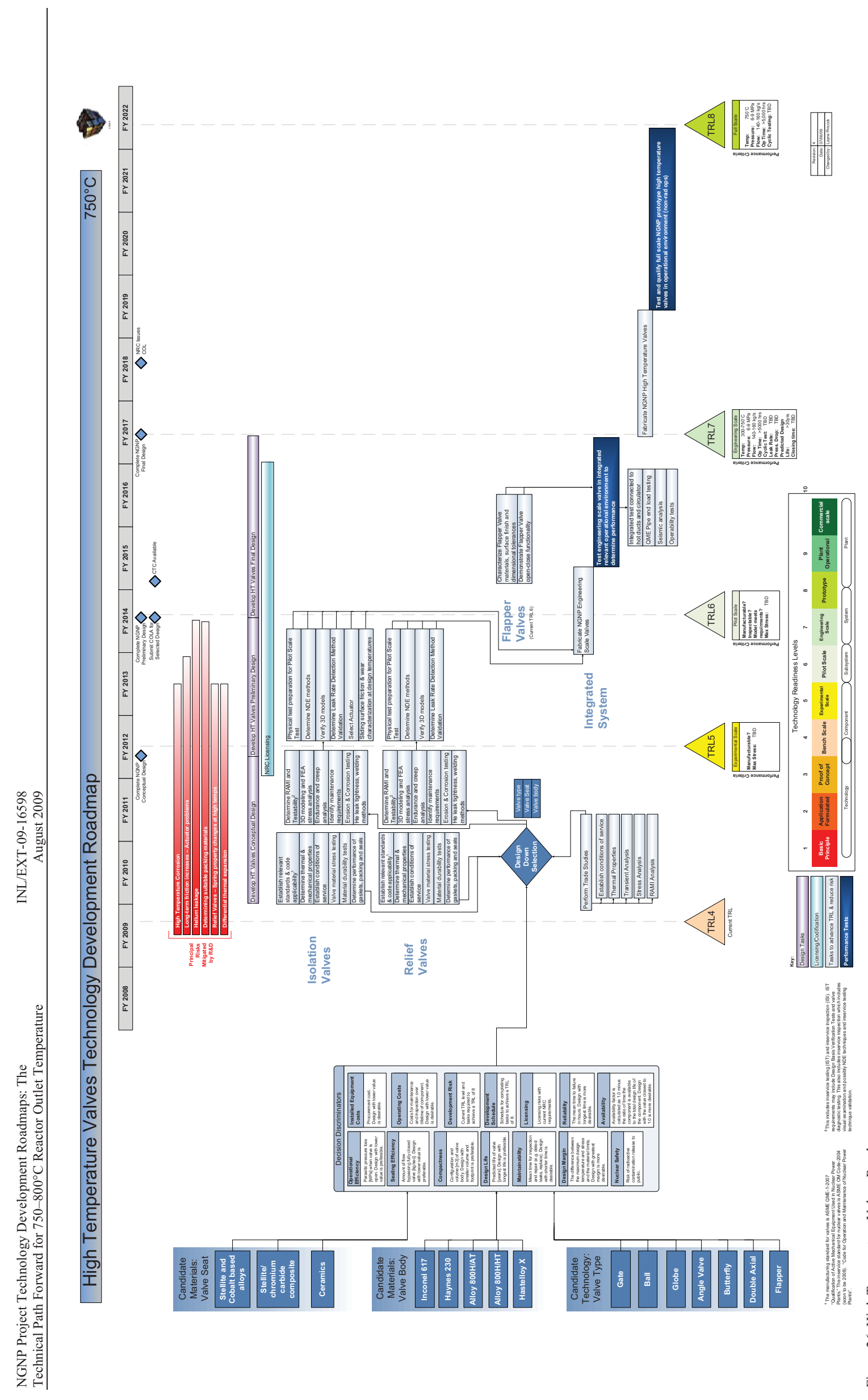

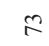


s.

Z 


\subsection{Mixing Chamber}

With an ROT of $750-800^{\circ} \mathrm{C}$, the mixing chamber is no longer considered critical as it is rated at a TRL of 7, and therefore not required for this report.

\section{HYDROGEN PRODUCTION SYSTEM}

The HPS is currently being evaluated for selection of the NGNP preferred technology. After this selection is made, a new consolidated roadmap, focusing on the selected technology with a potential backup technology, will be generated. For the purposes of a TDRM at $750-800^{\circ} \mathrm{C}$ ROT, the existing $950^{\circ} \mathrm{C}$ HPS TDRMs (Ref: INL.EXT-08-15148), coupled with the addition of induction heaters to increase the temperature for greater efficiency, adequately depict the current HPS path forward.

The goal of the national Nuclear Hydrogen Initiative is to demonstrate the economic, commercialscale production of hydrogen using nuclear energy, which could lead to a large-scale, emissions-free, domestic hydrogen production capability to fuel a future hydrogen economy. The NGNP is being designed to produce both electricity and hydrogen. Hydrogen will be produced by the Hydrogen Production System (HPS) within the Hydrogen Production Area, which is basically a demonstration facility consisting of the HPS and associated buildings and structures.

\section{POWER CONVERSION SYSTEM}

\subsection{Steam Generator}

The Steam Generator converts water into steam from a heat source, in this case heat produced in a nuclear reactor core, which drives turbines to generate electricity. Pressurized water is channeled through alloy tubes, which heats up water around the tube to form the steam.

\subsubsection{Steam Generator Design Description}

In the Steam Generator, sub-cooled feed water acquires heat from the higher temperature helium circulating in the SHTS and the water vaporizes, becoming superheated steam. Piping transports the steam to the turbine inlet to drive the turbine rotation. The Steam Generator design concept is a directcycle helical tube steam generator. It is a vertically oriented, counter-flow, shell-and-tube, once-through, non-reheat tubular heat exchanger with helium on the shell side and water/steam in the tubes. The Steam Generator will interface with the secondary heat exchanger and PCS, which is a significant departure from prior HTGR applications in which the Steam Generator was located in the PHTS. Internal structure materials (e.g., tube supports, tube surfaces, shrouds) are selected consistent with their respective operating temperatures. The Steam Generator incorporates an economizer, an evaporator, and first-stage superheater in one helical tube bundle, followed by a finishing superheater in a second helical tube bundle.

\subsubsection{Functions Performed}

The function of the Steam Generator is to produce superheated, high-pressure steam for conversion into mechanical work to turn a turbine that will generate electricity. 


\subsubsection{Design Options}

A serpentine design has been suggested as one alternative to the helical tube design. It has also been suggested that using multiple steam generators may have advantages. With the ROT of $750^{\circ} \mathrm{C}$ the material candidate for the economizer, evaporator, and superheater is Alloy $800 \mathrm{H}$ because it has been approved for use up to $760^{\circ} \mathrm{C}$ under ASME Boiler and Pressure Vessel Code Section III, Subsection NH and efforts are underway to extend its use to higher temperatures.

\subsubsection{Design Discriminators}

Key design discriminators include: thermal performance (heat transfer efficiency), mechanical performance (thermo-mechanical stresses, corrosion, and wear), and equipment and operating cost. Additional discriminators may include: compactness (power density of the steam), pressure drop, design margin, development risk, manufacturability, licensing, reliability, maintainability, and availability.

\subsubsection{Steam Generator TRL Status}

The NGNP rates the Steam Generator at a TRL of 4 (see Table 19). The suppliers rate the Steam Generator as further advanced, but with consideration for the R\&D needed to further mature the materials needed, a TRL of 4 is warranted.

Table 19. Steam Generator Summary TRL Table

\begin{tabular}{|c|c|c|c|c|}
\hline & AREVA & General Atomics & Westinghouse & NGNP \\
\hline TRL & 6 & 4 & 6 & 4 \\
\hline
\end{tabular}

\subsubsection{Steam Generator Maturation Path}

Some computer modeling needs to be developed and operated before at TRL 5 can be issued. Other items that must occur to justify a TRL of 5 include trade studies and structural testing of the materials.

Pilot-scale testing of the Steam Generator is necessary for a TRL of 6, including, manufacturability demonstrations, weld qualifications, and characterizations. The selection process of suppliers begins at TRL 6.

Fabrication and integrated testing of the Steam Generator, at an engineering-scale, needs to be completed for TRL 7. Integrated Steam Generator tests include a series of performance tasks associated with specific Steam Generator areas.

TRL 8 is granted once the NGNP Steam Generator is fabricated and installed, and non-radiological testing in the NGNP begins.

\subsubsection{Consolidated INL Technology Development Roadmaps}

A consolidated TDRM, produced from Steam Generator TDRM data from the suppliers combined with NGNP R\&D data, is shown in Figure 27. 


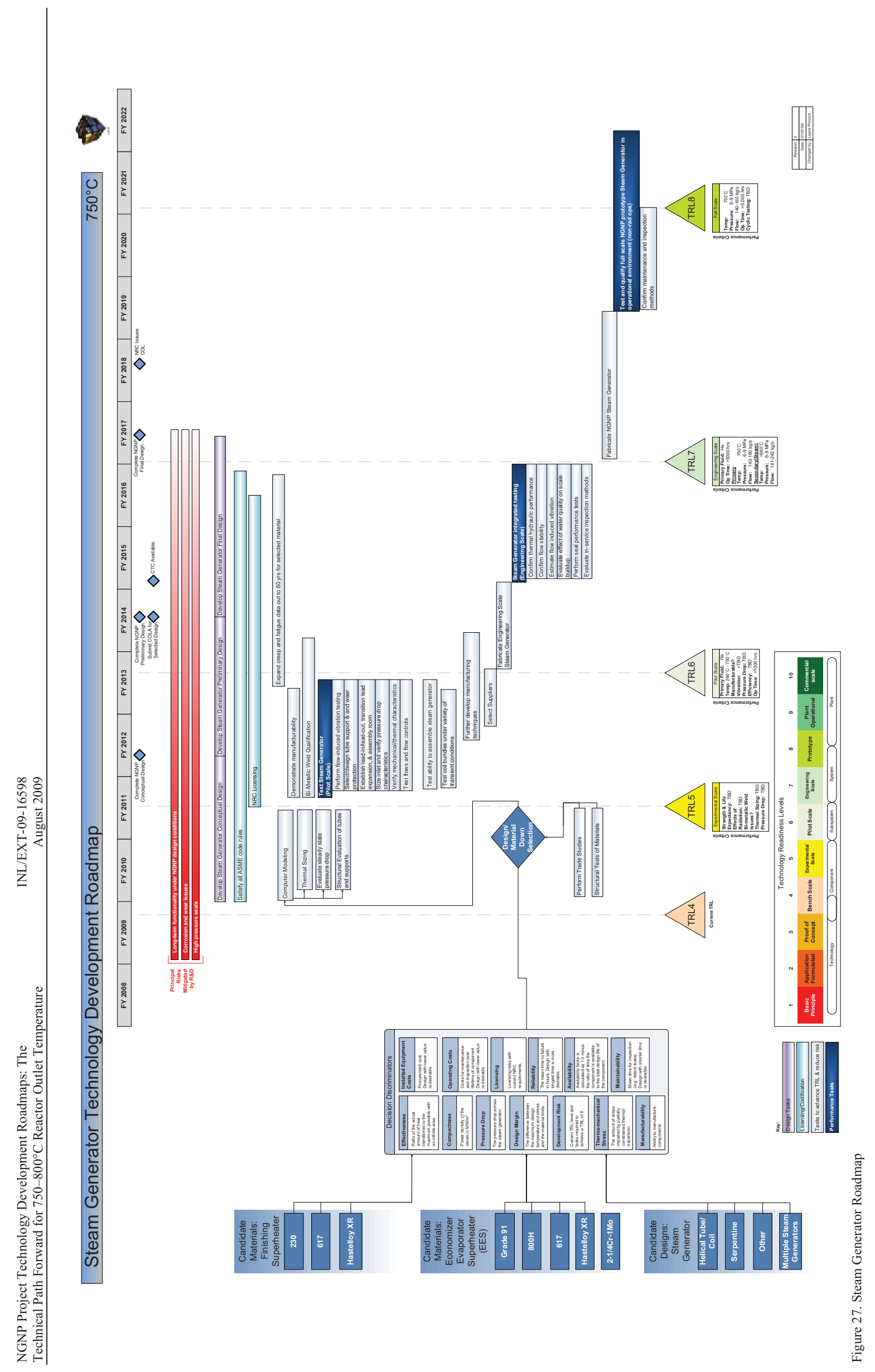


2.

Z 


\subsection{PCS Equipment for Direct Combined Cycle}

With an ROT of $750-800^{\circ} \mathrm{C}$, the mixing chamber is no longer considered critical as it is rated at a TRL of 7, and therefore not required for this report.

\section{BALANCE OF PLANT (BOP)}

\subsection{Fuel Handling System}

The Fuel Handling System (FHS) is used to refuel the reactor. The FHS consists of a series of machines and devices that transfer fuel and reflector blocks between the Reactor Core and the Near Reactor Spent Fuel Storage location. Two types of fuels are being considered by NGNP: Prismatic (AREVA and General Atomics) and Pebble Bed (Westinghouse).

\subsubsection{Fuel Handling System Design Description (Prismatic)}

The FHS is a robotic manipulator that can be inserted into an inner control rod drive penetration and is equipped with a grapple probe that can be inserted into the handling hole in the top of any hexagonal block. The probe can be expanded to engage the block so the machine can lift it. Blocks are grappled and raised one at a time. The FHS is equipped with a pantograph-like mechanism giving it the capability to extend the grapple out to a radius sufficient to reach all the blocks within a sector, including all hexagonal reflector blocks.

The FHS can rotate, extend, and raise/lower, so that it can access all the hexagonal blocks in a sector from an inner Control Rod Drive Mechanism (CRDM) nozzle. The FHS reduces the estimated refueling time using robotic machines that remove core blocks and transfer them to the adjacent Local Spent Fuel Storage cell, which is part of the Spent Fuel Storage System. Subsequently, new and irradiated fuel blocks are delivered to the FHS, which then places them into the reactor vessel. Access to the core region is provided by a fuel elevator, which is mounted at the central position. All fuel elements and reflector blocks go through this central position.

The components of the FHS are mobile and may be shared among all reactor modules in multimodule plants. The FHS also interacts closely with the control rod removal cask. The cask, which is part of the Reactor Service System, interfaces with the Fueling Adaptor and is used to remove and reinstall central column instrumentation and both inner and outer control rod and reserve shutdown assemblies. The Spent Fuel Storage System also interfaces closely with facilities for storage of graphite elements and waste treatment systems. Figure 28 and Figure 29 illustrate the general design concept and the interaction of some of these components. 


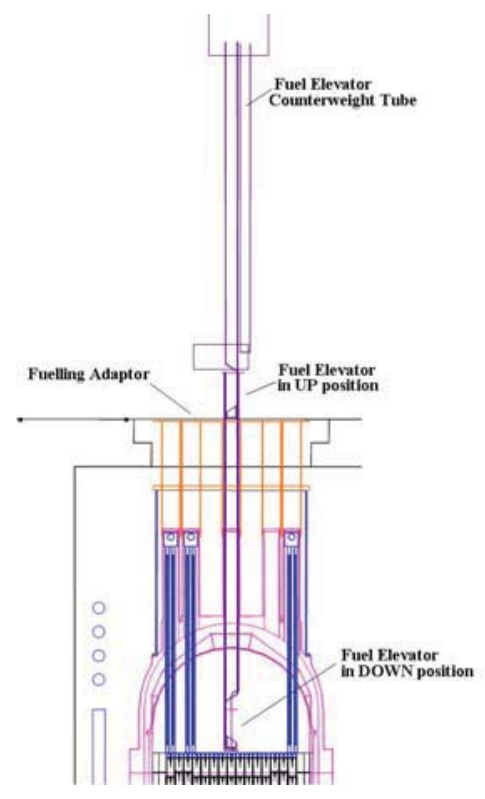

Figure 28. Fueling Adaptor and Fuel Elevator

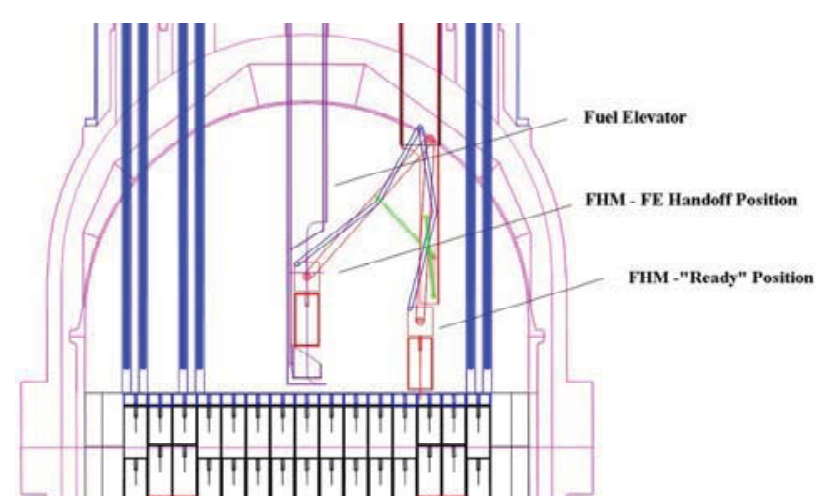

Figure 29. Fuel Handling Machine

\subsubsection{Functions Performed}

At a high level, the FHS is used to transfer fuel and reflector elements between the reactor and local storage facilities and between the local storage facilities and the packaging and shipping facility. The system is also used to manipulate special tools for in-service inspection of reactor components.

\subsubsection{Design Options}

No functionally alternative design concepts are presented; however, the specific designs proposed by a supplier will differ in the details.

\subsubsection{Design Discriminators}

Since there are no alternative designs, there are no design discriminators for comparing design concepts. When evaluating one specific design implementation against another, decision discriminators might include: helium sealing performance, high temperature performance, expected lifetime, replacement cost, primary system contamination, and past experience.

\subsubsection{Fuel Handling System (Prismatic)TRL Status}

The NGNP issues the FHS a TRL of 4 (see Table 20). Specific R\&D experimental scale tests and tasks need to be completed before advancement to the next level of maturity.

Table 20. Fuel Handling System Summary TRL Table

\begin{tabular}{|c|c|c|c|c|}
\hline & AREVA & General Atomics & Westinghouse & NGNP \\
\hline TRL & 6 & 4 & Not provided & 4 \\
\hline
\end{tabular}




\subsubsection{Fuel Handling System (Prismatic) Maturation Path}

Experimental-scale testing is necessary to advance the FHS from TRL 4 to TRL 5. This includes tasks like assessing the availability of suppliers, material qualification testing, packaging testing, and inspection testing. All of the down selection tasks must be started before a TRL 5 can be granted.

To mature the FHS from TRL 5 to TRL 6, the FHS will be demonstrated in a pilot-scale with a speed error margin of $\pm 0.15 \mathrm{ft} / \mathrm{min}$ and an accuracy of $\pm 2 \mathrm{~mm}$. The pilot-scale testing includes such tasks as structural tests; flow induced vibration tests; and speed, acceleration, and accuracy testing.

To mature the technology from TRL 6 to TRL 7, the FHS must undergo full engineering-scale testing of the integrated system within a relevant environment. Software validation testing in also required.

Advancement from TRL 7 to TRL 8 requires manufacture, installation, testing, and qualification of a full-scale NGNP Fuel Handling System within a non-radiological operating environment. Verified reliability must be performed at a rate $>99.5 \%$ with 25 successful operations.

\subsubsection{Fuel Handling System Design Description (Pebble Bed)}

The primary purpose of the FHSS is to circulate the spherical fuel elements through the reactor core while the reactor is operating at power. When the selected burn-up is reached, spent fuel is removed from the circulation loop and stored in intermediate storage tanks. The spent fuel is then replaced by fresh fuel, which is introduced into the circulation loop.

The FHSS transports, handles, and stores various types of fuel, damaged fuel, and contaminated graphite dust. It is therefore considered to perform a safety function. The FHSS is designed as a multifunction system with a number of its own support systems, and is controlled by the FHSS Control System, which selects the appropriate subsystems to carry out the required functions. The main FHSS subsystems follow:

- Sphere Conveying Subsystem (FSCS)

- Gas Conveying Subsystem (FGCS)

- Sphere Replenishment Subsystem (FSRS)

- Auxiliary Gas Subsystem (FAGS)

- Sphere Storage Subsystem (FSSS).

The FHSS layout configuration is shown in Figure 30. 


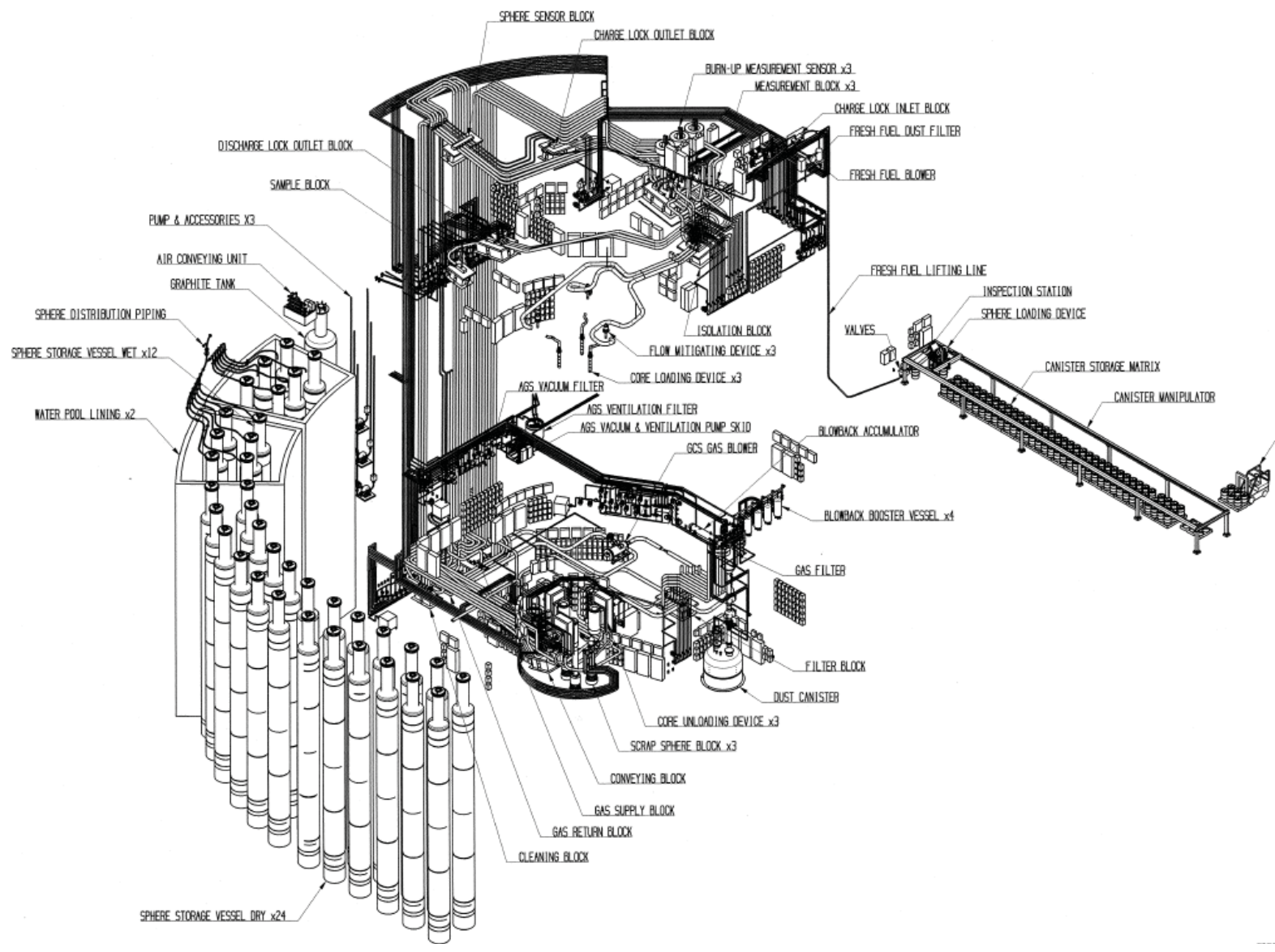

Figure 30. Typical Layout of the Prismatic Fuel Handling and Storage System.

\subsubsection{Functions Performed}

The main functions of the FHSS are to perform the following:

- Replace the graphite spheres with fresh fuel spheres intermixed with graphite spheres during initial start-up

- Gradually change the start-up core composition of graphite and fuel to a fuel only composition, and then to a core consisting of fuel to be used in the equilibrium state

- Load and unload the fuel into and from the reactor core while the reactor is operating at power

- Load the core of the reactor with graphite spheres after a complete unload

- Discharge spent fuel to spent fuel vessels

- Load fresh fuel to compensate for spent fuel discharges

- Remove broken or damaged spheres, or spheres worn down to minimum diameter.

The simplified process flow diagram of the FHSS is shown in Figure 31. 


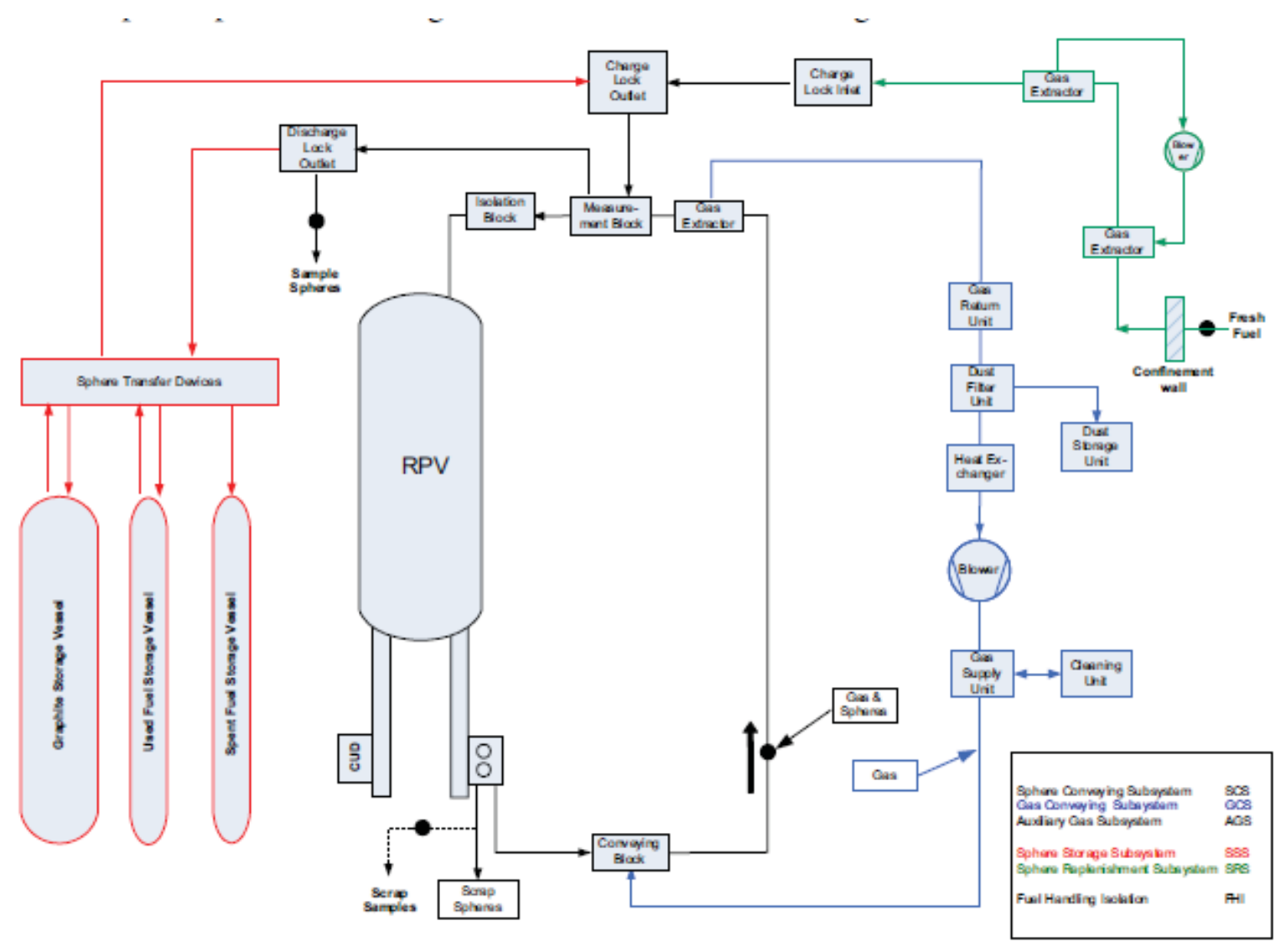

Figure 31: The simplified process flow diagram of the Prismatic FHSS.

\subsubsection{Design Options}

No alternative design concepts are presented for the pebble bed fuel handling and storage system.

\subsubsection{Design Discriminators}

Since there are no alternative designs, there are no design discriminators for comparing design concepts. When evaluating the performance of this design, decision discriminators might include: helium sealing performance, high temperature performance, expected lifetime, replacement cost, primary system contamination, and past experience.

\subsubsection{Fuel Handling System (Pebble Bed) TRL Status}

The NGNP issues the FHS a TRL of 5 (see Table 21). Specific R\&D experimental scale tests and tasks need to be completed before advancement to the next level of maturity.

Table 21. Fuel Handling System Summary TRL Table

\begin{tabular}{|c|c|c|c|c|}
\hline & AREVA & General Atomics & Westinghouse & NGNP \\
\hline TRL & Not provided & Not provided & 5 & 5 \\
\hline
\end{tabular}




\subsubsection{Fuel Handling System (Pebble Bed) Maturation Path}

To mature the pebble bed fuel handling technology from TRL 5 to a TRL 6, some testing is required. The performance/functional testing of fuel handling and storage system must satisfy the following tests:

- Leak and seal test

- Process simulations

- Component performance under different pressure and temperatures

- Gas slow tests

- Verification of simulation software

- Control of different components in the system.

To mature the technology from TRL 6 to TRL 7, the FHS must undergo full engineering-scale testing of the integrated system within a relevant environment. Software validation testing in also required.

Advancement from TRL 7 to TRL 8 requires manufacture, installation, testing, and qualification of a full-scale NGNP Fuel Handling System within a non-radiological operating environment. Verified reliability must be performed at a rate $>99.5 \%$ with 25 successful operations.

\subsubsection{Consolidated INL Technology Development Roadmap}

A consolidated TDRM, produced from Fuel Handling System TDRM data from the suppliers combined with NGNP R\&D data, is shown in Figure 32. 


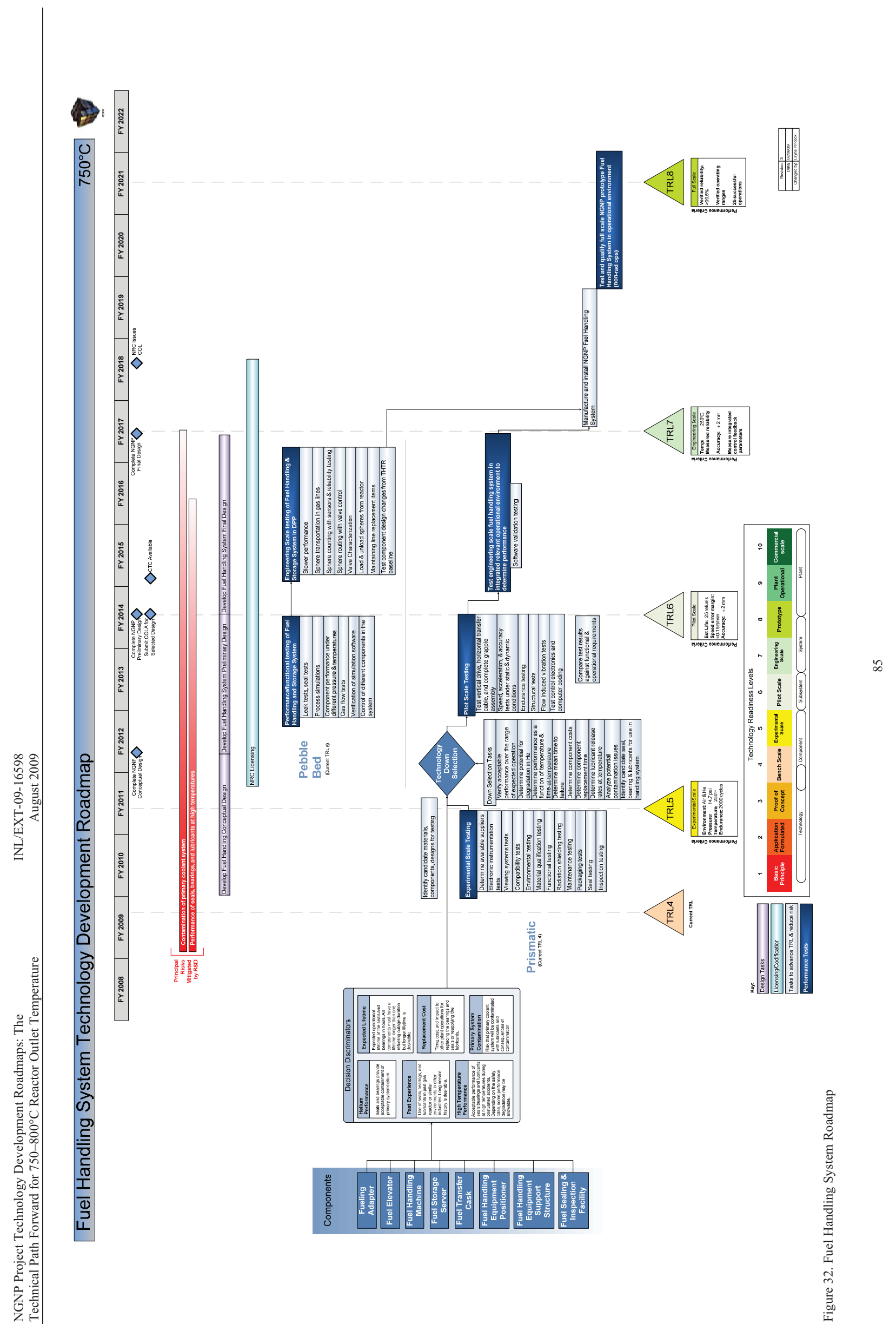




\subsection{Instrumentation and Control}

The NGNP Instrumentation and Control (I\&C) provides the sensors and I\&C systems needed to remotely operate the NHS and other critical systems of the NGNP. The I\&C provides an interface for operators to monitor the operating parameters of critical NGNP systems. Information retrieved from I\&C systems will include: temperature, flow rates, pressure, radiation leakage, and other system malfunctions. Information provided to operators from I\&C systems will enable them to take necessary action to keep the investment impact and the plant safe to the public.

\subsubsection{Instrumentation and Control Design Description}

The I\&C system consists of the primary components of the reactor control and protection systems. This includes determining and verifying the plant control room layout, the operational and safety interfaces, remote shutdown facilities, plant-wide distribution of control and protection functions, and the overall plant control architecture for effective, reliable plant operation. It also includes development of the reactor control and protection algorithms. It is assumed that the plant control architecture and the operator interface will employ modern digital hardware and software, including the necessary testing and qualification to ensure reliability and safety with this type of equipment.

Additionally instrumentation associated with the primary circuit and the BOP is included. Some of the instrumentation will be placed in the primary helium circuit or reactor building to detect leakage of radioactive materials, potentially affecting the public or plant personnel. BOP measurements, comprised of steam flow rate, temperature, pressure, etc., provide defense-in-depth protection of reactor cooling functions. Instrumentation within the primary circuit or included in the secondary boundary provided by the reactor building, is considered primary circuit instrumentation.

\subsubsection{Functions Performed}

At a high level, the I\&C provides an interface for the operators to monitor the operations of critical NGNP systems. Some functions of the I\&C include:

1. Detect primary coolant leakage through measurement of pressure, temperature, or radiation levels within the Reactor Building or in helium-to-helium heat exchanger piping

2. Detect steam leakage via moisture monitoring, which provides safety-related input to the reactor trip system and provides information to alert operators at operating consoles

3. Measure the helium flow in each of the helium flow circulators using helium flow-rate Instrumentation.

Measurements from the I\&C include steam or feed water flow rate, temperature, and pressure.

\subsubsection{Design Options}

Previous designs of the BOP I\&C systems have been proven in existing reactor systems; however, advances in digital instrumentation have occurred in sensing, transmission, and control and will be exploited for application in the NGNP.

\subsubsection{Design Discriminators}

Issues that may help the selection of appropriate sensors, instruments, and control schemes include: detector accuracy and drift, preference towards passive systems, reliability, maintainability, repeatability, and precision. 


\subsubsection{Instrumentation and Control TRL Status}

As the critical Instrumentation and Control is currently defined, a TRL rating of 3 is recommended (See Table 22). This rating is based on the information supplied by the reactor suppliers and NGNP R\&D and I\&C experts.

Table 22. Instrumentation and Control Summary TRL Table

\begin{tabular}{|c|c|c|c|c|}
\hline & AREVA & General Atomics & Westinghouse & NGNP \\
\hline TRL & 6 & 3 & Not provided & 3 \\
\hline
\end{tabular}

\subsubsection{Instrumentation and Control Maturation Path}

To mature I\&C technology from TRL 3 to TRL 4, material issues must be resolved to prove viability. Preliminary design testing and associated tasks are necessary to advanced to TRL 4 . The down selection process begins at this stage as well. Actions to achieve TRL 4 include the following:

- Verify that preliminary control/protection requirements for NGNP plant operation can be met

- Gather I \& C research information from experiments at the HTTR

- Perform dimensionless analysis to determine if the logic of individual physical state I\&Cs can be integrated to address commercial feasibility at larger scales.

Additional analysis needs to show that indirect properties, such as radial flux profiles or detect fatigue, can be sensed and algorithms formed to project plant life.

Final technology down selection is completed during TRL 5. Experimental-scale testing and associated tasks, as shown in the TDRM, are necessary for TRL 5 issuance.

To advance the I\&C from TRL 5 to TRL 6, the sensors and I\&C system must undergo pilot-scale testing in a relevant environment. At least eight tasks are needed at the pilot-scale to grant the I\&C a TRL of 6 . A key concern needing resolution during and after TRL 6 is leak detection instrumentation, equipment condition monitoring, and PCS I\&C.

To mature the BOP I\&C from TRL 6 to TRL 7, the BOP I\&C subsystems will be integrated as an engineering-scale test to determine integration performance. Such a test will most likely be performed at a component test capability.

To mature from TRL 7 to TRL 8, the I\&C will be integrated into the NGNP for full-scale system operability testing. Manufacture and installation of the NGNP I\&C, along with testing and qualification in a non-radiological operating environment, must be complete before the final issuance of TRL 8 .

\subsubsection{Consolidated INL Technology Development Roadmap}

A consolidated TDRM, produced from I\&C TDRM data from the suppliers combined with NGNP R\&D data, is shown in Figure 33. 


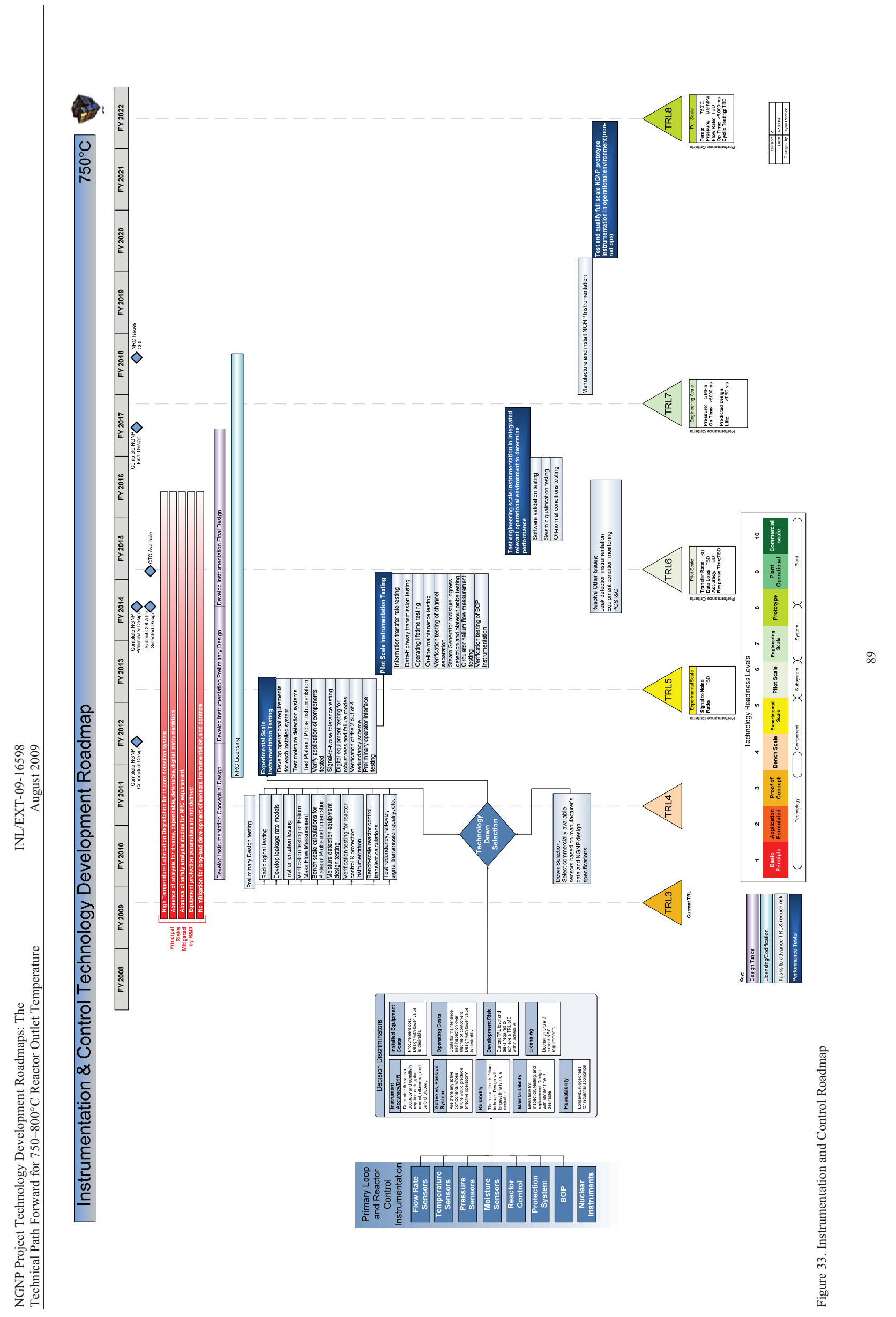


2.

Z 


\section{CONCLUSIONS}

Conclusions and needed actions discovered during the Technology Readiness Assessment and the creation of TDRMs are as follows:

1. Conclusion: The NGNP technology readiness level is inherently higher for an ROT of 750$8^{\circ} 0^{\circ} \mathrm{C}$ versus $950^{\circ} \mathrm{C}$. However, due to the significant number of discrete steps with each TRL advancement, these differences are not all reflected in the raw TRL scores. Instead, the differences are reflected in the reduced difficulty in achieving the next TRL rating at $750-800^{\circ} \mathrm{C}$ versus $950^{\circ} \mathrm{C}$.

Action: At an ROT of $750-800^{\circ} \mathrm{C}$ versus $950^{\circ} \mathrm{C}$, expedite the near-term TDRM tasks to meet schedule.

2. Conclusion: Two PASSCs are no longer considered critical by the suppliers due to the reduction in ROT to $750-\mathbf{8 0 0}^{\circ} \mathrm{C}$. The mixing chamber, proposed by Westinghouse, and the Power Conversion System for direct combined cycle, proposed by General Atomics, were removed from the critical list.

Action: Focus resources on the remaining critical PASSCs.

3. Conclusion: Differences exist between the PASSCs determined to be critical by each supplier. Some of the designs proposed by the suppliers are at differing levels of technical maturity. Hence, one supplier might consider a system to be more mature and not satisfy the definition for a critical system. For example, the Core Conditioning System is not considered critical by all suppliers.

Action: Use the technical maturity of the proposed designs as one criterion in evaluating and down selecting the design used in the NGNP, such as in the due diligence reviews.

4. Conclusion: Differences exist between the NGNP Project and the suppliers on the current TRL of each critical PASSC and on the steps needed for technology maturation. For example, when materials issues are yet to be resolved, NGNP has not granted a TRL higher than 4.

Action: Resolve the differences in TRL assessment by convening an independent TRL validation board and generate a set of validated NGNP TRLs.

5. Conclusion: Most NGNP Critical PASSCs are currently at a low level of technical maturity. The minimum PASSC TRL is a 3 . This lack of maturity is primarily due to the fact that materials issues and the lack of demonstrated component operability.

Action: Expedite the work called on in the TDRM to increase technology readiness.

6. Conclusion: Major decisions must be made at key points in the project life cycle to select technologies and design strategies that reduce risk and enhance the opportunity for project success. The major decision options and technology hurdles will be addressed through the TDRM process as a basis for conceptual, preliminary, and final design, and for updating the integrated project schedule. These decisions are summarized in Table 23 and will be made as the TDRM process is followed.

Action: Work the TDRM process, including the down selection of technologies based on identified decision discriminators, to provide the technology readiness input needed to make design decisions. Accelerate key risk-reducing tasks to inform decisions. 
7. Conclusion: A component test capability is required to reduce the risk and fully mature critical PASSCs prior to insertion in the NGNP (see Table 24). Based on reviews of the available international test capabilities/facilities, the reactor suppliers have identified 90 tests to be performed in a component test capability to adequately mature the technologies and components prior to insertion in the NGNP.

Action: Develop a component test capability needed to conduct supplier-identified tests.

Table 23. Major Technical Issues and Options

\begin{tabular}{|c|c|c|}
\hline PASSC & Major Technical Issues & Options \\
\hline Reactor Pressure Vessel & Materials of Construction & \\
\hline Reactor Internals & Materials of Construction & \\
\hline Reactor Core \& Core Structure & Graphite Qualification & \\
\hline Fuel Elements & Qualification & \\
\hline \multicolumn{3}{|l|}{ Reserve Shut Down System (RSS) } \\
\hline Reactivity Control System (RCS) & Materials of Construction & \\
\hline \multicolumn{3}{|l|}{ Core Conditioning System (CCS) } \\
\hline $\begin{array}{l}\text { Reactor Cavity Cooling System } \\
\text { (RCCS) }\end{array}$ & & $\begin{array}{l}\text { Air-cooled } \\
\text { Water-cooled }\end{array}$ \\
\hline Intermediate Heat Exchanger & $\begin{array}{l}\text { Material Qualification } \\
\text { Design Configuration Qualification }\end{array}$ & $\begin{array}{l}\text { Materials - Alloy } 800 \mathrm{H} \text { or } \\
\text { Hastelloy X } \\
\text { Design - Helical Coil, Printed } \\
\text { Circuit }\end{array}$ \\
\hline Circulators & $\begin{array}{l}\text { Bearing Type, Motor Type, } \\
\text { Impeller Type }\end{array}$ & $\begin{array}{l}\text { Impeller Type - Submersible or } \\
\text { Not, Electromagnetic Bearings, Oil } \\
\text { Bearings }\end{array}$ \\
\hline Mixer Chamber & $\mathrm{N} / \mathrm{A}$ at $750-800^{\circ} \mathrm{C} \mathrm{ROT}$ & \\
\hline Cross Vessel Piping & $\begin{array}{l}\text { Materials of Construction, } \\
\text { Insulation }\end{array}$ & \\
\hline High Temperature Valves & Materials, Spring, Actuator & \\
\hline Steam Generator & Materials of Construction & \\
\hline PCS Turbo Machinery & $\mathrm{N} / \mathrm{A}$ at $750-800^{\circ} \mathrm{C} \mathrm{ROT}$ & \\
\hline \multicolumn{3}{|l|}{ Fuel Handling System } \\
\hline Instrumentation and Control & Sensors, Instruments, Controls & \\
\hline
\end{tabular}


Table 24. Tests Requiring Component Test Capability.

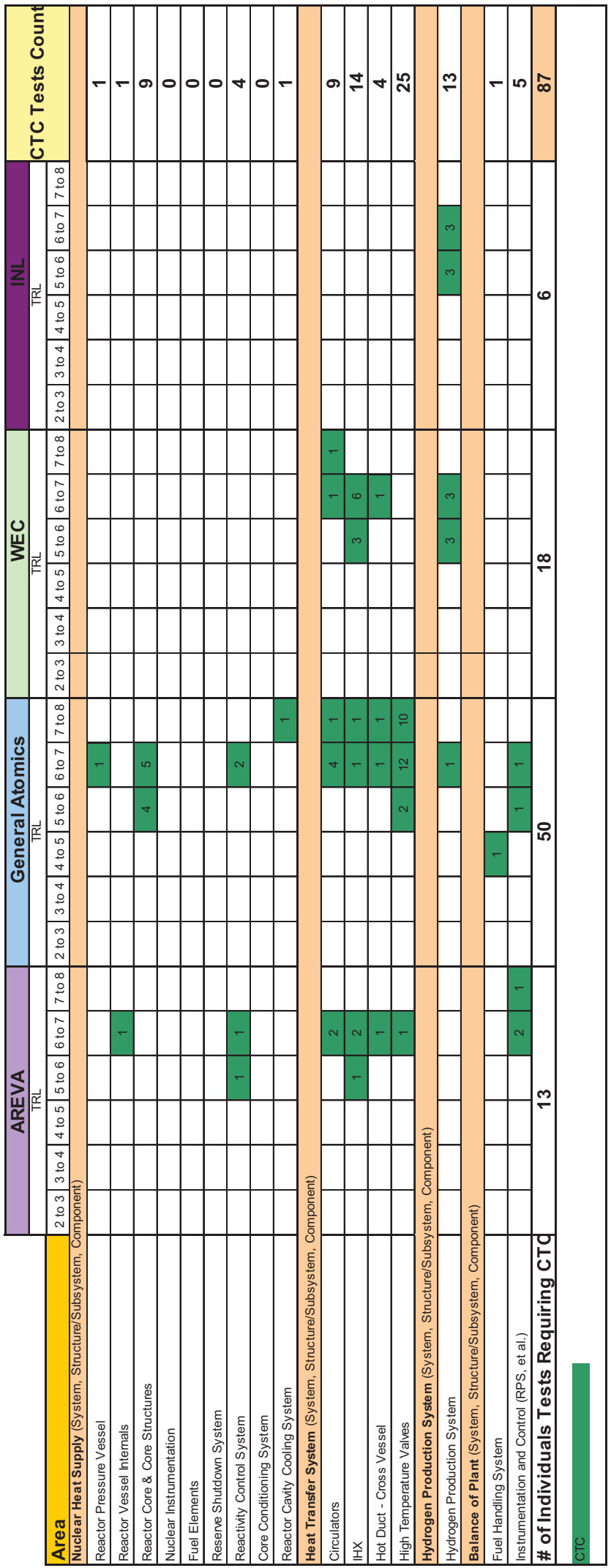




\section{REFERENCES}

General Atomics, Engineering Services for The Next Generation Nuclear Plant (NGNP) with Hydrogen Production, Effect of Reactor Outlet Helium Temperature on the Need for Composites in the NGNP, Report number 911175, Revision 0, June 11, 2009.

U.S. Government Accountability Office (2007), Department of Energy: Major Construction Projects Need a Consistent Approach for Assessing Technology Readiness to Help Avoid Cost Increases and Delays, GAO-07-336, March 2007.

Idaho National Laboratory (2008a), NGNP System Requirements Manual, INL/EXT-07-12999, Revision 1, June 2008.

Idaho National Laboratory (2008b), Summary of Bounding Requirements for the NGNP Demonstration Plant F\&ORs, INL/EXT-08-14395, June 2008.

\section{APPENDICES}

The set of supplier provided TRLs, TDRMs, and Test Plans along with their associated documentation is presented in the following appendices:

- Appendix A: Supplier Reports for $750-800^{\circ} \mathrm{C}$ ROT and Large Consolidated Roadmaps

- AREVA NGNP TDRM, TRLs, and Test Plans

- General Atomics NGNP TDRM, TRLs, and Test Plans

- Westinghouse NGNP TDRM, TRLs, and Test Plans

- NGNP Consolidated Roadmaps (Printable E-size Drawings).

- $\quad$ NGNP Project Technology Readiness Level Rating Sheets for $750-800^{\circ} \mathrm{C}$ ROT 


\section{Appendix A}

\section{Supplier Reports, Large Consolidated Roadmaps, and TRL Rating Sheets for $750-800^{\circ} \mathrm{C}$ ROT}


This page intentionally left blank. 


\section{Appendix A Supplier Reports, Large Consolidated Roadmaps, and TRL Rating Sheets for $750-800^{\circ} \mathrm{C}$ ROT}

- AREVA NGNP TDRMs, TRLs, and Test Plans

- General Atomics NGNP TDRMs, TRLs, and Test Plans

- Westinghouse NGNP TDRMs, TRLs, and Test Plans

- NGNP Consolidated Roadmaps (Printable E-size Drawings)

- NGNP Project Technology Readiness Level Rating Sheets for $750-800^{\circ} \mathrm{C}$ ROT 